\title{
SUSTAINABLE SUPPLY CHAIN MANAGEMENT IN CANADIAN CORPORATIONS
}

\author{
by \\ Oguz MORALI, MBA, BBA, Toronto, 2013 \\ DISSERTATION \\ presented to Ryerson University \\ in partial fulfillment of the requirements for the degree of \\ Doctor of Philosophy \\ in the Program of \\ Environmental Applied Science and Management (ENSCIMAN) \\ in the Yeates School of Graduate Studies (YSGS) \\ Toronto, Ontario, Canada, 2013 \\ (C) (Oguz MORALI) 2013
}




\begin{abstract}
AUTHOR'S DECLARATION
I hereby declare that I am the sole author of this dissertation. This is a true copy of the dissertation, including any required final revisions, as accepted by my examiners.

I authorize Ryerson University to lend this dissertation to other institutions or individuals for the purpose of scholarly research.
\end{abstract}

I further authorize Ryerson University to reproduce this dissertation by photocopying or by other means, in total or in part, at the request of other institutions or individuals for the purpose of scholarly research.

I understand that my dissertation may be made electronically available to the public. 


\title{
Title: Sustainable Supply Chain Management in Canadian Corporations
}

\section{Degree: Doctor of Philosophy, 2013, Oguz MORALI}

\section{Environmental Applied Science and Management Program, Ryerson University}

\begin{abstract}
The purpose of this dissertation is twofold: (1) to examine the extent of integration and implementation of corporate sustainability (CS) into supply chain management (SCM) practices in corporations; and (2) to provide a basis for improved supplier selection with respect to sustainability criteria. Three interrelated research objectives were developed to achieve the purpose: (1) explore the extent to which CS principles are integrated into SCM in corporations; (2) investigate how sustainable supply chain management (SSCM) has evolved in corporations; and (3) develop a model to integrate the environmental and social criteria of CS into supplier assessment and selection. The dissertation is comprised of three main phases corresponding directly to the research objectives stated above. Canada is used as a case study to achieve this goal. Consequently, the first phase explores the extent to which CS principles are integrated into SCM in Canadian corporations. The study includes a primary content analysis of 100 Canadian corporate sustainable development reports (CSDRs) and in-depth interviews with thirty Canadian experts on SSCM. The second phase investigates how SSCM has evolved in Canadian corporations over a five-year period. The study is based on a sequential content analysis of 26 CSDRs to compare the findings with the results from the primary content analysis from Phase 1. The third phase aims to develop supplier assessment and selection models based exclusively on the environmental and social criteria of CS. This phase employs case
\end{abstract}


studies of two major Canadian companies to develop a sustainable supplier selection model.

The dissertation makes numerous contributions to the SSCM field. Taken together, Phase 1 and Phase 2 provide a holistic perspective for a range of interrelated criteria on SSCM; provide corporations and other supply chain partners with opportunities to learn from the best practices and shortcomings of the integration of CS practices into SCM; and encourage thinking and discussion into how the key gaps in the theory and practice of SSCM might be addressed. Phase 3 provides SCM professionals with a contingencybased, effective, and practical bespoke modeling approach to supplier assessment and selection within the context of SSCM. 


\section{ACKNOWLEDGEMENTS}

I am eternally thankful to Dr. Cory Searcy for his kind, thoughtful, and enthusiastic navigation throughout this process.

Special thanks to Dr. Michal Bardecki for his support and assistance along the way.

With gratitude to my family, Filiz K. Morali, David N. Coop, Mufit Kopran, and Clifford E. Laird who always offered generous support throughout my journey. 


\section{DEDICATION}

In loving memory of Dr. Hilmi Ozcelik, who touched many lives and hearts in his lifetime. 


\section{TABLE OF CONTENTS}

Author's Declaration $\quad$ ii

Abstract iii

Acknowledgements $\quad$ V

Dedication vi

Table of Contents vii

List of Abbreviations $\quad \mathrm{x}$

List of Tables $\quad$ xi

List of Figures xiii

List of Exhibits xiv

CHAPTER 1 Introduction 1

1.1 Overview 1

1.2 Problem Definition 3

1.3 Research Objectives and Methodological Approach 7

$\begin{array}{lll}\text { 1.3.1 Content Analysis } & 10\end{array}$

$\begin{array}{lll}\text { 1.3.2 Interviews } & 15\end{array}$

$\begin{array}{lll}\text { 1.3.3 Case Studies } & 19\end{array}$

$1.4 \quad$ Structure of the Dissertation 24

CHAPTER 2 A Review of Sustainable Supply Chain Management in 27 Canadian Corporations

$\begin{array}{lll}2.1 & \text { Introduction } & 27\end{array}$

2.2 Literature Review 28

2.2.1 Sustainability and Supply Chain Management 29

2.2.2 Sustainable Supply Chain Management: Implementation 31

2.3 Research Objective and Related Questions 36

2.4 Methodology 41

2.4.1 Content Analysis 43 
2.4.2 Interviews with Corporate Experts 45

$\begin{array}{lll}2.5 & \text { Results } & 47\end{array}$

2.5.1 Results from the Content Analysis 47

2.5.2 Results from the Interviews 53

$\begin{array}{lll}2.6 & \text { Discussion } & 60\end{array}$

$\begin{array}{lll}2.7 & \text { Conclusions } & 65\end{array}$

CHAPTER 3 Evolution of Sustainable Supply Chain Management 67

3.1 Introduction $\quad 67$

3.2 Literature Review 68

$\begin{array}{lll}3.3 & \text { Methodology } & 71\end{array}$

$\begin{array}{lll}3.4 & \text { Results } & 73\end{array}$

3.4.1 Supply Chain Governance $\quad 74$

3.4.2 Supply Chain Strategy 75

3.4.3 Performance Indicators 77

$\begin{array}{ll}3.4 .4 & \text { Standards for SSCM }\end{array}$

3.4.5 Supplier Monitoring $\quad 79$

3.4.6 Collaboration $\quad 80$

3.4.7 Forward-Looking Statement $\quad 81$

$\begin{array}{lll}3.5 & \text { Discussion } & 82\end{array}$

$\begin{array}{lll}3.6 & \text { Conclusions } & 87\end{array}$

CHAPTER 4 Integration of Corporate Sustainability into Supplier Selection 89

$\begin{array}{llr}4.1 & \text { Introduction } & 89\end{array}$

4.2 Literature Review 90

4.2.1 Supplier Assessment and Selection 90

4.2.2 Supplier Selection for Sustainable Supply Chain 93 Management

4.3 Methodology 96

$\begin{array}{lll}4.4 & \text { Case Studies } & 99\end{array}$ 
4.4.1 First Case Company Profile 100

4.4.2 Second Case Company Profile 111

$\begin{array}{lll}4.5 & \text { Discussion } & 124\end{array}$

$\begin{array}{lll}4.6 & \text { Conclusions } & 128\end{array}$

CHAPTER 5 Research Summary and Conclusions 130

$\begin{array}{lll}5.1 & \text { Research Summary } & 130\end{array}$

5.1.1 A Review of Sustainable Supply Chain Management in 130 Canadian Corporations

5.1.2 Evolution of Sustainable Supply Chain Management 133

5.1.3 Integration of Corporate Sustainability into Supplier 134 Selection

5.2 Conclusions and Recommendations 136

5.3 Research Limitations and Areas for Further Research 139

5.3.1 A Review of Sustainable Supply Chain Management in 139 Canadian Corporations

5.3.2 Evolution of Sustainable Supply Chain Management 141

5.3.3 Integration of Corporate Sustainability into Supplier 142 Selection

$\begin{array}{lll}5.4 & \text { Research Contributions } & 143\end{array}$

$\begin{array}{ll}\text { APPENDICES } & 147\end{array}$

APPENDIX A - Primary Content Analysis Worksheet 147

APPENDIX B - Corporate Experts Interviewed 150

APPENDIX C - Interview Protocol 151

APPENDIX D - Sequential Content Analysis Worksheet 152

APPENDIX E - Environmental KPIs Identified Through Content 153

Analysis of CSDRs of Case Utility`s Major Suppliers

REFERENCES 


\section{LIST OF ABBREVIATIONS}

Corporate Social Responsibility (CSR)

Corporate Sustainability (CS)

Corporate Sustainable Development Report (CSDR)

Environmental Procurement Policy (EPP)

Global Reporting Initiative (GRI)

Green Supply Chain Management (GSCM)

Key Performance Indicator (KPI)

Multi-Criteria Decision-Making (MCDM)

Purchasing and Asset Disposal Policy (PADP)

Request for Proposal (RFP)

Resource-Based View (RBV)

Resource Dependence Theory (RDT)

Strategic Sourcing Group (SSG)

Supply Chain Management (SCM)

Sustainable Development Indicator (SDI)

Sustainable Supply Chain Management (SSCM)

Sustainable Supplier Development (SSD)

Sustainable Supplier Selection (3S)

Two Tiered Sustainability Equilibria (TTSE)

Valuable-Rare-Imperfectly Imitable-Nonsubstitutable (VRIN) 


\section{LIST OF TABLES}

CHAPTER 1

Page

Table 1.1 Mixed-Model Research Design Employed 8

Table 1.2 Analytic Approaches Employed to Content Analyses 12

Table 1.3 Steps of Content Analyses Employed 12

$\begin{array}{lll}\text { Table } 1.4 & \text { Steps of Interview Process } & 17\end{array}$

Table 1.5 Steps of Case Studies Employed 20

\section{CHAPTER 2}

Table 2.1 Literature Review Search Terms 28

Table 2.2 Themes Applied to SSCM Related Studies 34

Table 2.3 Summary of Theories Applied to Research Objective 1

Table 2.4 Selection of Content Analysis Criteria 44

Table 2.5 Keywords Applied to Themes 45

$\begin{array}{lll}\text { Table } 2.6 \quad \text { Interview Questions } & 47\end{array}$

Table 2.7 SSCM Standards and Management Instruments Cited 50

\section{CHAPTER 3}

Table 3.1 Definitions Characterizing SSCM 69

Table 3.2 Selection of Content Analysis Criteria 72

Table 3.3 Key Findings from Sequential and Primary Content Analyses 74

Table 3.4 Example Citations of Supply Chain Governance 75

Table 3.5 Example Citations of Supply Chain Strategy 76

Table 3.6 Example Citations of Performance Indicators 77

Table 3.7 Example Citations of SSCM Standards and Management 78 Instruments

Table $3.8 \quad$ Example Citations of Supplier Monitoring 79

Table $3.9 \quad$ Example Citations of Collaboration 80

Table 3.10 Example Citations of Forward Looking Statements 81 


\section{CHAPTER 4}

Table 4.1 Application of the 3S Design Process to Case Studies 99

Table 4.2 Key Environmental Issues for the Case Utility's Suppliers 104

Table 4.3 Feedback on Finalizing the Model 107

Table 4.4 Integrating the Model at the Case Utility 111

Table 4.5 Case Financial Services Interview Questions 115

Table 4.6 Case Financial Services Interview Summary Results 116

Table 4.7 Key Issues for the Case Financial Services' Suppliers 117

Table 4.8 Integrating the Model at the Case Financial Services 123 


\section{LIST OF FIGURES}

CHAPTER 1

Page

Figure 1.1 Research Gaps Identified in SSCM Literature 6

Figure 1.2 Synopsis of the Methodological Approach 9

Figure 1.3 Holistic Multiple-case Design 21

\section{CHAPTER 2}

Figure 2.1 Methodological Approach

\section{CHAPTER 4}

Figure 4.1 The 3S Design Process 97

Figure 4.2 Screenshot of the Green Supplier Selection Model 108

Figure 4.3 Application of Green Supplier Selection Model (Part 1) 109

Figure 4.4 Application of Green Supplier Selection Model (Part 2) 110

Figure 4.5 Application of Green Supplier Selection Model (Part 3) 110

Figure 4.6 Screenshot of the Sustainable Supplier Selection Model 120

Figure 4.7 Application of Sustainable Supplier Selection Model (Part 1) 121

Figure 4.8 Application of Sustainable Supplier Selection Model (Part 2) 122

Figure 4.9 Application of Sustainable Supplier Selection Model (Part 3) 122 


\section{LIST OF EXHIBITS}

CHAPTER 4

Page

Exhibit 4.1 The Prototype Questionnaire 105

Exhibit 4.2 Sustainable Procurement Questionnaire 118 


\section{CHAPTER 1 - INTRODUCTION}

\subsection{Overview}

The concept of managing supply chains has been discussed in the management and engineering literature since the early $20^{\text {th }}$ century (Svensson, 2001; Carter and Easton, 2011; Sarkis and Zhu, 2011). However, supply chain management (SCM) is still an emergent field in which theory and practice lack quality theoretical development, discussion, and coherence (Harland et al., 2006; Storey et al., 2006). The research on SCM has been particularly fast evolving over the last two decades. Wide ranges of academic disciplines and diverse theoretical perspectives have studied the SCM field in an attempt to claim ownership (Burgess et al., 2006). As a result, many terms have been offered to define SCM, including supply strategy, pipeline management, demand chains and network sourcing, demand management, and value stream management (Lowson, 2002). In fact, the literature (Stock et al., 2010) identifies 166 unique definitions of SCM that centre around three major themes: activities, benefits, and constituents/components. The following definition of SCM (Mentzer et al., 2001, p.18) clearly represents these three themes:

\footnotetext{
Supply chain management is defined as the systemic, strategic coordination of the traditional business functions and the tactics across these business functions within a particular company and across businesses within the supply chain, for the purposes of improving the long-term performance of the individual companies and the supply chain as a whole.
}

Although definitions of SCM differ among authors, prior to the 1980s these definitions primarily focused around logistics and operational efficiency issues, such as manufacturing performance, inventory control, distribution, and trans-shipment issues (Mentzer et al., 2001; Cousins et al., 2006). By the early 1980s, the recognition of the strategic nature of supply chains resulted in a shift in focus from a narrower to a broad and encompassing one. New strategic insights into inventory, production, and quality induced a cooperative model between buyers and suppliers (Matthyssens and Van den Bulte, 1994; Stuart and McCutcheon, 2000). A number of studies explored the benefits 
and the importance of the strategic management of purchasing to the success of the firm (Heide and John, 1990; Carter and Narasimhan, 1996; Pearson et al., 1996).

During the 1990s, the significance of environmental impacts resulting from a firm's operational activities became increasingly evident to the public. This, in turn, prompted organizations to interact upstream or downstream with other organizations in the supply chain and to integrate environmental issues into their SCM practices (Tattum, 1993; Sarkis, 2001; Zhu and Sarkis, 2004; Preuss, 2005). The late 1990s and early 2000s also gave rise to the recognition and integration of social issues in supply chains (Roberts, 2003; Sisodia et al., 2007; Beske et al., 2008; Mueller et al., 2009). The increase in environmental and social issues in supply chains coincides with the popularization of the sustainable development concept during the same era. In 1987, the Brundtland Report by the World Commission on Environment and Development (WCED, 1987) had recognized the interdependencies among economic, environmental, and social issues i.e., the three pillars of sustainability - for sustainable global development. Following that, Pezzey (1992) identified 27 concepts of sustainable development built around the definition of sustainable development provided by the Brundtland Report (WCED, 1987). However, the examination, and therefore understanding, of the concept of sustainability goes centuries back (Lumley and Armstrong, 2004) and continues to date. For example, Lozano (2008) factors in a fourth dimension, time, into the sustainability discussion.

The boundaries among interconnected dimensions of sustainability may not always be clear (Seghezzo 2009; Lozano, 2012). However, from an operational standpoint, recognizing and meeting the social, environmental, and economic responsibilities towards key stakeholders on a voluntary basis falls under the domain of corporate social responsibility (CSR) (Dahlsrud, 2008; Carbo et al., 2010). The Commission of the European Communities provides a definition of CSR as: "the responsibility of enterprises for their impacts on society" (COM, 2011). This updated definition of CSR lacks the specificity of the former definition of CSR, which is: "a concept whereby companies integrate social and environmental concerns in their business operations and in their interaction with their stakeholders on a voluntary basis" (COM, 2001). The contributions of this new definition of CSR (COM, 2011) to business implementation and academic 
debate are as ambiguous as the definition itself. Guided by the new definition, the CSR initiatives of firms might take a turn in two different directions. On the positive side, the indistinct allusion to the "impacts" of an enterprise "on society" might lead firms to divert the understanding and, therefore, practice of CSR to an all-embracing and ambitious level in which any negative externality becomes the responsibility of a firm for the benefit of its stakeholders. From this perspective, the notion of CSR converges one more step with the agency principle and, thus, with the notion of CS (Marrewijk, 2003). Nevertheless, the exclusion of the three key components of CSR - social concerns, environmental concerns, and the voluntary aspect - from the former definition might provide little guidance as to the kind and variety of "impacts" for which firms are supposed to be responsible. Further, deemphasizing the nature of "voluntary" interactions with stakeholders might lead the agents of firms to deliberately scale back CSR practices to the limits of regulations while claiming and communicating that the firm addresses its impacts on society.

The literature provides many examples of the adoption and practices of CSR issues in the supply chain (Maignan et al., 2002; Carter and Jennings, 2004; Maloni and Brown, 2006; Salam, 2009). A taxonomy by Ciliberti et al. (2008) identifies 47 different constructs of CSR as they relate to logistics and SCM. However, the recent research on CSR in the supply chain fails to explicitly include an organization's economic responsibility in current models and definitions of purchasing social responsibility (Carter and Rogers, 2008).

\subsection{Problem Definition}

The conceptualization of the three pillars of sustainability of both the CSR and CS constructs are similar (Montiel, 2008). For example, the constructs of CSR and CS both encompass issues such as ethical behaviours, human rights, philanthropy, stakeholder interests, cultural norms, and the ecological relationship with individuals and organizations (Clarkson, 1995; Jennings and Entine, 1999; Sisodia et al., 2007; Mueller et al., 2009). The literature provides many definitions of CS. One representative definition is: "demonstrating the inclusion of social and environmental concerns in interactions with 
stakeholders" (Marrewijk, 2003, p.102). A second representative definition is provided by the International Institute for Sustainable Development (IISD, 1992): “adopting business strategies and activities that meet the needs of the enterprise and its stakeholders today while protecting, sustaining, and enhancing the human and natural resources that will be needed in the future."

Sustainable supply chain management (SSCM) emerged as a result of the integration of the concept of CS with SCM. As it will be seen in Chapter 2 and 3, the literature provides a wide variety of definitions that characterize the notion of SSCM. The diversity of SSCM definitions stems from the range of the understanding of sustainability. Thus, due to the distinct CS criteria that are incorporated into SCM, the concept of SSCM varies widely (Beamon, 2005; Hervani et al., 2005; Carter and Rogers, 2008; Winkler, 2011). Further, the concept and understanding of sustainability is an evolutionary process (Lumley and Armstrong, 2004). However, the effects of time elapsed on the adoption and integration of sustainability criteria into SCM practices are relatively unknown and understudied (Lozano, 2008; Seghezzo, 2009).

The integration of CS principles into SCM is not without its challenges. Some of the key challenges to such integration include: a clear identification of the system boundaries between the three pillars of sustainability, cost associated with the implementation of SSCM, risk mitigation, performance measurement of SSCM initiatives, reporting and stakeholder communication, alignment of SSCM strategies at intra-and interorganizational levels, and supplier assessment and selection (Storey et al., 2006; Carter and Rogers, 2008; Seuring and Muller, 2008a; Bai and Sarkis, 2010). The literature is growing on many of those challenges. However, with the ever-increasing stakeholder pressures on businesses to consider and measure the environmental and social impacts of their supply chain decisions (Sarkis and Talluri, 2002; Hutchins and Sutherland, 2008; Akyuz and Erkan, 2010), the need for assessing supplier performance on the basis of the environmental and social criteria of CS is particularly urgent (Buyukozkan and Cifci, 2011; Amindoust et al., 2012; Baskaran et al., 2012).

As can be seen above, there is a growing body of research on the theory and practice of 
SSCM. However, as will be seen in further detail in Chapters 2, 3, and 4, the review of the literature on SSCM has identified three interrelated key research gaps:

1. The extent to which CS principles are integrated into SCM in corporations;

2. The evolution of SSCM practices in corporations; and

3. The integration of the environmental and social criteria of CS into supplier assessment and selection.

This dissertation is comprised of three main research phases that correspond directly to these three key interrelated research gaps (Figure 1.1).

Phase 1 of this dissertation addresses the first key research gap: the extent to which CS principles are integrated into SCM in corporations. The literature review conducted to identify the first research gap provides the starting point for this dissertation in that it has helped identify the second and third research gaps: the evolution of SSCM practices in corporations; and sustainable supplier assessment and selection. Further, the in-depth interviews conducted to address the first research gap (Chapter 2) further substantiated the third research gap on sustainable supplier assessment and selection. Phase 2 and Phase 3 of the dissertation address the second and third research gaps respectively. With this in mind, the purposes of this dissertation are: (1) to examine the extent of integration and implementation of CS into SCM practices in corporations; and (2) to provide a basis for improved supplier selection with respect to sustainability criteria. Canada is used as a case study to achieve this goal. 


\section{Focal Company}
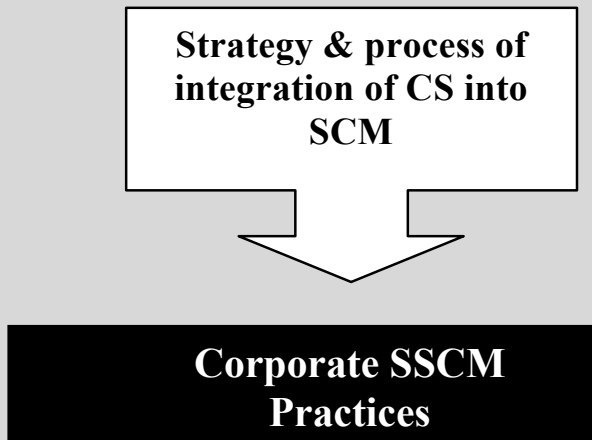

- Governance

- Performance measurement

- Standards/management instruments

- Supplier monitoring

- Collaboration

- Reporting

- Other
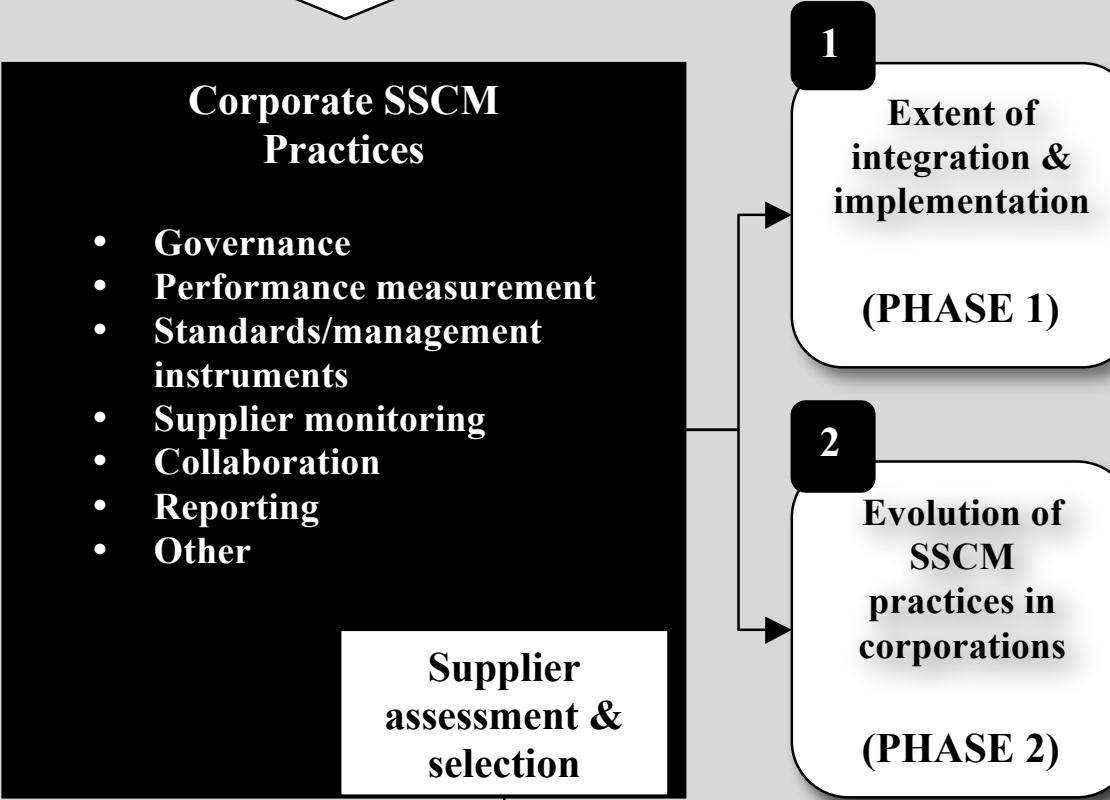

(PHASE 1)

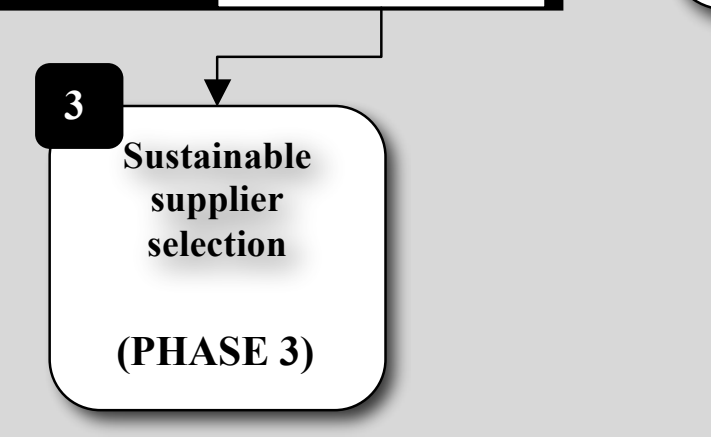

(PHASE 2)

Notes: Research gaps identified in the SSCM field: 1.The extent of integration and implementation of CS principles in SCM practices; 2. Evolution of SSCM practices and; 3. Integration of the environmental and social criteria of CS into supplier assessment and selection.

\section{Figure 1.1 Research Gaps Identified in SSCM Literature}




\subsection{Research Objectives and Methodological Approach}

To achieve its major goal, the dissertation has three objectives corresponding directly to the three key research gaps identified above.

The first objective is: to explore the extent to which CS principles are integrated into SCM in corporations. The research methods utilized to achieve this objective involve: an extensive review of the literature on the theory and practice of SSCM, a primary content analysis of corporate sustainable development reports (CSDRs) of 100 Canadian corporations, and in-depth interviews with 30 corporate experts representing 26 Canadian corporations. It is important to acknowledge that while several theoretical perspectives such as institutional theory, contingency theory, and stakeholder theory, resource based view, and resource dependence theory (see Chapter 2, Section 2.3) - emphasize the importance of external factors in determining the nature and scope and content and drivers for SSCM practices, the focus of this study is on the internal factors. Therefore, external stakeholder groups to the corporations - such as suppliers, governments, industry associations, NGOs, standards organizations, and consumer associations - were not included in the interviews. Consequently, minimal attention was devoted to the description of the external environment. With that in mind, the role of the external environment for SSCM practices provides an important area and ample opportunities for further research.

The second objective is: to investigate how SSCM has evolved in corporations. The main research method utilized to achieve this objective involves a sequential content analysis of CSDRs of 26 Canadian corporations. The sequential content analysis hereby refers to a content analysis that was conducted in sequence to the primary content analysis that was conducted in Phase 1. Therefore, the sequential content analysis is in effect a longitudinal study, which involves the repeated observations of the same variables from the same sample across time (Giele and Elder, 1998).

The third objective is: to develop a model to integrate the environmental and social criteria of CS into supplier assessment and selection. This objective involves: an 
extensive literature review on supplier assessment and selection, and case studies of two major Canadian case companies, an electric utility and a financial services corporation.

To achieve these three objectives, the overall strategic inquiry of the dissertation was based on a mixed-model research design. From a method perspective, mixed-model research design refers to mixing qualitative and quantitative approaches and methods within or across the different phases of the research process (Johnson and Christensen, 2004; Johnson and Onwuegbuzie, 2004). A mixed-model research design was particularly suited to this dissertation in order to: focus on different aspects of the three interrelated research objectives simultaneously; facilitate between-methods triangulation; inform the development of the criteria of analysis for distinct methods; and analyze the findings from a holistic perspective. The details of the research design are presented in Table 1.1.

Table 1.1 Mixed-Model Research Design Employed

\begin{tabular}{|c|c|c|c|c|}
\hline Research Objective & $\begin{array}{l}\text { Corresponding } \\
\text { Phase }\end{array}$ & $\begin{array}{l}\text { Method(s) } \\
\text { Employed } \\
\end{array}$ & $\begin{array}{l}\text { Data } \\
\text { Collected }\end{array}$ & Analysis Performed \\
\hline Objective 1 & Phase 1 & $\begin{array}{l}\text { 1) Content } \\
\text { Analysis } \\
\text { 2) Interviews }\end{array}$ & $\begin{array}{l}\text { Qualitative } \\
\& \\
\text { Quantitative }\end{array}$ & $\begin{array}{c}\text { Qualitative } \\
\& \\
\text { Quantitative }\end{array}$ \\
\hline Objective 2 & Phase 2 & $\begin{array}{l}\text { 1) Content } \\
\text { Analysis }\end{array}$ & $\begin{array}{c}\text { Qualitative } \\
\& \\
\text { Quantitative }\end{array}$ & $\begin{array}{c}\text { Qualitative } \\
\& \\
\text { Quantitative }\end{array}$ \\
\hline Objective 3 & Phase 3 & $\begin{array}{l}\text { 1) Case Studies } \\
\text { a) content } \\
\text { analyses } \\
\text { b) interviews }\end{array}$ & $\begin{array}{c}\text { Qualitative } \\
\& \\
\text { Quantitative }\end{array}$ & $\begin{array}{c}\text { Qualitative } \\
\& \\
\text { Quantitative }\end{array}$ \\
\hline
\end{tabular}

As shown in Table 1.1, the research design of this dissertation is "across-stage mixedmodel design" (Johnson and Onwuegbuzie, 2004) because the mixing takes place, concurrently, across the three phases of the research process. The across-stage mixedmodel design approach is particularly useful in conceptualizing a single study as having multiple phases with corresponding research objectives, and methods to reach these objectives (Johnson and Christensen, 2004). Further, the dissertation employs "withinstage mixed-model" design in Phase 1 by utilizing content analysis (qualitative and 
quantitative data collection) and survey interviews (qualitative data collection) to address Objective 1. Similarly, within-stage mixed-model design (Johnson and Onwuegbuzie, 2004) is employed in Phase 3 by utilizing content analyses and survey interviews to address Objective 3. The methodological approach of the dissertation is illustrated in further detail in Figure 1.2.

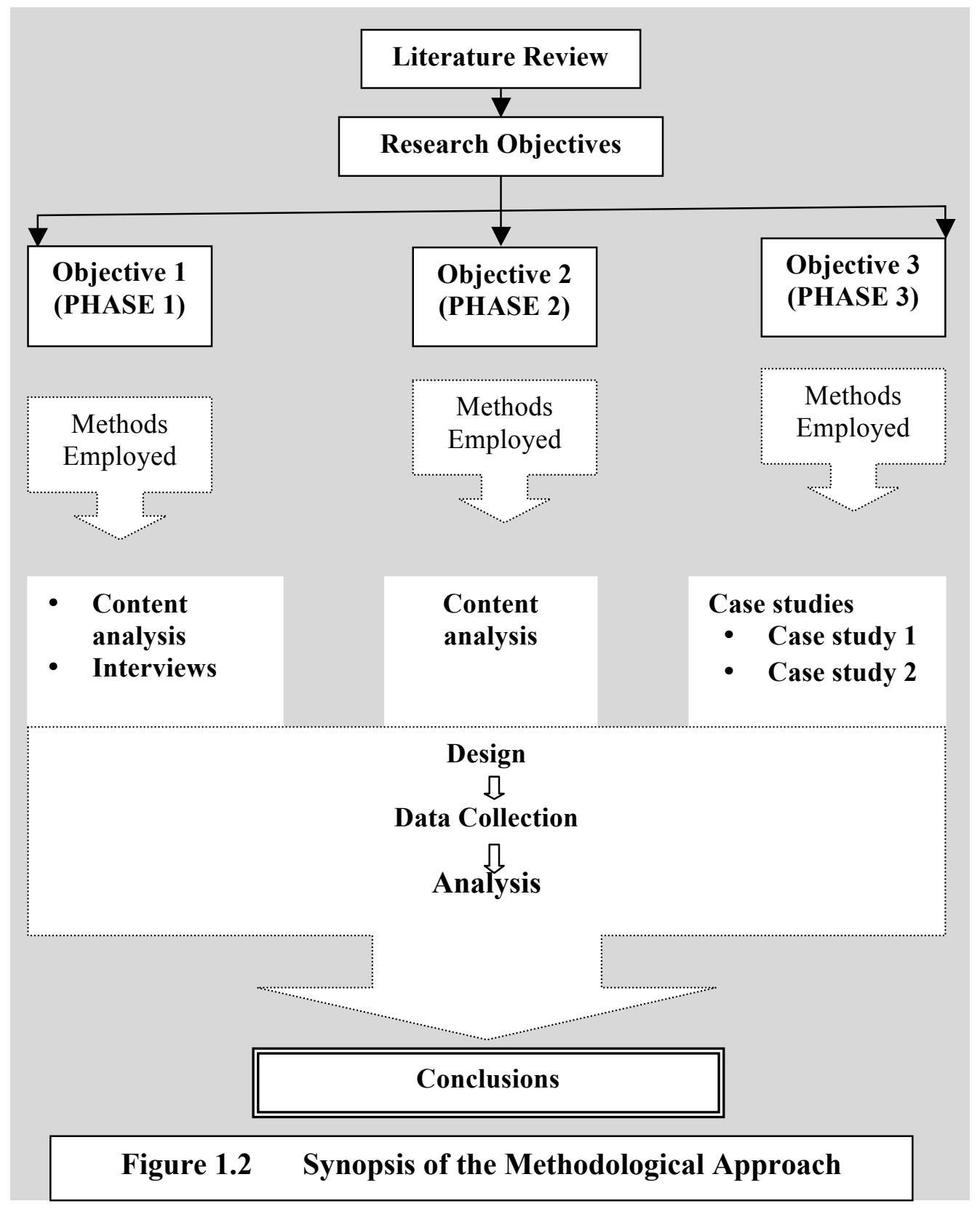

As can be seen in Figure 1.2, the dissertation employs three research methods: content analysis, interviews, and case study research. Further, the dissertation recognizes 
feedback between its methodological components. For example, the results from the primary content analysis helped inform the development of the interview questions. Similarly, the results from the interviews substantiated the research objective with regard to integrating CS into supplier selection and helped identify some criteria of analysis for the case studies. The details regarding the research methods employed are discussed in the following subsections 1.3.1 through 1.3.3.

\subsubsection{Content Analysis}

A representative definition of content analysis is: "any methodological measurement applied to text (or other symbolic materials) for social science purposes" (Shapiro and Markoff, 1997, p. 14). As can be seen from this definition, content analysis is a flexible method for analyzing text data which may apply a number of analytic approaches such as deductive, inductive, and strict textual analyses (Rosengren, 1981). Although this flexibility has made content analysis a research method that has wide use in both qualitative and quantitative research, the multiplicity of content analysis definitions and procedures has posed limitations to the application of the method (Tesch, 1990). The definition and specific type of analytic approach to content analysis depends on the problem being studied and the theoretical and substantive interests of the researcher (Rosengren, 1981). For example, the quantitative approach, with text data coded into explicit categories and then analyzed using statistics, is emphasized in the definition: "content analysis is a research technique for the objective, systematic and quantitative description of the manifest content of communication" (Berelson, 1952, p. 55). The qualitative approach to content analysis or qualitative content analysis, on the other hand, examines language to classify large amounts of text into an efficient number of categories that represent similar meanings (Weber, 1990). Qualitative content analysis focuses on

the characteristics of language as communication, in particular, the content or contextual meaning (Krippendorff, 2004). This systematic conceptualization of the text is also referred to as meaning categorization (Kvale, 2007). Therefore, qualitative content analysis can be defined as: "a research method for the subjective interpretation of the content of text data through the systematic classification process of coding and identifying themes or patterns" (Hsieh and Shannon, 2005, p. 1278). 


\subsubsection{Applications of qualitative content analyses}

Hsieh and Shannon (2005) identify three distinct approaches to qualitative content analysis: conventional, directed, and summative content analysis. The key difference among these three approaches is the process of category identification to provide a means to increasing the understanding of the phenomenon (Cavanagh, 1977). In conventional content analysis, researchers avoid applying preconceived categories to texts and derive category descriptions from the data (Weber, 1990). Also described as the inductive approach to category development, categories are induced by employing an iterative process of reading, testing, and revising the data (Eisenhardt 1989; Mayring, 2000). In an inductive approach, data analysis commences with reading and re-reading all data to achieve immersion and obtain an overall impression (Tesch, 1990; Kvale, 2007). As this process continues, initial thoughts and analysis emerge and then become the initial coding scheme. The process continues until these emergent coding schemes become meaningful clusters or coding categories (Krippendorff, 2004).

Directed content analysis provides a more structured process than in an inductive approach (Hickey and Kipping, 1996). In directed content analysis, researchers utilize existing theory or research to help determine the initial coding categories or criteria of analysis. Any text that cannot be categorized within the initial coding category is assigned a new code, i.e. based on existing theory or research. This is referred to as deductive approach to category development (Eisenhardt 1989; Mayring, 2000). Another strategy to deductive approach is to initiate coding categories with the predetermined codes at once.

In summative content analysis, researchers first identify and quantify occurrences of specific words and content in text by hand or by using computer programs. These words and content are then interpreted to discover underlying the meanings of certain words or context (Babbie, 2004). Also described as manifest content analysis (Potter and LevineDonnerstein, 1999), a summative approach can provide insights as to how words are used in relation to context. 


\subsubsection{Methodology of content analyses as employed}

The primary focus of the content analyses employed in this dissertation was a qualitative approach. The use of analytic approaches to category coding and analysis is summarized in Table 1.2.

Table 1.2 Analytic Approaches Employed to Content Analyses

\begin{tabular}{|c|c|c|c|c|}
\hline Research Phase & $\begin{array}{l}\text { Content } \\
\text { Analysis } \\
\text { Employed }\end{array}$ & $\begin{array}{l}\text { Unit(s) of } \\
\text { Analysis }\end{array}$ & $\begin{array}{l}\text { Qualitative } \\
\text { Analytic } \\
\text { Approach } \\
\text { Employed } \\
\end{array}$ & $\begin{array}{l}\text { Extent of } \\
\text { Quantitative } \\
\text { Approach }\end{array}$ \\
\hline Phase 1 & $\begin{array}{l}\text { Primary Content } \\
\text { Analysis }\end{array}$ & CSDRs & $\begin{array}{l}\text { Inductive } \\
\& \\
\text { Deductive }\end{array}$ & $\begin{array}{l}\text { Descriptive Statistics on } \\
\text { CSDR Demographics \& } \\
\text { the Criteria of Analysis }\end{array}$ \\
\hline Phase 2 & $\begin{array}{l}\text { Sequential } \\
\text { Content Analysis }\end{array}$ & CSDRs & $\begin{array}{l}\text { Inductive } \\
\& \\
\text { Deductive }\end{array}$ & $\begin{array}{l}\text { Descriptive Statistics on } \\
\text { CSDR Demographics \& } \\
\text { the Criteria of Analysis }\end{array}$ \\
\hline Phase 3 & $\begin{array}{l}\text { Content } \\
\text { Analyses }\end{array}$ & $\begin{array}{l}\text { Case Company } \\
\text { Documents \& } \\
\text { CSDRs of Key } \\
\text { Suppliers }\end{array}$ & $\begin{array}{l}\text { Inductive } \\
\& \\
\text { Deductive }\end{array}$ & $\begin{array}{l}\text { Descriptive Statistics on } \\
\text { the Criteria of Analysis }\end{array}$ \\
\hline
\end{tabular}

As can be seen in Table 1.2, a combination of inductive and deductive approaches comprised the majority of the overall analytic approach whereas the use of the quantitative approach was rather limited. Referring to Mayring (2000) and Krippendorff (2004) the methodological process of content analyses in this study is further explained in four key steps (Table 1.3).

\section{Table 1.3 Steps of Content Analyses Employed}

\begin{tabular}{|c|c|}
\hline Steps & Summary Description \\
\hline Step 1: Material Collection & Define and collect the units of analysis. \\
\hline Step 2: Descriptive Analysis & Devise the background for subsequent content analysis. \\
\hline Step 3: Category Identification & $\begin{array}{l}\text { Establish the categories of analysis and apply them to the units of } \\
\text { analysis. }\end{array}$ \\
\hline Step 4: Material Evaluation & Analyze the material according to rules of analysis. \\
\hline
\end{tabular}




\section{Material Collection}

The units of analysis for the primary content analysis (Phase 1) and sequential content analysis (Phase 2) were CSDRs. CSDRs characteristically report and evaluate corporate initiatives from the perspective of environment, health, safety, and other sustainability related aspects (Karen, 2008). The details regarding the sampling procedures and material collection for Phase 1 and Phase 2 are presented in Chapter 2 (see Section 2.4) and Chapter 3 (see Section 3.3) respectively. In addition to CSDRs, the units of analysis for Phase 3 included case companies' key internal documents and CSDRs of major suppliers (see Chapter 3, Section 4.4).

\section{Descriptive Analysis}

Information about CSDRs was assessed and presented to use in subsequent analysis through establishing demographic patterns. This was achieved by conducting univariate analysis to present the sample demographics, e.g., the industry sectors, and occurrences of the coding categories across CSDRs.

\section{Category Identification}

The application of the deductive approach was informed by the existing research on SSCM. The literature review resulted in identifying six themes applied to SSCM related research. These included: reporting, governance, integration of CSR into SCM, performance measurement, standards and monitoring, and collaboration (see Chapter 2, Table 2.2). These six themes constituted the initial coding categories. The inductive approach to qualitative content analysis began with reading the units of analysis from end-to-end to inform initial thoughts and get an overall impression. The initial coding schemes that started emerging from this process were then tested and corroborated with the six initial coding categories that resulted from the deductive approach. This iterative process continued until the identification of seven coding categories or criteria of analysis: supply chain governance, supply chain strategy, performance indicators, standards, supplier monitoring, supply chain collaboration, and forward looking statements on SSCM. The extent of the quantitative approach to content analyses was 
peripheral in that descriptive statistics - i.e., univariate analysis - were used to present the sample demographics and occurrences of the coding categories.

\section{Material Evaluation}

Finally, as informed by the coding categories and existing research, keyword searches were systematically applied to CSDRs. The resulting statements from the keyword searches were categorized on the basis of each individual CSDR. Further, the results were recorded in a worksheet for each corporation (by row) according to the each individual criterion employed (by column). A " $y$ " - indicating the existence of an individual criterion - or an " $n$ " - indicating the absence of an individual criterion - was entered in the worksheet. The results were, then, presented and discussed in detail (see Chapter 2, Section 2 and Chapter 3, Section 3).

\subsubsection{Reliability and validity issues}

Reliability of content analysis refers to the clarity and interpretation of categories coded by researchers. Validity refers to the degree to which a coding category is capable of measuring for which it was constructed (Krippendorrf, 2004). The findings of content analysis can be rather subjective if based solely on the judgements of a single researcher (Potter and Levine-Donnerstein, 1999). The most commonly recommended measure to address this inherent bias is to calculate Cohen's kappa to identify the level of agreement, or discrepancy, of interpretations between different coders (Potter and LevineDonnerstein, 1999; Lombard et al., 2002; Krippendorff, 2004). Another challenge to inductive approach to content analysis is failing to achieve a complete immersion of the context, thus failing to develop key categories of analysis (Krippendorff, 2004).

Similarly, a major limitation to deductive approach is that using theory or research may

prompt researchers to find evidence that is supportive rather than unsupportive of existing theory or research (Hsieh and Shannon, 2005). Further, overemphasizing the existing theory and research in category coding has a negative impact on the concept of neutrality or objectivity of analysis (Lincoln and Guba, 1985). 
This study did not address inter-coder reliability by calculating Cohen's kappa simply because the coding was employed by a single researcher. However, the reliability and validity issues were addressed by using other measures. For example, reliability may be improved by re-coding (Krippendorff, 2004). Re-coding was initially employed during the inductive approach to category identification by re-reading and testing the data with the six initial coding categories that resulted from the deductive approach. Further, prior to the primary content analysis, a pilot content analysis of 25 CSDRs was conducted (see Morali and Searcy, 2010a). The seven coding categories (supply chain governance, supply chain strategy, performance indicators, standards, supplier monitoring, supply chain collaboration, and forward looking statements on SSCM) from this pilot content analysis were re-coded during the primary content analysis. Another measure is the comparison of results with existing research in the sense of triangulation (Mayring, 2000). This measure was employed during the discussions of the results (see Chapter 2, Section 2.6; Chapter 3, Section 3.4; Chapter 4, Section 4.5). From this perspective, the use of the deductive approach to content analysis was particularly helpful in providing evidence with linkages to existing theory or research. To address the reliability and validity issues, other authors emphasize the transparency, i.e., demonstrating a link between the results and the data by detailed description and documentation of the methodological approach (Weber, 1990; Kolbe and Burnett, 1991; Polit and Beck, 2004). Increasing the trustworthiness of the research by using authentic citations is another measure (Patton, 1990). The evidence, in particular, "can be presented by showing codes with exemplars and by offering descriptive evidence" (Hsieh and Shannon, 2005, p. 1282). All of these measures were employed by describing the process in as much detail as possible and providing citations, tables, and appendices as relevant.

\subsubsection{Interviews}

Kvale (1983) defines the qualitative research interview as: "an interview, whose purpose is to gather descriptions of the life-world of the interviewee with respect to interpretation of the meaning of the described phenomena" (p. 174). Interview is a conversation where "inter-views" are exchanged and "knowledge is constructed in the inter-action between the interviewer and interviewee" (Kvale and Brinkmann, 2009, p. 2). The interview 
method is commonly employed in qualitative research because it enables researchers to obtain information that might otherwise be difficult to obtain to answer a research question (Kvale, 1983). Further, interviews can be employed at any point in the process of data collection and can be employed together with other research methods within the same study (Brewerton and Millward, 2001).

Interviews can be categorized into three forms: structured, unstructured, and semistructured. The use of the appropriate form depends on the research question and analytic strategy (Kvale, 2007). Structured interviews utilize a predetermined set of questions, which prompts the interviewee to choose from a number of prearranged answers. This form of interviews is similar to a self-administered questionnaire with the added benefit of enabling an interviewer to clear out any queries. However, structured interviews are not conducive to analysis using inductive approaches. Unstructured interviews, on the other hand, begin with broad open-ended questions and evolve as the interview process unfolds. Although the process results in rich and in-depth data, the use of unstructured interviews is very limited outside sociology due to a number of significant validity and reliability issues (Kvale, 2007; Cachia and Millward, 2011).

In semi-structured interviews: "a predetermined set of questions is used as an interview guide but additional questions can be introduced to facilitate further exploration of issues brought up by the interviewee, thus almost taking the form of a managed conversation (Cachia and Millward, 2011, pp. 268-269). Further, semi-structured interviews can centre on both closed-ended and open-ended questions to enrich the data collection by allowing interviewees to elaborate on points of interest. To reach this objective, interviews can employ a variety of communication media such as face-to-face, telephone, and internet, i.e., e-mail and video conference (Opdenakker, 2006). Researchers choose the type of interview media depending on the research question and analytic strategy, convenience and accessibility, and level of information and social cues desired by the interviewer, e.g., voice, intonation, and body language (Opdenakker, 2006; Kvale and Brinkmann, 2009). 


\subsubsection{Methodology of interviews as employed}

The type of the interviews employed in this dissertation was semi-structured. Interviews in Phase 1 were conducted exclusively over the telephone whereas interviews in Phase 3 employed both face-to-face and telephone. The use of the telephone as an interview medium is appropriate if access is otherwise difficult or not possible (Creswell, 1998). Miller (1995) explains: "telephone interviews are not better or worse than those conducted face-to-face" (p. 37). The choice for telephone versus face-to-face interviews is heavily influenced by logistics (Burke and Miller, 2001). Further, Sturges and Hanrahan (2004) find that both telephone and face-to-face media as being equally convenient, with the telephone medium offering additional privacy. Referring to Kvale (2007) and Weisberg et al. (1996), the methodological process of semi-structured interviews followed four key steps (Table 1.4).

Table 1.4 Steps of Interview Process

\begin{tabular}{ll}
\hline Steps & Summary Description \\
\hline \hline Step 1: Thematization & Introduce the purpose of the interviews. \\
Step 2: Design & Provide details of the interview and list the interview questions. \\
Step 3: Transcription & Take notes during the interviews. \\
Step 4: Analysis & Analyze the data \\
\hline
\end{tabular}

\section{Thematization}

Prior to the design stage, the purpose of the interviews was identified as to explore the research questions in greater depth. Interview protocols - both for Phase 1 and Phase 3 interviews - summarizing the key objectives, interview process, and the interview questions were prepared.

\section{Design}

The design stage commenced with acquiring the Research Ethics Board's (REB) approval at Ryerson University. The interview questions were derived from a 
combination of the research questions and the results from the primary content analysis. The participants were identified on the basis of topic knowledge, ability to provide detailed experiential information about SSCM, and their willingness to talk (Morse, 1991). Therefore, in Phase 1, invitations to participate in the interviews along with the interview protocol and informed consent form were sent electronically to senior level employees of Canadian corporations. These employees represented business units in supply chain management or sustainability departments, or equivalent, of: 100 Canadian corporations whose reports were reviewed in the content analysis; and 92 Canadian corporations which were listed in the Network for Business Sustainability (NBS) membership directory. Non-responders were e-mailed a reminder message two weeks after the initial e-mailing. A duplicate message was e-mailed one month following the initial e-mailing for remaining non-responders. A final reminder message was e-mailed two weeks after the duplicate message for remaining non-responders (Dillman et al., 2009).

In Phase 3, the participants were the internal experts who were identified by the Strategic Sourcing Group (SSG) at the case financial services company. Interviewees were senior level executives and managers, representing business units in Community and Environment, Corporate Marketing, SSG, Human Resources, Compliance, and Enterprise Real Estate. The key informant from the case financial services did not want to involve any external stakeholder, e.g., suppliers or customers, in the interview process. Therefore, the interviews solely involved the internal experts from the case company.

\section{Transcription}

Transcription of the interviews was done by taking summary notes during the interviews. Although the interviews could be tape recorded, with the permission of the interviewee, note taking option was chosen to prevent interviewee discomfort; therefore, to increase the participation rate. Participants were given the opportunity to review the notes.

\section{Analysis}


The analysis of the interview data focused on an inductive approach, in particular, an analytical method called "bricolage" (Kvale, 2007). This method involves reading and rereading the interview notes to establish a close familiarity with the data, and then analyzing it by meaning categorization and meaning interpretation. When the interviewees' answers were ambiguous or contradictory, the meaning interpretation approach was utilized. This approach simply involved rephrasing an answer or attempts at clarification during the interviews (Kvale, 2007). Meaning categorization, on the other hand, involved a systematic conceptualization of a statement. This was achieved by reading the interviews through and getting an overall impression (Kvale, 2007).

\subsubsection{Reliability and validity issues}

To enhance reliability and validity, a copy of the interview notes was e-mailed to the interviewees for verification of their responses to the questions. The interview notes were then finalized by incorporating revisions or additional comments from the interviewees. Another area of concern was the interviewer effect, which refers to influencing responses from participants by subtly communicating the expected answers (Kvale, 2007). However, this issue was mitigated by: carefully designing the interview protocol, being aware of the interviewer effect, and seeking alternative sources of information from publicly available data for confirmation (Kvale, 2007; Salkind, 2009).

\subsubsection{Case Studies}

Eisenhardt (1989) describes the case study method as: "a research strategy which focuses on understanding the dynamics present within single settings" (p. 534). The case study method is particularly suited to creating knowledge in management sciences since the method typically involves interaction with practitioners in organizational settings to investigate the phenomenon in its context where events related to the area of research are rapidly unfolding (Pettigrew, 1973; Amabile et al., 2001). Further, case studies can involve single or multiple cases, qualitative and quantitative data, and various levels of analysis (Yin, 2010). Therefore, case studies have a distinctive place in evaluation research and can be conducted with many different motives: to provide explanation or 
description of the phenomenon, test theory, generate theory, and seek answers to the types of research questions "how" and "why" (Eisenhardt, 1989; Yin, 2010). Case studies were used in this dissertation to address the third research objective: integration of the environmental and social criteria of CS into supplier assessment and selection.

\subsubsection{Case studies as employed}

Phase 3 of the research involved conducting two case studies to address a commonlycited challenge to SSCM implementation: sustainable supplier selection (see Chapter 2, Section 2.2). Therefore, the scope of the case studies within this study consisted of partnering with two Canadian corporations to develop original supplier evaluation models on the basis of environmental and social criteria. Referring to Eisenhardt and Graebner (2007) and Yin (2010) the methodological process of case studies is further explained in four key steps (Table 1.5).

Table 1.5 Steps of Case Studies Employed

\begin{tabular}{ll}
\hline Steps & Summary Description \\
\hline \hline Step 1: Design & $\begin{array}{l}\text { Identify study objectives, its unit(s) of analysis, and the logic linking } \\
\text { the process to the study objectives. }\end{array}$ \\
Step 2: Data Collection & Identify data sources and data collection approaches. \\
Step 3: Analysis & Analyze the material according to analytic approach chosen. \\
Step 4: Presentation & Write the case study report. \\
\hline
\end{tabular}

Design

The research objective for the case studies was identified as the integration of the environmental and social criteria of CS into supplier assessment and selection. The case companies were selected based on their willingness to commit internal resources to the study, their commitment to SSCM practices as identified in their CSDRs, and their interest in enhancing their supplier selection processes by integrating the CS criteria. With this in mind, the main strategy of the case study inquiry was a holistic multiple-case study design (Yin, 2010). In this particular case study design, each case company was the 
subject of an individual case study within the same context of inquiry: sustainable supplier selection. This holistic design approach enables addressing the research objective by considering the two case companies as a single unit of analysis. This, in turn, enables more accurate and generalizable analysis (all else being equal) of emergent findings (Eisenhardt, 1991). It should be noted that the results from the individual case studies were generalized as more contextual rather than statistical (Yin, 2010) (Figure1.3).

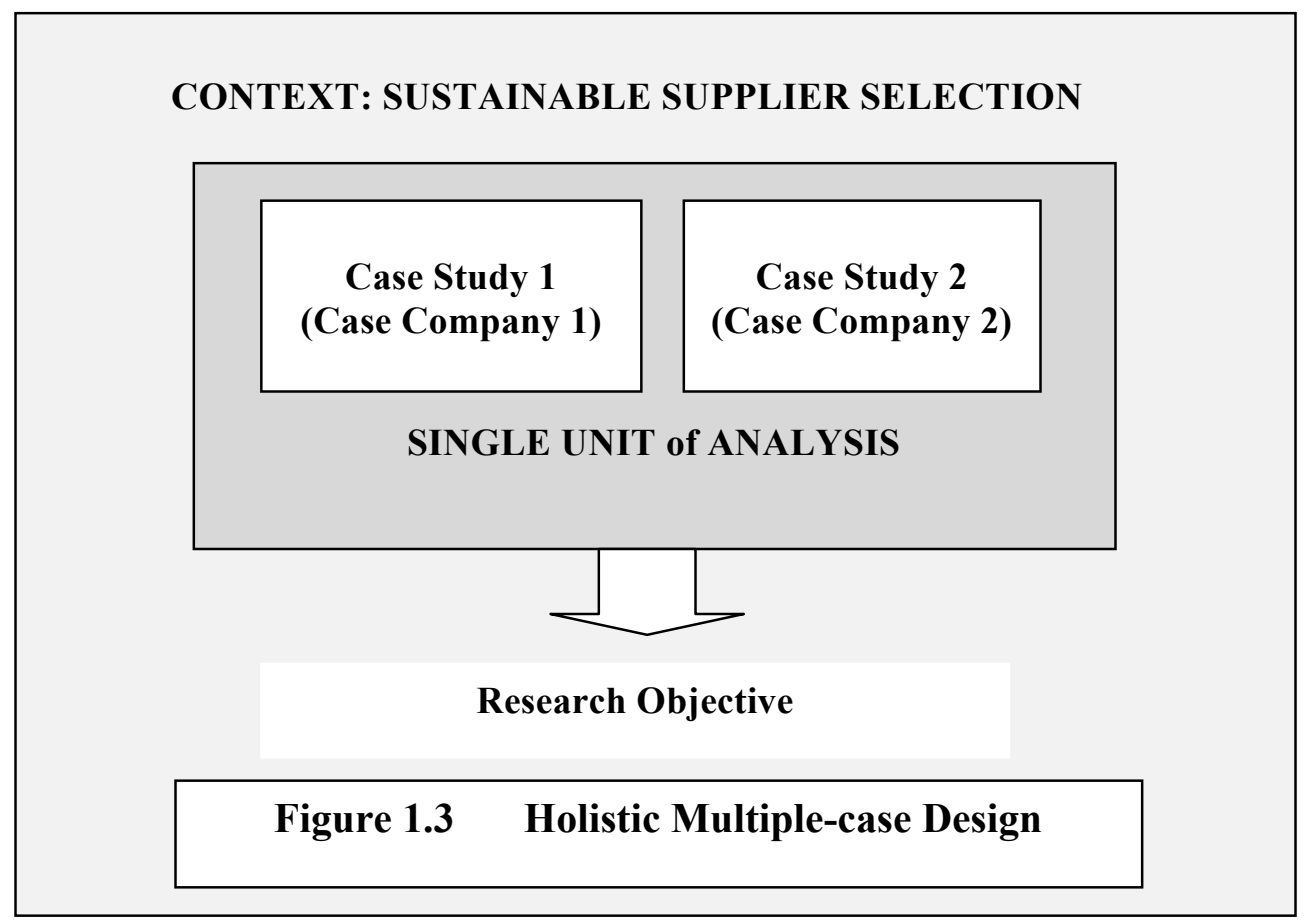

The case study process was linked to the research objective by employing a systemic approach: the Sustainable Supplier Selection (3S) Design Process (see Chapter 4, Section 4.3). The 3S Design Process provided a highly structured process to designing a system of indicators which characterize the environmental and social aspects of CS for the supplier selection model.

\section{Data Collection}

A key strength of the case study method is the opportunity to use various sources of evidence (Eisenhardt and Graebner, 2007). Yin (2010) identifies four overriding 
principles important to collecting case study data: "follow case study protocol; use multiple sources of evidence; create case study database; and maintain chain of evidence" (p. 98). According to this guideline, case study protocols which described the case study objectives, process, and likely data sources were prepared for both case companies. Data sources included: (1) CSDRs of Canadian corporations and, where applicable, the case company's suppliers; (2) interviews and consultations with the case companies' employees; and (3) other internal documents provided by the case company. Chain of evidence refers to allowing: "an external observer to follow the derivation of any evidence from initial research questions to ultimate case study conclusions" (Yin, 2010, p. 122). The 3S Design Process employed in the case studies was the main instrument in maintaining a chain of evidence. Further, consultations were structured with specific session agendas and, when appropriate, deliverables for the follow-up sessions. Finally, a case study database was created for each case company by documenting the data collected from each interview and consultation session and writing a case study report.

\section{Analysis}

The data from the content analyses, interviews, and consultations were analyzed by employing inductive and deductive analytic approaches that were explained in Section 1.3.1.2 and Section 1.3.2.1. The results from the case studies were discussed by employing "cross-case synthesis", an analytic technique which aggregates findings across individual case studies (Yin, 2010). Further, "theory triangulation" was employed to explain and verify case study findings by employing multiple theoretical perspectives. With that in mind, emphasis was devoted to show that the analysis covered the research objective while attending to all the evidence (Gibbert et al., 2008; Yin, 2010).

\section{Presentation}

Case study reports were written and, then, sent to the principal informants at the case companies for their review and record. These reports formed the basis for developing the journal manuscript, entitled: "Integrating Corporate Sustainability into Supplier 
Selection: Lessons from Two Canadian Case Studies" (see Section 1.4) and Chapter 4 of this dissertation.

\subsubsection{Reliability and validity issues}

The domain of reliability is replication of results or observations of a study under a similar methodology (Creswell, 1998). The general strategy to address the reliability concern is to minimize the random errors and biases through careful documentation and clarification of the research process (Yin, 2010). Internal validity refers to establishing causal relationships between variables and results (Creswell, 1998) and, therefore, it is only a concern for causal or explanatory case studies (Yin, 2010). One measure to enhance internal and external validity is to utilize theory triangulation. External validity, on the other hand, is concerned with the statistical and analytical generalizability of the study. Neither single nor multiple-case studies allow for statistical generalization, i.e., from samples to universes (Gibbert et al., 2008). Analytic generalization is the quest to: "generalize a particular set of results to some broader theory" (Yin, 2010, p. 43).

Eisenhardt (1989) suggests multiple-case studies of 4 to 10 cases to form a good basis for such generalization. Similarly, Yin (2010) argues the necessity of replicating the findings in 9 to 12 cases to develop analytical generalization, which is imperative to developing theoretical frameworks. Finally, construct validity concerns with the subjective measures of data collection and quality of operationalization of the study, i.e., the extent to which a process results in a true observation of reality (Yin, 2010). These three types of validity are interdependent of one another: "Without a clear theoretical and causal logic (internal validity), and without a careful link between the theoretical conjecture and the empirical observations (construct validity), there can be no external validity in the first place" (Gibbert et al., 2008, p. 1468).

The reliability and, at the same time, construct validity of the study in this dissertation was mitigated by employing a systematic and replicable procedure: The 3S Design Process. Moreover, the 3S Design Process markedly helped establish a chain of evidence. 
The reliability was further increased by using case study protocols and creating case study databases. As suggested by Gibbert et al. (2008) and Yin (2010), the construct validity was addressed by using multiple sources of evidence, establishing a chain of evidence, and having a key informant (the principal informants at both case companies) review the draft case study reports. Although the case studies conducted in this dissertation did not aim causal claims, nor did it seek to make statistical or analytical generalizations, theory triangulation was employed in the analysis of the findings (see Chapter 4, Section 4.5) to enhance the internal and external validity.

\subsection{Structure of the Dissertation}

This dissertation is organized around four remaining chapters as follows:

\section{Chapter 2 (A Review of Sustainable Supply Chain Management in Canadian}

Corporations) addresses Phase 1 of the research. The chapter is based on the paper:

Morali, O., Searcy, C.: 'A Review of Sustainable Supply Chain Management in Canada', Journal of Business Ethics (JBE), (forthcoming), DOI: 10.1007/s10551-012-1539-4.

The primary author of the paper is Mr. Oguz Morali. Mr. Morali's involvement with the development of the paper includes: concept development, category identification for analysis, conducting the research, writing, and corresponding with the journal with respect to its publication. The secondary author, Dr. Cory Searcy's involvement with the development of the paper includes: concept development, supervision of the research process, and review of the paper for publication. Building on the literature review that focuses on the concept, theoretical background, and implementation of SSCM, the manuscript addresses Objective 1 and two associated research questions. The research questions provide the basis for structuring the criteria for reviewing SSCM practices in Canadian corporations. Further, Chapter 2 informs and substantiates the second and third research gaps that were identified in Section 1.2 above.

Chapter 3 (Evolution of Sustainable Supply Chain Management) addresses Phase 2 of the research. The chapter is based on a manuscript that is currently being revised for 
resubmission for publication as follows:

Morali, O., Searcy, C.: 'Evolution of Corporate Sustainability in Supply Chain Management: A Canadian Perspective', Journal of Purchasing and Supply Management (JPSM).

The primary author of the manuscript is Mr. Oguz Morali. Mr. Morali's involvement with the development of the manuscript includes: concept development, category identification for analysis, conducting the research, writing, and corresponding with the journal with respect to its publication. The secondary author, Dr. Cory Searcy's involvement with the development of the manuscript includes: concept development, supervision of the research process, and review of the paper for publication. Based on the manuscript, the Chapter presents a longitudinal case study in which the emphasis is placed on Canadian corporations. The selection of the criteria of analysis for this study i.e., sequential content analysis - is based on the primary content analysis that is presented in Chapter 2.

Chapter 4 (Integration of CS into Supplier Assessment and Selection) addresses Phase 3 of the research. The chapter is based on a manuscript that is currently being revised for resubmission for publication as follows:

Morali, O., Searcy, C. 'Integrating Corporate Sustainability into Supplier Selection: Lessons from Two Canadian Case Studies', Supply Chain Management: an International Journal.

The primary author of the manuscript is Mr. Oguz Morali. Mr. Morali's involvement with the development of the manuscript includes: concept development; conducting the research, e.g., case company identification, developing case study proposals and protocols, carrying out interviews and consultations, and writing the case study reports; writing; and corresponding with the journal with respect to its publication. The secondary author, Dr. Cory Searcy's involvement with the development of the manuscript includes: concept development; supervision of the research process, e.g., case company identification, participating in case study consultations, and developing indicators; and 
review of the paper for publication. Based on the manuscript, the Chapter addresses the integration of the environmental and social dimensions of CS into supplier assessment and selection. This is achieved by conducting two case studies of Canadian corporations to develop two sustainable supplier selection models: one exclusively based on environmental criteria and one based on environmental and social criteria.

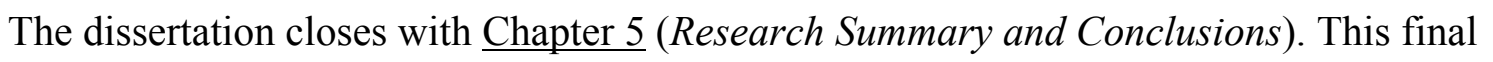
chapter builds on the research phases that are presented in Chapters 2, 3, and 4: to summarize the results and list the key findings; to present the conclusions and recommendations; to identify the research limitations and areas for future research; and to review the contributions of the dissertation. 


\section{CHAPTER 2 - A REVIEW OF SUSTAINABLE SUPPLY CHAIN MANAGEMENT PRACTICES IN CANADIAN CORPORATIONS}

\subsection{Introduction}

Over the past two decades, increasing pressures from governments, customers, employees, shareholders, and other stakeholder groups have prompted businesses to address the economic, environmental, and social implications of their activities. As a result, the concept of sustainability and its applications to business practices have gained prominence. Integrating the concept of sustainability with core business functions that fall within the domain of supply chain management (SCM), such as procurement, logistics, and knowledge management, has led to a critical and interdisciplinary field: sustainable supply chain management (SSCM). However, although the theory and practice of SSCM have been evolving fast, many corporations are still searching for the best ways to incorporate and implement sustainability principles into their supply chain. Further, while the literature on SSCM is plentiful and growing, a rather small amount of research has been conducted on the extent to which corporations have built sustainability principles into their SCM practices. The purpose of this study is to shed light on this issue, provide insight and examples into current practices, encourage thinking and discussion into how the key gaps might be addressed, and provide a basis for future studies. Canada was used as a case study, which employed a content analysis of 100 CSDRs and interviews with 30 corporate experts.

With that in mind, this chapter presents the results of a study designed to address the first research objective: Explore the extent to which CS principles are integrated into SCM in corporations and two interrelated research questions:

$R Q-1$ : What are the organizational structures, standards, and management instruments and processes that corporations adopt to implement sustainability initiatives within SCM?

$R Q-2:$ How do corporations utilize the collaborative paradigm to address sustainability issues within SCM, particularly as they relate to supplier encouragement? 
The structure of the chapter is organized around seven sections. In Section 2.2, a review of the literature on SSCM is provided. Focus is particularly devoted to the relationship between the principles of sustainability and their integration into the SCM field. In Section 2.3, the research questions are presented. In Section 2.4, the methodology of the study is introduced. In Section 2.5, the results from a content analysis of 100 Canadian CSDRs and in-depth interviews with 30 corporate experts are presented. In Section 2.6, a discussion of the results is provided. Finally, the chapter ends with a section on the conclusions.

\subsection{Literature Review}

The literature review has two primary objectives. The first objective is to introduce the concept of sustainable development and SSCM, with particular emphasis given to theoretical background and discussions. The second objective is to report the state of SSCM implementation by corporations. A two-phase approach was employed to increase the transparency and improve the replicability of the literature review (Fink, 2005). The first phase involved using a preliminary set of keywords (Table 2.1) to guide the search process by identifying the peer-reviewed research that explicitly included SSCM in its title.

Table 2.1 Literature Review Search Terms

\begin{tabular}{|c|c|c|c|}
\hline \multicolumn{4}{|c|}{ Keywords } \\
\hline $\begin{array}{l}\text { Preliminary } \\
\text { search term }\end{array}$ & Sustainable suppl & ement & \\
\hline $\begin{array}{l}\text { Sequential } \\
\text { search terms }\end{array}$ & $\begin{array}{l}\text { Accountability } \\
\text { Audit } \\
\text { Buying } \\
\text { Code } \\
\text { Collaboration } \\
\text { Cooperation } \\
\text { Economic } \\
\text { Encourage(ment) } \\
\text { Environment(al) } \\
\text { Evaluation } \\
\text { Governance } \\
\text { Green }\end{array}$ & $\begin{array}{l}\text { Ethic(al) } \\
\text { Health } \\
\text { Human rights } \\
\text { Integration } \\
\text { Indicator } \\
\text { Legitimacy } \\
\text { Manufacturing } \\
\text { Measure(ment) } \\
\text { Network } \\
\text { Logistics } \\
\text { Monitor } \\
\text { Purchasing } \\
\text { Performance }\end{array}$ & $\begin{array}{l}\text { Risk (management) } \\
\text { Social } \\
\text { Social enterprise } \\
\text { Social responsibility } \\
\text { Stakeholder } \\
\text { Supplier management } \\
\text { Supply chain management } \\
\text { Standard } \\
\text { Strategic } \\
\text { Value chain } \\
\text { Vendor } \\
\text { Theory }\end{array}$ \\
\hline
\end{tabular}


This resulted in identifying 59 articles for initial inclusion in the search database. A review of the titles and keywords from these 59 articles helped in further identification of the keywords (see the sequential search terms in Table 2.1) for the second part of the literature review. The second phase involved the application of different combinations of the keywords from Table 2.1.

Keyword searching presents challenges to literature reviews. These include: locating the first article, locating the quality sources to search, using the field-specific buzzwords, and identifying all the applicable keywords for an unknown field (Levy and Ellis, 2006).

Therefore, it was necessary to go beyond keywords and use the backward approaches to mitigate these challenges (Webster and Watson, 2002; Levy and Ellis, 2006). Backward approaches included backward references search (reviewing the references of the articles yielded from the preliminary and sequential keyword searches noted in Table 2.1 above), backward authors search (reviewing the authors' previous works), and previously used keywords search (reviewing the keywords from the articles yielded from the preliminary and sequential keyword searches noted in Table 2.1 above).

Another measure was to include the top ranking management and business journals from the ranked journal lists of the Financial Times top 45 journals (FT 45), Australian Research Council, and the Journal Citation Reports (JCR). Webster and Watson (2002) suggested: "the major contributions are likely to be in the leading journals. It makes sense, therefore, to start with them" (p. 16). Further, to maximize the number of relevant articles in quality sources, keyword searches included JSTOR, ProQuest, Science Direct, Scholars Portal, and Google Scholar databases. To limit the articles to a manageable number, the articles that did not meet the two primary objectives in conducting the literature review were excluded.

\subsubsection{Sustainability and Supply Chain Management}

A prevalent and far-reaching definition of sustainable development is: "development that meets the needs of the present without compromising the ability of future generations to meet their needs" (World Commission on Environment and Development, 1987, p. 8). At 
the core of sustainability is the interrelated relationship between the three pillars of sustainability, which have been translated into a corporate context by many authors (e.g.., Marrewijk, 2003; Garriga and Mele, 2004; Steurer et al., 2005; Gray, 2010), leading to different definitions of CS with different system boundaries. Dyllick and Hockerts (2002, p. 131) provide one representative definition of CS as: "meeting the needs of a firm's direct and indirect stakeholders (such as shareholders, employees, clients, pressure groups, communities, etc.), without compromising its ability to meet the needs of future stakeholders as well."

Marrewijk (2003) points to the application of the concept of CS to supply chain issues as particularly complex and challenging. During the 1990s and early 2000s, increased concerns over the environmental impacts of firms' activities prompted the extension of supply chains to include by-products and to consider the entire lifecycle of a product. Within this context, organizations have adopted and integrated various environmental principles and management practices, such as the Cleaner Production Programme, Valdez Principles, and the EMAS environmental management systems with SCM (Tsoulfas and Pappis, 2006; Vachon and Klassen, 2006a). While research has shown that environmental decision-making tools and green supply chain practices positively affect corporate and environmental performance (Handfield et al., 1997; Melnyk et al., 2003; Zhu and Sarkis, 2004; Michelsen et al., 2006; Darnall et al., 2008), focusing solely on environmental parameters may be counterproductive to improving the "triple bottom line" (Elkington, 1998, 2004) of corporate performance (Matos and Hall, 2007). From the micro-economic perspective, SSCM has emerged as a result of marrying the three pillars of sustainability with core business practices, such as procurement, logistics, knowledge management, marketing, and operations.

The literature provides many definitions of SSCM. Carter and Rogers (2008, p. 9) define SSCM as: "The strategic, transparent integration and achievement of an organization's social, environmental, and economic goals in the systemic coordination of key interorganizational business processes." However, several authors have noted that a theoretical background for SSCM is found to be still developing (Svensson, 2007; Carter and Rogers, 2008; Seuring and Muller, 2008b) and efforts to introduce theoretical 
frameworks for SSCM are in still in their infancy (Gold et al., 2010). Therefore, the SSCM field has drawn from a number of theories. A recent theoretical review of literature by Sarkis et al. (2011) highlights that SSCM literature relates to nine different organizational theories, which are complexity theory, ecological modernization theory, information theory, institutional theory, resource based view (RBV), resource dependence theory (RDT), social network theory, stakeholder theory, and transaction cost economics. Font et al. (2008) assert that SSCM draws from a number of theories with the principle that corporations must engage in their supply chain upstream towards producers, and downstream towards consumers in order to ascertain that every component of their products and services are sustainable. For example, a SSCM framework developed by Bowen et al. (2001) drew explicitly on the RBV to link organizational resources with triple-bottom-line performance. Carter and Rogers (2008) borrowed from four distinct theories from four different disciplines - RDT from sociology and political science, transaction cost economics from economics, population ecology from biology, and the RBV of the firm from strategic management - in an attempt to build a framework and advance future research propositions in theory development for the SSCM field. As a result, Carter and Rogers (2008) provided a theoretical framework for SSCM in which firms create a competitive advantage when long-term sustainability strategies are integrated throughout the supply chain. Further, this framework illustrates that firms that simultaneously integrate all three pillars of sustainability will achieve higher economic performance than firms that integrate only one or two. Gold et al. (2010) confirm the positive and sustained effect of SSCM on a firm's performance and - based on the framework of Bowen et al. (2001) - propose a theoretical conceptualization of SSCM as a catalyst of inter-firm resources and inter-firm competitive advantage. Derived from the RDT and RBV, Svensson (2007) also provides a conceptual framework that expands the boundaries of theory in SCM through the requisition of first- and second-order supply chains.

\subsubsection{Sustainable Supply Chain Management: Implementation}

Several authors have explored the motives for SSCM implementation. These are commonly listed as government regulations, pressures from customers and other 
stakeholders, managing company image, competitive advantage, supplier management for risks and performance, and environmental and social advocacy (Sarkis, 2001; Roberts, 2003; Darnall et al., 2008; Seuring and Muller, 2008b; Bjorklund, 2011). However, the integration of environmental and social principles between a firm and its suppliers requires upstream or downstream interaction with other organizations in the supply chain. This integration, which can be implemented at an operational or strategic level, helps generate risk management measures and environmental and social standards to which suppliers may be expected to conform, such as ISO 14001 for environmental management systems and SA8000 for social accountability (Vachon and Klassen, 2006b; Koplin et al., 2007; Mueller et al., 2009). International standards may bear sufficient legitimacy among stakeholder groups to be perceived as appropriate risk reduction mechanisms (Rosen et al., 2002; Roberts, 2003). The risk management aspect is particularly vital for firms in a global economy where increased demands of integration have broadened the definition of the supply chain. This is because firms' brand image and competitiveness in the marketplace may be dependent upon their suppliers' practices that defy the principles of sustainability (Meixell and Gargeya 2005; Cousins et al., 2004; Matos and Hall, 2007). A systematic approach to risk management can help firms provide sustainable benefits to all supply chain partners while presenting them competitive advantages over others (Teuscher et al., 2006). In particular, integrating and implementing supplier assessment methods on sustainability risks present opportunities in developing core capabilities, which lead to competitive advantage for firms (Foerstl et al., 2010).

As mentioned above, there are many different factors that motivate corporations to adopt SSCM practices. The same factors also have an impact on the level of integration (quantity and diversity of initiatives taken) and intensity (suppliers involved) of the related practices in the supply chain (Font et al., 2008). Hence, agreeing on the successful execution of SSCM practices is not an easy task. The literature lists many challenges to integration and implementation of SSCM, such as: (a) Lack of understanding the intricate interplay between the three pillars of sustainability and how that affects the economic bottom line, (b) capital investment commitments, (c) risk management and supplier 
monitoring, (d) measurement, (e) transparency of information and knowledge, (f) alignment of corporate strategy with SSCM initiatives, and (g) corporate culture (Storey et al., 2006; Carter and Rogers, 2008; Seuring and Muller, 2008a; Linton et al., 2007 cited in Morali and Searcy, 2010a).

The literature presents relatively few studies on many of those challenges. Several authors have conducted research focused on large multinational companies or focused exclusively on the environmental dimension of sustainability (Michelsen et al., 2006; Koplin et al., 2007; Beske et al., 2008; Nawrocka et al., 2009; Sharfman et al., 2009; Zhu et al., 2010a). For example, the existing performance evaluation models and tools provided in the literature mostly cover green SCM practices (Veleva et al., 2003; Mintcheva, 2005; Hervani et al., 2005; Preuss, 2005; Baboulet and Lenzen, 2010), with very little research that explicitly integrates the sustainability discussion into the supplier evaluation modeling area (Hutchins and Sutherland, 2008; Bai and Sarkis, 2010). Some authors have examined the link between environmental and economic dimensions of sustainability to successful SCM implementation (Trowbridge, 2001; Vachon and Klassen, 2006a). However, the research is very limited on exploring the social dimension of sustainability within the context of SCM. Although a limited number of researchers have presented supplier evaluation schemes that incorporate environmental and social dimensions (Koplin et al., 2007; Yakovleva, 2007), the practice and understanding of SSCM is still heavily oriented to the environmental dimension of sustainability. For example, a comprehensive literature review on SSCM identified that out of 191 papers, 140 addressed the environmental dimension while only 20 addressed the social dimension (Seuring and Muller, 2008b).

The research has introduced many conceptual and anecdotal contributions to the theory and practice of SSCM field. Overall, the review of the literature has resulted in identifying six themes applied to SSCM related research (Table 2.2). 
Table 2.2 Themes Applied to SSCM Related Studies

\begin{tabular}{|c|c|}
\hline Theme & Current SSCM related study \\
\hline 1. Reporting & $\begin{array}{l}\text { Gray et al., 1995; Esrock and Leichty, 1998; Line et al., 2002; Pollach, 2003; } \\
\text { Perrini, 2005; Karen, 2008; Steurer and Konrad, 2008; Isaksson and Steimle, } \\
\text { 2009; Schneider et al., 2010; Tate et al., } 2010\end{array}$ \\
\hline 2. Governance & $\begin{array}{l}\text { Rasheed and Geiger, 2001; Gereffi, 2001; Konefal et al., 2005; Ghosh and } \\
\text { Fedorowicz, 2008; Vurro et al., 2009; Vermeulen, 2010; Alvarez et al., 2010; } \\
\text { Pullman and Dillard, 2010; Martinelli and Midttun, 2010; Blowfield and Dolan, } \\
\text { 2010; Awaysheh and Klassen, 2010; Huang, 2010; Tallontire et al., } 2011\end{array}$ \\
\hline 3. Integration of CSR practices & $\begin{array}{l}\text { Drumwright, 1994; Gildia, 1995; Sarkis, 1995a; Sarkis, 1995b; Green et al., } \\
\text { 1996; Carr and Pearson,1999; Preuss, 2000; Carter, 2000; Maignan, 2001; } \\
\text { Sarkis, 2001; Trowbridge, 2001; Feitelson, 2002; Murphy and Poist, 2002; } \\
\text { Maignan et al., 2002; Deakin, 2002; Carter and Jennings, 2002; Zhu and Sarkis, } \\
\text { 2004; Chen, 2005; Facanha and Horvath, 2005; Foran et al., 2005; Michelsen et } \\
\text { al., 2006; Maloni and Brown, 2006; Seyfang, 2006; Tsoulfas and Pappis, 2006; } \\
\text { Matos and Hall, 2007; Koplin et al., 2007; Ciliberti et al.. 2008; Darnall et al., } \\
\text { 2008; Font et al., 2008; Walker et al., 2008; Zhu et al., 2008; Vermeulen and } \\
\text { Seuring, 2009; Salam, 2009; Pagell and Wu, 2009; Bjorklund, 2011; Cowper- } \\
\text { Smith and de Grosbois, 2011; Large and Gimenez Thomsen, } 2011\end{array}$ \\
\hline 4. Performance measurement & $\begin{array}{l}\text { Noci, 1997; Veleva et al., 2003; Mintcheva, 2005; Hervani et al., 2005; Preuss, } \\
\text { 2005; Quintens et al., 2006; Sarkar and Mohapatra, 2006; Yakovleva, 2007; } \\
\text { Searcy et al., 2008; Hutchins and Sutherland, 2008; Hervani Zhu et al., 2008; } \\
\text { Hubbard, 2009; Chia et al., 2009; Chae, 2009; Bhagwat and Sharma, 2010; } \\
\text { Allesina et al., 2010; Baboulet and Lenzen, 2010; Sloan, 2010; Bai and Sarkis, } \\
\text { 2010; Roca and Searcy, } 2012\end{array}$ \\
\hline 5. Standards and monitoring & $\begin{array}{l}\text { Pearson and Seyfang, 2001; Kimerling, 2001; Morrow and Rondinelli, 2002; } \\
\text { Whitehouse, 2003; Roberts, 2003; Miles and Munilla, 2004; Castka and } \\
\text { Balzarova, 2007; Nadvi, 2008; Mueller et al., 2009; Ciliberti et al., 2009; Jiang, } \\
\text { 2009; Foerstl et al., } 2010\end{array}$ \\
\hline 6. Collaboration & $\begin{array}{l}\text { Spekman, 1998; Hoyt and Huq, 2000; Daugherty et al., 2002; Balakrishan and } \\
\text { Geunes, 2004; Daugherty et al., 2005; Cousins and Menguc, 2005; Rodríguez- } \\
\text { Díaz and Espino-Rodríguez, 2006; Emberson and Storey, 2006; Vachon and } \\
\text { Klassen, 2006a; Vachon and Klassen, 2006b; Cheung and Myers, 2008; Sodhi } \\
\text { and Son, 2009; Fawcett et al., } 2010\end{array}$ \\
\hline
\end{tabular}

The research on the "reporting" theme has focused on corporations' self-disclosure of their CS practices through the Global Reporting Initiative (GRI) reporting (Isaksson and Steimle, 2009), corporate ethics (Pollach, 2003) or CSR initiatives (Perrini, 2005; Tate et al., 2010) amongst others. The literature on the "governance" theme centred on the 
different elements of SCM governance such as the determinants of governance structure (Rasheed and Geiger, 2001; Vurro et al., 2009) and the relationship between governance, CSR practices, and firms' performance (Awaysheh and Klassen, 2010; Huang, 2010). The literature on the "integration of CSR practices" into SCM includes a wide-range of studies. For example, some research focused only on the strategic integration of environmental issues into SCM (Sarkis, 1995b; Seyfang, 2006), whereas other research studied both environmental and social aspects of SSCM (Maignan et al., 2002; Koplin et al.; 2007; Cowper-Smith and de Grosbois, 2011). Some studies analyzed the relationship between the manufacturing strategies and environmental issues (Sarkis, 2001; Sarkis, 2005a). Other topics include the relationship between operational practices and SSCM performance (Zhu and Sarkis, 2004), drivers and barriers to SSCM (Walker et al., 2008; Seuring and Muller, 2008b), integrating SSCM with other management systems and initiatives (Chen, 2005; Foran et al., 2005), best management practices from 10 case studies in creating SSCM (Pagell and Wu, 2009), and the theoretical aspects and frameworks of SSCM (Carter and Rogers, 2008; Seuring and Muller, 2008a). The research on "performance measurement" focused predominantly on measuring the environmental pillar of sustainability in the supply chain (Noci, 1997; Veleva, 2003), with only a limited number of studies that have taken the three pillars into account (Bhagwat and Sharma 2009; Bai and Sarkis, 2010). The research on supply chain "standards and monitoring" examined the diffusion of voluntary environmental and social standards such as codes of conduct, ISO 14001, and ISO 26000, and other global standards in the supply chain (Pearson and Seyfang, 2001; Morrow and Rondinelli, 2002; Castka and Balzarova, 2007; Nadvi, 2008). Finally, studies under the "collaboration" theme looked at the different characteristics of the collaborative paradigm within SCM such as the level of collaboration and best practices (Daugherty et al., 2005), system boundaries of the collaborative paradigm (Vachon and Klassen, 2006b), and effects of collaboration on the triple-bottom-line performance (Cao and Zhang, 2010).

As can be seen above, the literature has significantly contributed to the SSCM field across several themes. However, the literature on the integration of CS criteria into SCM (Table 2.2, theme 3) is fragmented. Many studies focused only on the environmental 
aspects (Drumwright, 1994; Feitelson, 2002; Sarkis, 2009) or social aspects (Cousins and Menguc, 2006; Castka and Balzarova, 2007; Hutchins and Sutherland, 2008; Ciliberti et al., 2009) of SSCM. Only a limited number of the published studies addressed all three dimensions of sustainability in SCM (Foran et al., 2005; Maloni and Brown, 2006; Koplin et al., 2007). Moreover, while the research on the conceptual and theoretical aspects of SSCM (Seuring and Muller, 2008b; Sarkis et al., 2011) has grown, the research on what is actually being done by corporations in practice is scarce. The existing research on corporate SSCM practices employed single and multiple-case study designs, which involved corporations from a variety of industry sectors and national settings (Michelsen et al., 2005; Koplin et al., 2007; Pagell and Wu, 2009; Foerstl et al., 2010). However, there is very little research on cross-case analysis (Yin, 2010), examining patterns of integration of sustainability principles in to SCM across organizations with respect to the institutional environments within which these organizations operate. The literature on corporate SSCM practices, in particular, presents major gaps in examining the variety of the formal structures and processes adopted by corporations and the degree to which they are implemented. Similarly, while the research on SCM collaboration is abundant (Hoyt and Huq, 2000; Balakrishan and Geunes, 2004; Daugherty et al., 2005; Cheung and Myers, 2008; Sodhi and Son, 2009), the literature that explicitly commits to how the collaborative paradigm is leveraged to address SSCM issues, particularly as they relate to supplier encouragement is sparse. Therefore, there is an ongoing need for case studies that investigate the extent to which CS principles are integrated in to SCM practices, particularly as they relate to investigating multiple criteria on SSCM, such as governance, collaboration, and supplier encouragement, from a holistic perspective. This study aims to highlight these gaps and offer a foundation for future research by addressing the key research objective: "Explore the extent to which CS principles are integrated into SCM in corporations."

\subsection{Research Objective and Related Questions}

The research questions for this study are derived from the key research objective noted above. The literature finds an increased use of multiple theories within the same SSCM study (Carter and Easton, 2011). 
Table 2.3 Summary of Theories Applied to Address Research Objective 1

\begin{tabular}{|c|c|c|}
\hline Theory & $\begin{array}{l}\text { Originating } \\
\text { Discipline }\end{array}$ & Summary Description of Theory \\
\hline $\begin{array}{l}\text { Contingency } \\
\text { Theory }\end{array}$ & $\begin{array}{l}\text { Organizational } \\
\text { theory, psychology, } \\
\text { strategy }\end{array}$ & $\begin{array}{l}\text { The optimal design and leadership style of an organization is } \\
\text { contingent upon various internal and external restraints. } \\
\text { Therefore, an effective organization and its subsystems must } \\
\text { fit with the environment in which it operates (Fiedler, 1971; } \\
\text { Lawrence and Lorsch, 1967; Kast and Rosenzweig, 1973; } \\
\text { Donaldson, 2001). }\end{array}$ \\
\hline $\begin{array}{l}\text { Institutional } \\
\text { Theory }\end{array}$ & $\begin{array}{l}\text { Organizational } \\
\text { theory, sociology, } \\
\text { psychology }\end{array}$ & $\begin{array}{l}\text { Institutional theory examines how social structures, } \\
\text { including schemas, rules, norms, and routines act as external } \\
\text { pressures to influence organizational and individual } \\
\text { behaviour (DiMaggio and Powell, 1983; Scott, 1987; Oliver, } \\
\text { 1991). }\end{array}$ \\
\hline $\begin{array}{l}\text { Resource based } \\
\text { view (RBV) }\end{array}$ & $\begin{array}{l}\text { Strategic } \\
\text { management, micro- } \\
\text { economics }\end{array}$ & $\begin{array}{l}\text { To achieve and sustain competitive advantage, firms must } \\
\text { possess valuable, rare, imperfectly imitable, and non- } \\
\text { substitutable (VRIN) resources (Wernerfelt, 1984; Barney, } \\
\text { 1991). }\end{array}$ \\
\hline $\begin{array}{l}\text { Resource } \\
\text { dependence theory } \\
\text { (RDT) }\end{array}$ & $\begin{array}{l}\text { Sociology, political } \\
\text { science }\end{array}$ & $\begin{array}{l}\text { The environment poses organizations with uncertainty in } \\
\text { resource acquisition. Organizations are comprised of internal } \\
\text { and external coalitions to acquire control over resources that } \\
\text { minimize their dependence on other organizations and } \\
\text { control over resources that maximize the dependence of } \\
\text { other organizations on themselves (Pfeffer and Salancik, } \\
\text { 1978; Ulrich and Barney, 1984). }\end{array}$ \\
\hline Stakeholder theory & Business ethics & $\begin{array}{l}\text { Stakeholder theory suggests that every individual or party } \\
\text { (stakeholder) participating in the activities of a firm do so to } \\
\text { obtain benefits. All stakeholder interests are intrinsically } \\
\text { valuable; however, due to externalities produced by firms, } \\
\text { the priority of these interests is not self-evident. Therefore, } \\
\text { stakeholders exert pressures on companies to reduce negative } \\
\text { impacts (externalities) and increase positive ones (Freeman, } \\
\text { 1984; Donaldson and Preston, 1995; Freeman et al., 2010). }\end{array}$ \\
\hline
\end{tabular}

The theories and theoretical frameworks presented in Section 2.1 provide an implicit background for this study. Building on that literature, the research questions addressed in this chapter are explicitly based on five theories: contingency theory, institutional theory, RBV, RDT, and stakeholder theory (Table 2.3 above). 
The basic premise of stakeholder theory is that internal and external parties exert pressure on firms to change organizational practices (Freeman, 1984; Freeman et al., 2010). Donaldson and Preston (1995) elaborated three aspects of stakeholder theory descriptive, instrumental, and normative - and placed the normative aspect at the 'core base' of stakeholder theory because agents of firms recognize all stakeholders' interests with 'intrinsic' moral values. From that perspective, stakeholder theory is particularly applicable to SSCM because stakeholders' pressure may lead firms to adopt some SSCM practices that are initially economically unfavourable (Sarkis et al., 2011).

Institutional theory and new institutionalism (Meyer and Rowan, 1977; DiMaggio and Powell, 1983; Meyer, 2000) is particularly helpful for elucidating how institutional factors, including regulative, normative, and cognitive processes act as incentives for corporations to adopt organizational structures and processes so that they operate in socially responsible ways or discourage them from operating in socially irresponsible ways. Businesses' interactions with their stakeholders and socially responsible behaviours are heavily influenced by the institutional structures and countries within which they operate (Fligstein and Freeland, 1995; Maignan and Ralston, 2002; Bartley, 2003; Bjorklund, 2010). Therefore, institutional theory facilitates the ability to scrutinize interactions among different stakeholders and to understand how corporate governance differs across nations (Aguilera and Jackson, 2003).

The institutional environment is a source of coercive isomorphism, which refers to a direct mechanism that prompts institutional diffusion based on stakeholder coercion (DiMaggio and Powell, 1983). Further, institutional factors promote such socially responsible corporate behaviour at the transnational level due to the global spread of organizational practices (Guler et al., 2002). For example, Brown et al. (2009) refer to GRI as a successful institutionalization and find that organizations adopt the GRI to gain and sustain competitive advantage and pre-empt formal regulations. Campbell (2007) argues that various institutional conditions such as state regulation, collective industrial self-regulation, NGOs and other independent organizations, and a normative institutional environment mediate the economic conditions to which firms are exposed. This, in turn, affects the degree of socially responsible corporate behaviour. Matten and Moon (2008) 
compare institutional frameworks in the United States and Europe on four institutional features - workers' rights, environmental protection, education, and corporate irresponsibility - and illustrate how adoption of CSR practices differ by national institutional frameworks. There are a number of studies that focus on the comparative analysis of ethical organizational behaviour across nations (Ardichvili et al., 2012), the concept of corporate responsibility from stakeholders' perspective in specific institutional environments (Hillenbrand et al., 2012), and the effects of the institutional distance between the home and host country on multinational corporations' decisions to standardize environmental issues (Aguilera-Caracuel et al., 2012), amongst others. However, the level of integration and implementation of SSCM practices in different institutional environments, within which corporations operate, requires further investigation. These discussions provide a basis for Objective 1:

Key research objective: Explore the extent to which CS principles are integrated into $\mathrm{SCM}$ in corporations.

Akin to institutional theory, contingency theory provides reasons for the adoption of CS practices. Paloviita and Luoma-aho (2010) show the link between institutional theory, stakeholder theory, and contingency theory by identifying the need to change stakeholder strategies since any stakeholder, including suppliers, can exert authority on organizations. The central premise of contingency theory is that an organization fits its structure to its strategy to increase its bottom line results (Donaldson, 2001). There is a relationship between contingencies, such as size and strategy, and organizational structure. For example, large corporations are more likely to adopt and implement CS practices (Pagell et al., 2004). Agents of organizations seek functional structures and processes that fit with contingencies to improve performance. Therefore, common external restraints result in similar contingencies, which in turn result in similar organizational structures (Donaldson, 2001). In fact, Rowlinson (2004) takes early institutionalism as an extension of contingency theory because the structure of an organization becomes meaningful for its members even though the structure is distorted of its rational purposes. For example, there is a growing number of global initiatives, codes of conducts, industry standards, management instruments, and best practices that organizations have adopted to help 
operationalize their strategies as they relate CS goals and objectives (Delmas, 2002; McIntosh, 2004; Castka and Balzarova, 2007; Bondy et al., 2008; Ball and Craig, 2010). However, there still is a need to examine the effects of contingencies on the diversity of the organizational structures and processes adopted to address sustainability issues in supply chains. Based on these arguments, the following research question is proposed:

$R Q-1:$ What are the organizational structures, standards, and management instruments and processes that corporations adopt to implement sustainability initiatives within SCM?

Stakeholder theory and institutional theory suggest that normative pressures prompt organizations to interact with its communities - suppliers, employees, and customers - to divide the costs and benefits of externalities. Such interaction is best characterized as cooperation or collaboration (Dunham et al., 2006). Supply chains provide platforms for collaboration to address accountability by internalizing environmental and social externalities (Carter and Jennings, 2002; Roberts, 2003; Chien and Shih, 2007; Sarkis et al., 2010). The RDT justifies collaboration and inter-organizational relationship management to maximize power and, therefore, to increase long-term performance and sustain growth (Pfeffer and Salancik, 1978; Ulrich and Barney, 1984). According to RDT, firms are dependent upon other parties to harness critical resources; consequently, managing this dependency is critical for firms' survival and growth (Ulrich and Barney, 1984). From this perspective, upstream and downstream collaboration in supply chains and the quality of relationships among supply chain partners are important strategic mechanisms for SSCM to reduce the external uncertainty of firms and, in due course, increase the bottom-line results (Cao and Zhang, 2010; Zhu et al., 2010b). The RBV strives for improved efficiency and effectiveness of a firm by controlling valuable, rare, imperfectly imitable, and non-substitutable (VRIN) resources to gain and sustain competitive advantage (Barney, 1991). In fact, as dependence on VRIN resources increases, firms should increase vertical coordination (Pfeffer and Salancik, 1978). Upstream and downstream collaboration through the supply chain may result in the development and integration of VRIN resources and capabilities such as organizational reputation, green marketing, and brand image (Sarkis, 2009; Shang et al., 2010). Carter and Rogers (2008) state the positive relationship between resource dependence and 
vertical integration in the supply chain, and provide examples from the literature as to different forms of coordination and collaboration.

The literature, in particular, provides examples of the effects of various collaborative initiatives on encouraging suppliers to adopt sustainability principles. For example, when buying firms work with their suppliers in implementing certain SSCM standards - e.g., environmental policies and governance standards - the suppliers become more likely to adopt and maintain these practices (Carr and Pearson, 1999; Krause et al., 2007; Jiang, 2009). Reuter et al. (2010) elaborate on the "sustainable supplier development" (SSD) process by presenting how the prevalence of collaboration positively correlates to supplier assessment, selection, and SSD. In fact, as shown in Table 2.2, the literature provides many examples of the collaborative paradigm in SCM. However, the exact nature and elements of the collaborative paradigm to address CS issues are still not well understood (Cao and Zhang, 2010; Nyaga et al., 2010; Tulder, 2010). With that in mind, the second research question becomes:

$R Q-2:$ How do corporations utilize the collaborative paradigm to address sustainability issues within SCM, particularly as they relate to supplier encouragement?

\subsection{Methodology}

In this research Canada was used as a case study. Case studies can be conducted with many different motives and have a distinctive place in evaluation research in that they seek answers to research questions focused on how and why (Yin, 2010). Canada has various national institutions that are formed to address sustainable development issues (UNCSD, 2012). The Government of Canada's approach to sustainable development is integrated into government planning, reporting, programming and decision-making within the federal government (Government of Canada, 2012). Further, the regulatory authority of the provincial governments has a great level of influence on corporate behavior with respect to CS. Canada's diversified economy has strong ties to the global economic network. According to the World Economic Forum (WEF), Canada's economy ranks eighth among 125 economies worldwide in terms of having the necessary attributes 
in place for enabling trade (WEF, 2010). Moreover, Canada has held leading roles at the Organization for Economic Cooperation and Development (OECD) since its establishment in 1961 (OECD, 2011). Therefore, it is particularly relevant to use Canada as a case study to address the key research objective and the supporting research questions. However, this case study is offered without making any claims about transferring the results across different institutional boundaries since case studies are difficult to generalize (Yin, 2010). As Matten and Moon (2008) showed, institutional features have an effect on the adoption of CSR initiatives by companies across different nations. Canada's peculiarities in cultural, political, business and economic systems have major implications for corporations in adopting CS principles.

Completion of the case study involved combining two different qualitative methods content analysis and interviews (Figure 2.1).

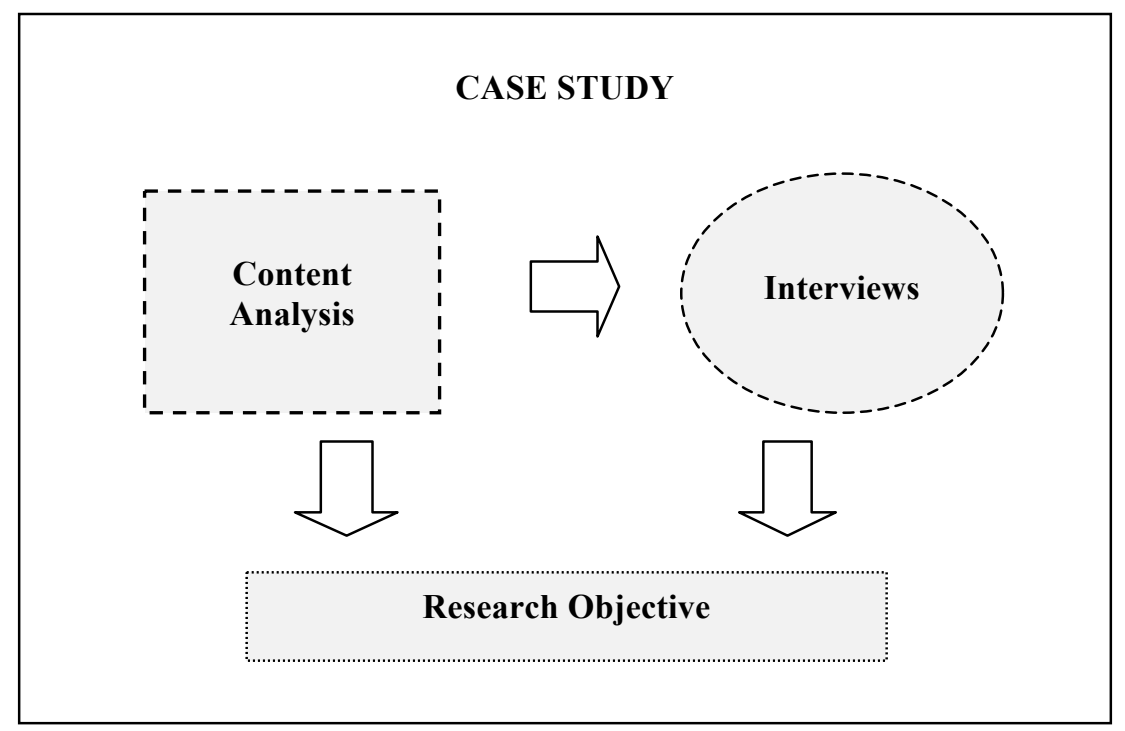

Figure 2.1 Methodological Approach

Between-methods triangulation is particularly useful when both methods concentrate on different aspects of knowledge in data. By investigating a complex phenomenon, i.e., the key research objective, from different angles, a triangulation of two methods aims at a mutual validation of their results (Flick, 2007). For this reason, the overall 
methodological strategy of the inquiry consisted of two sequential and complementary key phases. The first phase of the research focused on a content analysis of 100 Canadian CSDRs. The results from the content analysis informed the development of the second phase: in-depth interviews with 30 Canadian experts on SSCM. Details on the approach for each phase are provided below.

\subsubsection{Content Analysis}

The key research objective and associated research questions identified in Section 3 along with the themes applied to SSCM related research identified in Table 1 provided the basis for structuring the criteria of analysis for the content analysis of Canadian CSDRs. CSDRs typically report and evaluate corporate initiatives from the perspective of sustainability or environment, health, safety, and other social aspects (Karen, 2008). Content analysis allows researchers to gather and analyze data by categorizing texts into more controllable sections and, therefore, is a prolific research methodology in the social sciences for studying the content of recorded human communications (Krippendorff, 2004). The average length of a CSDR was approximately 45 pages (in PDF format), resulting in over 4500 pages to analyze. Therefore, the use of content analysis to address the key research objective was well suited. The content analysis focused on the eight criteria of analysis: report demographics, supply chain governance, supply chain strategy, performance indicators, standards, supplier monitoring, supply chain collaboration, and forward looking statements on SSCM (Table 2.4).

The study was focused on large corporations since they were most likely to implement and, therefore, report on their CS practices (Pagell et al., 2004). A representative list of Canadian CSDRs in English was developed based on a review of the Corporate Register website, the GRI website, and via Google search. All reports published before the year 2007 were removed from the list. As of July 1, 2010, a total of one hundred Canadian CSDRs were identified. These one hundred reports formed the sample for this study. 
Report Demographics

Supply Chain Governance

Supply Chain Strategy/Policy

Performance Indicators

Standards

Monitoring

Collaboration
Useful in subsequent analysis through establishing demographic patterns, including cross-associations with other criteria.

In order to determine the top management mandate and accountability on SCM. This criterion relates to the key research objective and $R Q-1$.

In order to determine the importance of the supply chain and whether or not companies are implementing a supply chain strategy. This criterion relates to the key research objective and $R Q-1$.

In order to determine what indicators are currently used to measure company performance as they relate to environmental, economic, and social dimensions of sustainability. This criterion relates to the key research objective and $R Q-1$.

In order to find out what the minimum acceptable standards or management instruments are for SSCM. This criterion relates to the key research objective, $R Q-1$ and $R Q-2$.

In order to find out how companies screen their suppliers. This criterion relates to the key research objective, $R Q-1$ and $R Q-2$.

In order to find out how suppliers are encouraged to be more sustainable and where in the supply chain a company's accountability stops. This criterion relates to the key research objective and $R Q-2$.

Reflects on top management commitment and future strategic priorities on SCM. This criterion relates to the key research objective and $R Q-1$.

After the sample of CSDRs was established, the content analysis of reports was conducted manually, sequentially examining reports according to alphabetical (company name) order. A conceptual analysis (Krippendorff, 2004) was applied through keyword searches (Table 2.5) to determine the existence of the criteria identified in Table 2.4. 
Table 2.5 Keywords Applied to Themes

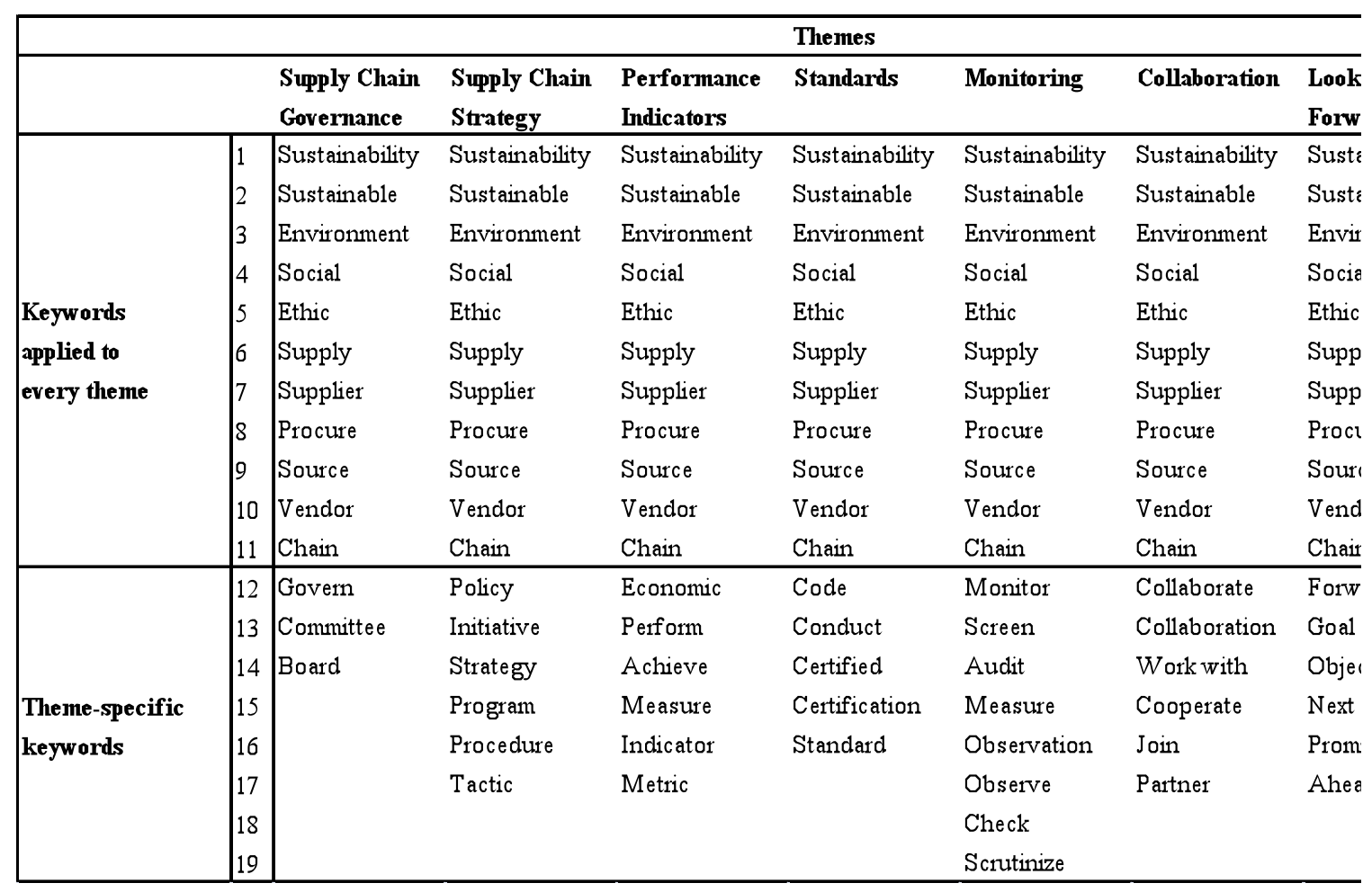

The results from the keyword searches were recorded in a database for each corporation (by row) according to the each individual theme (by column) (Appendix A). The keyword searches were supplemented by additional qualitative analysis of meaning categorization, which involved a systematic conceptualization of the statements before placing them in relevant themes. This was achieved by reading through the references that turned out as a result of the keyword searches and getting an overall impression (Kvale, 2007).

\subsubsection{Interviews with Corporate Experts}

Interviews are commonly employed in social research because they enable obtaining information that might otherwise be difficult to obtain, and provide a basis for the comparison of participant responses in order to answer a research question (Kvale, 2007). The content analysis was supplemented by in-depth interviews for three interrelated reasons. First, CSDRs greatly vary in scope, and therefore, the depth of information communicated through them also varies (Roca and Searcy, 2012). Second, the text, i.e., 
CSDRs, may be devoid of the context that produced them in the first place (Krippendorff, 2004). Third, the state of the criteria examined in the content analysis may have changed after the CSDR was produced, therefore necessitating further probing.

Consequently, semi-structured interviews with 30 corporate experts (Appendix B) were conducted to collect views on the key research question and associated sub-questions. Invitations to participate in the interviews along with the interview protocol (Appendix C) and informed consent form were sent to 100 Canadian corporations whose reports were reviewed in the content analysis; and 92 Canadian corporations that were listed in the Network for Business Sustainability (NBS) membership directory. Thirty senior level employees from 26 corporations agreed to participate in the interviews. These corporations represented nine industry sectors: energy, financial, food, forestry, healthcare, manufacturing, metals-mining, telecom, and transportation. The interviewees represented business units in SCM or sustainability departments (or equivalent). The interviews centred on the eight open-ended questions, which were derived from a combination of the research questions identified in Section 2.3 and the results from the content analysis (Table 2.6).

Most of the interviews lasted between 25 and 45 minutes. All of the interviews were conducted via telephone between October 2010 and May 2012. Summary notes were taken during the interviews. These notes were then sent electronically to the interviewees for verification. The interview notes were read and re-read to establish a close familiarity with the text, therefore, facilitating the analysis. The interview data were analyzed by meaning categorization and meaning interpretation (Kvale, 2007) in alignment with the themes that formed the basis of the content analysis. 


Question
1. In your organization, what is the primary motivation for sustainability
or CSR initiatives?
2. How does your company measure the success of its sustainability
initiatives in the supply chain?
3. What indicators, if any, does your company currently use to measure
supplier performance in sustainability?

3. What indicators, if any, does your comp
supplier performance in sustainability?

4. Does your organization have any standards for SSCM? Do you require that your suppliers implement any standards for SSCM?

5. How can suppliers be encouraged to be more sustainable? Has your organization undertaken any initiatives to do so? If yes, can you provide any examples?

6. Where do you think a company's accountability stops in the supply chain? Why?

7. In your experience, what are the barriers to incorporating sustainability issues in SCM?

8. What areas do you see for future work in SSCM in corporation?

\section{Rationale}

This question forms a basis for the key research objective.

This question relates to the key research objective and $R Q-1$

This question relates to the key research objective and $R Q-1$

This question relates to the key research objective, $R Q-1$ and $R Q-2$.

This question relates to the key research objective and $R Q-2$.

This question relates to the key research objective and $R Q-2$.

This question relates to the key research objective and $R Q-1$.

This question relates to the key research objective and $R Q-1$.

\subsection{Results}

Section 2.5 focuses on describing the results of the study. The analysis of the results is presented in Section 2.6: Discussions. The results from the content analysis are presented in the subsection 2.5.1 and the results from the interviews are presented in the subsection 2.5.2.

\subsubsection{Results from the Content Analysis}

The results from the content analysis are presented in the following subsections 2.5.1.1 through 2.5.1.8. 


\subsubsection{Report Demographics}

Of the 100 CSDRs reviewed 5 were dated from 2007, 20 from 2008, 70 from 2009, and 5 from 2010. This signals that there may be a lag time of two to three years after the reference year for some reports to become available. Twenty three industry sectors were represented, with the metals-mining (23 reports), energy (22), and financial sectors (17) making up a large percentage (62\%) of the reports. This finding supports that the worst polluters tend to be the best reporters (Delmas and Blass, 2010). Other industry sectors represented include telecom (4), forestry (4), food (3), insurance (3), manufacturing (3), retail (3), transportation (2), infrastructure (2), government (2), chemical (2), agriculture (1), construction (1), consulting (1), engineering (1), gaming (1), lottery (1), media (1), real estate (1), service (1), and textiles (1).

\subsubsection{Supply Chain Governance}

This criterion was analyzed to assess the degree of management's accountability on SSCM issues. Only thirteen (13\%) of the reports included a reference to having a management mechanism in place that ties sustainability to procurement practices. In general, addressing the governance structure for SSCM is a marginal practice for corporations. In most cases, the governance structure was attributed to many other company functions, with indirect references to the supply chain. For example, Enbridge, a corporation in the energy industry sector, reports: "The company has a clearly defined management and governance structure for all major projects and in that regard strategic relationships have been developed with suppliers and contractors" (Enbridge, 2009, p.46). Furthermore, most references lacked clear descriptions of mandate or responsibility of the governing bodies, such as committees and councils.

The results from the governance theme helped inform the development of the interview questions 5, 6, and 8 (Table 2.6).

\subsubsection{Supply Chain Strategy}


This criterion was investigated by checking whether the company reported, or included any reference to, the corporation's SSCM policy, programs, or initiatives. Seventy two (72\%) of the corporations reported having a strategy or program in place. Most policy and/or program references explicitly addressed only the environmental criterion of sustainability and left the social and economic criteria unaddressed. Nevertheless, the social and economic criteria were implicit in the corporations' local-procurement preferences. In fact, the majority of the statements on supply chain strategy were on local purchasing practices. Overall, the majority of companies reported how they work with their supply chain partners at a strategic or operational level. Most of these references did incorporate at least one dimension of sustainability into their procurement strategy or supply chain operations.

The results from the supply chain strategy theme helped derive the interview questions 2 , 4, and 5 (Table 2.6).

\subsubsection{Performance Indicators}

This criterion was applied to find out what indicators are currently used to measure company performance in SSCM. Forty five companies (45\%) reported at least one procurement related key performance indicator. The majority of these companies cited policy, practices and proportion of spending on locally-based suppliers as an indicator. Many companies listed at least one environmental KPI. For some representative examples, Bank of Montreal (BMO) had "technology disposal program", "paper shredding/recycling", "renewable energy purchased", and "percentage of hybrid vehicles in service fleet" indicators (BMO, 2009); and TELUS, a corporation in the telecom industry sector, had a "wireless device recycled" indicator (TELUS, 2009). The most

frequently cited social KPI was similar to one used by the GRI: "percentage of significant suppliers and contractors that have undergone screening on human rights and actions taken" (GRI indicator HR2). However, the majority of companies that cited this particular indicator provided no company-specific data. Instead, they provided a clause stating that they did not review their suppliers' human rights performance. 
In general, more than half of the reports (55\%) did not include a KPI as it directly relates to SSCM. Moreover, the majority of the reported indicators focused on economic performance as they relate to local purchasing activities.

The results from the performance indicators theme helped inform the development of the interview questions 2,3 , and 8 (Table 2.6).

\subsubsection{Standards for SSCM}

Company reporting on SSCM related standards was investigated to shed light on the minimum acceptable standards for SSCM. Fifty (50\%) of corporations cited at least one relevant standard or management instruments and processes (Table 2.7). Most standards cited were in the form of business codes of conduct. Business code of conduct refers to: "commitments voluntarily made by companies, associations or other entities, which put forth standards and principles for the conduct of business activities in the marketplace" (Gordon and Miyake, 2001). Although all CSDRs mentioned a form of code of business conduct, in cases where this was not clearly associated with SCM practices, it was considered that the corporation did not report on any SSCM standards.

\section{Table 2.7 SSCM Standards and Management Instruments Cited}

\begin{tabular}{ll}
\hline Theme & Standards \\
\hline \hline Codes of Conduct & Code of Conduct, Code of Ethics and Business Conduct, Supplier Code of Business \\
& Conduct, Ethics and Compliance Guide, Code of Ethics and Professional Conduct, \\
& Standards of Business Conduct, Standard Terms and Conditions (STC), \\
& Environmentally Responsible Procurement Standard, Environmental Code of Practice, \\
& Supplier Guiding Principles
\end{tabular}

Product/Process- Energy Star, International Cyanide Management Code for the Gold Mining Industry, related Marine Stewardship Council (MSC), Forest Stewardship Council (FSC), FSC Chainof-Custody ( $\mathrm{CoC})$, Controlled Wood, Ontario Energy Board's Affiliate Relationships Code (ARC), GREENGUARD

Management Systems and Initiatives
Canada's Environmental Choice Program, United Nations Global Compact, ISO 9001, ISO 14001, OHSAS 18001, Outsourcing and External Supplier Risk Management Policies, Paper Purchasing Policy, Global Leadership and Commitment Standard, Global Food Safety Initiative (GFSI), Responsible Care ${ }^{\circledR}$ Initiative, Programme for the Endorsement of Forest Certification (PEFC), Sustainable Forestry Initiative (SFI), Canadian Standards Association (CSA), Chartered Institute of Purchasing and Supply (CIPS), Electric Power Supply Association's Sound Trading Practices 
Table 2.7 shows that the cited standards or management instruments and processes focused around three key themes: codes of business conduct; product/process-related certifications; and management systems and initiatives.

The results from the supplier standards theme helped inform the development of the interview questions $4,5,6$, and 8 (Table 2.6).

\subsubsection{Monitoring Supplier Performance}

This criterion was examined to find out how companies screen their suppliers. Thirty three companies (33\%) reported on a supplier management monitoring system. For example, Vancity, a corporation in the financial services industry sector, stated: "For strategic business relationships, such as our major suppliers and partners, we use our highest type of due diligence, which is a formal expert screen with 45 indicators across a broad range of environmental, social and governance criteria" (Vancity, 2008-2009, p.45). Only one report contained specific details on the outcome of monitoring activities. In that report, Loblaws, a corporation in the food industry sector, reported: "114 factories were required to implement a corrective action plan with a follow-up audit in six months [and] 6 factories were delisted because they failed to comply with Loblaw CSR standards" (Loblaws, 2009). Taken as a whole, the majority of the corporations did not report on monitoring supplier performance. Of those that were reported, the method of monitoring varied greatly, including assessment guides and questionnaires, CSR audits, social impact assessments, site inspections, and (unidentified) activities.

The results from the supplier performance theme helped derive the interview questions 2 , 3, 4, 5, 6, and 8 (Table 2.6).

\subsubsection{Collaboration within the Supply Chain}

The search for any collaborative relationship to encourage sustainability between a company and its supply chain partners yielded forty one companies (41\%) reporting on 
such collaboration. References on the collaborative initiatives were predominantly focused on upstream initiatives with suppliers. Only a small number of companies reported on downstream collaborations with customers. However, they provided little or no details. For example, Coca Cola noted: "By working with suppliers and customers to reduce the amount of material used in our packaging, we are working to ensure that this packaging is sustainable" (Coca Cola, 2007-2008, p.12).

On the whole, forty-one companies (41\%) cited collaboration either with their suppliers or with their customers. This may suggest that corporations are attempting to extend accountability and enhance sustainability in the supply chain.

The results from the collaboration theme helped inform the development of the interview questions 3, 4, 5, 6, and 8 (Table 2.6).

\subsubsection{Looking Forward on SSCM}

As an indication of top management commitment on SSCM, thirty two corporations (32\%) provided references about their plans to further incorporate sustainability into their supply chain. Most of the statements were strategic objectives or goals on supply chain related topics. Other reports briefly described what they intend to do next without getting into the specifics. For example, AXA, a corporation in the insurance industry sector, noted that it intended to "Extend the corporate responsibility clause to all suppliers" (AXA, 2009) and Hydro Quebec, a corporation in the energy industry sector, had an objective to "Establish specifications for sustainable procurement" (Hydro Quebec, 2009). Including company objectives on SSCM indicates the recognition of sustainability issues and strategic importance of supply chains in improving the corporate triplebottom-line results.

The results from the forward looking statements helped inform the development of the interview questions 7 and 8 (Table 2.6). 


\subsubsection{Results from the Interviews}

The results from the interviews are presented in the following subsections 2.5.2.1 through 2.5.2.8.

\subsubsection{Primary Motivation for Sustainability Initiatives}

Several driving forces for adopting sustainability initiatives were cited in the interviews. Fourteen experts identified the need to respond to internal and external pressure that agents of firms feel from stakeholders, which they noted include customers, shareholders, government, employees, NGOs, and the community in general. In fact, institutional pressures, which are internal and external pressures that the companies feel from stakeholders, had the greatest influence value for every expert. For some representative examples, one expert cited market forces, particularly driven by customers; another cited the desire to be respected by the community; and another cited government relations as an incentive to address sustainable development issues. Eight experts referred to CS initiatives as core organizational values that were embedded in every strategic and operational activity. Other commonly cited motivators included risk management, regulatory concerns, increased profit, increased operational efficiencies, reduced costs, corporate image and brand concerns, and corporate culture.

Taken collectively, the experts referred to the need to address institutional pressures, improve stakeholder relations and triple bottom-line results as the major drivers of sustainability in their corporations. The literature identifies these drivers similarly (Bansal and Roth, 2000; Sarkis, 2001; Roberts, 2003; Darnall et al., 2008; Seuring and Muller, 2008b). Economic benefits were cited under two categories: cost savings through reduced health and safety costs, reduced mitigation related costs, and increased operational efficiencies; and revenue increases through enhanced brand image and gaining competitive advantages by simply being a good corporate citizen.

\subsubsection{Measuring Company Success on Sustainability Initiatives in the Supply Chain}

The experts provided a wide-range of answers to the question: "How does your company 
measure the success of its sustainability initiatives in the supply chain?" For example, two experts mentioned that success was measured by comparing the audit results of the company's own facilities against previously set company goals. Two other experts noted that success was measured through the number of supplier audits the company conducted. Another expert cited the number of new contracts that include responsible product specifications. Two experts referred to the market success or financial outcomes achieved as a result of such initiatives. Many others noted local procurement policies and practices, consolidated shipments, returnable packaging, results of supplier assessment questionnaires, updating and implementing a code of conduct, waste reduction, packaging reduction, workplace diversity, energy efficiency and conservation, and recycled/refurbished procurement values as performance measures. All but two of the experts referred to measuring success upstream in the supply chain. In the two exceptions, one expert referred to a carbon calculator tool developed by the company to help customers calculate their total carbon footprint from transportation emissions and the other referred to the increase in the number of green product offerings by the company. One expert stated that the measurement of success was contingent upon the definition of sustainability, and added that the company had some health and safety indicators. Another expert cited that the success was measured qualitatively by communicating the company initiatives in annual reports. Finally, six experts stated that they did not have any specific indicators, but were in the process of developing them. Overall, the experts highlighted a small number of quantitative performance measures. Although the need to measure the success of sustainability initiatives is recognized, it is generally addressed through green procurement policies, market success and brand recognition.

\subsubsection{Measuring Supplier Performance in Sustainability}

Probing measurement practices on the supplier side yielded additional insights. Twelve experts noted that they do not have any specific indicators to assess how a supplier does in the supply chain. For example, one expert said: "Aside from quality requirements and commercially-related matters, there are no other specific measurements in use. We are just getting into this area. The challenge is that there are many suppliers, including small 
suppliers, with different organizational capabilities". Five experts cited their company's supplier assessment questionnaires as the only measures. However, the specific questions or indicators within these supplier questionnaires were not identified, except for three experts who noted that economic, social and environmental elements are included in the evaluation criteria. Further, corporations' supplier evaluation schemes are rarely made public. The interviews highlighted this reality as a challenge to integrating sustainability with SCM while stressing the need to share information and best practices among industry practitioners. Other measures included: health and safety indicators, compliance with business code of conduct, and vendor performance program. For example, one expert cited a "robust supplier score card", which evaluated suppliers on a variety of categories such as "quality, price, food safety, availability, and recalls." Other examples of supplier evaluation include: three experts cited third party certifications, such as Forest Stewardship Council (FSC) and Electronic Product Environmental Assessment Tool (EPEAT); one expert cited a suite of health and safety KPIs; and another cited measurement of the suppliers' carbon footprint.

In general, the experts expressed that there is relatively little emphasis on sustainability in the supplier evaluation area. Only three experts specifically referred to plans of developing KPIs in the supplier base. Further, while there are some exceptions such as for health and safety indicators and some elements of third-party verifications, the limited number of cited indicators focuses primarily on addressing the environmental dimension of sustainability.

\subsubsection{Standards for SSCM}

Similar to the results from the content analysis, codes of business conduct were the mostcited standards. One expert noted that suppliers are required to comply with the company's code of conduct and have to sign a certificate of business principles. As many experts noted, companies always reserved the right to audit their suppliers. Nevertheless, only four experts noted that their companies actually conduct audits. The scope of these audits ranged from asking for proof of third-party verifications to site inspections. Five experts referred to corporate policies and directives that specifically require that products 
and services comply with the company's procurement criteria. One expert referred to a supplier policy that requires the company's suppliers be evaluated on 17 different items, some of which are sustainability oriented. Beyond codes of business conduct and directives, the types of standards varied by industry. For example, one expert cited ISO 14001 certification and another cited standard templates based on the Equator Principles. Another expert noted "sustainable purchasing policy" which required suppliers with transaction value of $\$ 50 \mathrm{~K}$ and over to abide by the supplier code of conduct. However, in many cases it was stressed that these policy directives and supplier assessment schemes were internal and that they were not made publicly available. For example, one expert noted that sustainability was such a broad term that it was hard to say that they had specific standards. Another expert stated that: "Although sustainability is weaved through our company's supply chain, it is hard to say there is a standard or management tool that explicitly commits to sustainability." These statements relate to two of the implementation issues of SSCM: transparency of information and lack of understanding the concept of sustainability (Storey et al., 2006; Seuring and Muller, 2008a; Linton et al., 2007). Finally, six corporate experts noted that they had no specific standard; however, efforts to incorporate specific standards for their suppliers were an area of priority for the near future.

\subsubsection{Supplier Encouragement}

Seventeen of the experts interviewed noted that their corporations have developed supplier collaboration initiatives. As the experts noted, this is reflected in on-site subcontractor training in some instances and supplier appreciation events in others. Some experts cited joining collaborative platforms, such as Bureau de Normalisation $d u$ Québec (BNQ), with the goal of optimizing the integration of sustainability principles within Québec organizations. Seven experts referred to their companies' codes of conduct and supplier contract requirements as the main source of encouraging their suppliers to be more responsible. As one expert noted: "We deal with a number of suppliers in China [and] we send teams to those companies [in China] to do systematic checks with respect to their health, safety, and other environmental practices." Another expert noted, adopting new product specifications gives a clear message of the corporation's environmental 
priorities and drives change to the market. Five other experts made similar remarks about their company's supplier self-assessment questionnaires, noting that they communicate what they expect from their suppliers and their products and services. As one expert stressed, responsible procurement requires dealing with responsible suppliers who produce responsible products. One expert referred to market forces which would eventually encourage suppliers to be more sustainable. Finally, one expert stated that it was dependent upon leadership, which held responsibility for educating company's suppliers to understand and implement what they are expected of. Based on the expert interviews, it is apparent that the environmental pillar of sustainability tends to be more prevalent when it comes to supplier standards and encouragement. However, there were a limited number of examples offered on how social issues were included, for instance, in competitive bidding process and procurement contracts.

\subsubsection{Accountability in the Supply Chain}

All but five experts cited that responsibility must be shared by all supply chain partners, including intra and inter-organizational stakeholders, and a life cycle analysis approach should be integrated as a way to address accountability in the supply chain. For example, one expert cited: "[Accountability] does not stop. You have a role to play; everyone has a role to play. It is the same for the sustainability of the product; everyone needs to be aware and do his job." Another expert noted: "[Accountability] is right across the board: within the organization, every business unit has responsibility implementing the sustainability initiatives." Some experts added that this was not currently being implemented due to the barriers noted above. For example, one expert cited: "Although we try to get in touch with our subcontractors, it gets challenging to address accountability beyond the first tier suppliers."

There were three exceptions to the common view of shared responsibility. Two experts noted that the accountability ends with the suppliers the company interacts with (i.e., primary supplier). The other expert noted that the company held a second tier supplier (i.e., one that supports a primary supplier in the delivery of goods and services) accountable only when a sub-contractor is working on-site. Finally, one expert stated: 
"Responsibility belongs to the business owners (of business units); ultimately, the business leaders must own it, therefore hold accountability." Overall, the experts predominantly referred to shared responsibility across the supply chain.

\subsubsection{Barriers to Incorporating Sustainability into Supply Chain Management}

The experts' answers regarding the challenges of incorporating sustainability into SCM centred on three key areas:

1. Resources required: All thirty of the experts referred to the required resources, such as time, people, and financial costs, as the primary barrier. Four experts referred to the hardships in making the business case for allocating the resources. For example, one company had to re-adopt its less environmentally friendly packaging for a certain product due to plummeting sales caused by unappealing characteristics of environmentally friendly packaging.

2. Lack of understanding the concept of sustainability: Eleven experts commented on the lack of clear understanding and knowledge of the very concept of sustainability among suppliers and customers. As one expert noted, the principles of sustainability could not be integrated without stakeholders' fully understanding what they really are. Many experts referred to education both as a barrier and remedy.

3. Risk management and monitoring: Eight experts cited audit-related challenges. As one expert noted, some suppliers might perceive audits as harassment. One expert referred to the difficulties in conducting audits in developing countries. Three experts cited the transparency of information and data gathering from suppliers, particularly as they relate to performance measurement.

For example, one expert stated: "The first challenge is the integration of multiple and disparate supply chains with the principles and measurements of sustainability. How to craft [sustainability] policies and codes with all the globally-dispersed suppliers, and maintain your supply chain?" Another sample citation includes: "We have a number of initiatives and policies as they relate to sustainability in the supply chain. However, 
suppliers do not really know what that [sustainability] really means. There is a lack of understanding of the concept of sustainability as to what it really entails."

Overall, the barriers to integration match the ones quoted in the literature (Carter and Rogers, 2008; Seuring and Muller, 2008a; Linton et al., 2007). However, the experts cited other important challenges such as lack of leadership from policy makers (cited by two experts), lack of platforms to share expertise and best practices (cited by one expert), required formal processes and bureaucracy to adopt and implement sustainability initiatives (cited by one expert), communication or lack thereof across supply chain partners (cited by one expert), and supplier reluctance to comply (cited by one expert).

\subsubsection{Areas for Future Work in SSCM in Corporations}

Nine experts cited the need to collaborate among all supply chain partners. This was reflected in comments on creating platforms to share information and best practices among industry practitioners by some and engaging suppliers in making business decisions by others. In related comments, some experts referred to overcoming the technical barriers in integrating sustainability principles with existing business systems and practices. As one expert explained, sustainability initiatives put procedural and administrative burdens on corporations and the question then becomes how to integrate sustainability while removing these burdens. Two experts specifically referred to improving the tendering processes and raising the standard for product specifications. Nine experts noted education as an area for future work. For example, one expert cited the need to educate customers while another expert cited the need to educate the industry practitioners. One expert emphasized the need to educate all supply chain partners as: "Every company or supply chain partner has a different understanding and/or different stage of implementing sustainability. Therefore, [an area of future work is] education throughout supply chain - upstream and downstream- and increasing transparency and traceability while doing so". Four experts highlighted the need to address the difficulties in supplier audits and monitoring. Two experts referred to increasing transparency and communication. One expert posed the question as: "What other criteria can be added to supplier codes of conduct and make sure that they are implemented?" Seven experts cited 
measurement of both company performance and supplier performance through developing meaningful KPI. As one expert cited:

It is the need for standards that corporations must abide by and metrics to measure performance. Another area is sharing information amongst supply chain partners in a coherent and easy way. Another area is to collaborate with your key suppliers and customers. Supplier monitoring is another area: how to come up with robust processes to bring all of different audits together?

Other areas included balancing the interests of different stakeholders, the need to exercise life cycle thinking, consumer management, setting the right supplier standards, and developing practitioner skills and expertise (each cited by one expert). In general, the comments were not surprising: they focused specifically on the barriers to incorporating sustainability into SCM noted above.

\subsection{Discussion}

Overall, the results highlight a range of interesting trends in which Canadian corporations address SSCM issues. In terms of report demographics, the metals-mining, energy, and financial services industry sectors represented the majority of CSDRs in Canada. This finding supports earlier research that industries with higher ecological footprint have better reporting practices and communicate more with stakeholders on CSR initiatives than other industries (Deegan and Gordon, 1996; Delmas and Blass, 2010).

The interviews revealed that sustainability initiatives in the supply chain are a strategic and/or operational response from corporations to address stakeholder concerns, and while doing so, to increase their triple-bottom-line results. This is found to be congruent with the literature (Lipmann, 2001; Sarkis, 2001; Darnall et al., 2008; Seuring and Muller, 2008b). Stakeholder theory, institutional theory, RDT, RBV, and contingency theory lend an interconnected perspective as to the reasons Canadian corporations behave in a sustainable way. As stated earlier, stakeholder theory asserts the need to address the pressure that the corporations feel from a variety of stakeholders (Freeman, 1984), whereas contingency theory emphasizes the fit between an organization and its 
subsystems with its environment (Fiedler, 1971; Donaldson, 2001). Further, institutional theory focuses on external pressures exerted on organizations that result in changed organizational and individual behaviour (DiMaggio and Powell, 1983). Taken collectively, these three theories are applicable in explaining the finding that Canadian corporations address stakeholder pressures by adapting to their environment and adopting new organizational structures. RDT and RBV frame a particularly useful perspective in explaining firms' desire to increase their economic, environmental, and social performance. RDT holds that firms increase their long-term performance by managing inter-and intra-organizational dependencies (Pfeffer and Salancik, 1978; Ulrich and Barney, 1984), whereas RBV necessitates creating new core competencies and capabilities such as green marketing and increased reputation to gain competitive advantage (Barney, 1991; Sarkis, 2009).

The relationship between sustainability initiatives and corporate value creation is also highlighted by the definition of SSCM. As previously indicated, SSCM emphasizes an achievement of an organization's social, environmental, and economic goals in the systemic coordination of key inter-organizational business processes, which includes SCM.

The majority of the corporate reports explained how the corporations address sustainability issues within the supply chain at the strategic or tactical level. However, both the reports and the interviews indicate that the integration of all three dimensions of sustainability into supply chain operations is relatively limited. Further, most of the references on supply chain strategy in the reports related to local purchasing policies and practices. This indicates that most companies focus their SSCM strategies primarily on the economic dimension of sustainability, which, in turn, affects the scope of their measurement practices. Further, corporations that reported on supply chain governance are still in the minority $(13 \%)$, with most reports lacking clear definitions on the mandates of corporate governing bodies. Although the causality between corporate governance and CSR needs further investigation, the elements ${ }^{1}$ of corporate governance

\footnotetext{
${ }^{1}$ These corporate governance variables are: “internal and external monitoring by board, leadership, independent boards, institutional investors, and security analysts" (Jo and Harjoto, 2012).
} 
are positively related to CSR activities (Jo and Harjoto, 2012). Given the importance of transparent corporate governance, the findings might explain the inefficiencies in addressing accountability and overall sustainability engagement in the supply chain. The interviews reinforced these findings by highlighting that accountability in the supply chain generally stops at the primary suppliers.

The interviews stress the need to measure company performance on sustainability initiatives within the supply chain, but most companies lack quantitative performance measures to do so. The review of CSDRs revealed that less than half of the companies $(45 \%)$ measure the success of their sustainability initiatives within the supply chain. The interviews further reveal that there is less emphasis on measuring supplier performance than on measuring a company's own success. The indicators disclosed predominantly relate to the environmental and economic dimensions of sustainability. For example, most indicators concentrate on eco-efficiency, such as waste reduction and carbon footprint, with only a few indicators measuring the effects throughout the life-cycle of the products. In a critical literature review analyzing a collection of 24 studies on supply chain performance measurement, Akyuz and Erkan (2010) point to the need to develop measurement frameworks that include the social dimensions of sustainability, such as collaboration and partnership metrics among others. Further, the interviews provided a wide-range of answers on measuring company success on sustainability initiatives in the supply chain. This is congruent with the literature (Matthews, 2003; Veleva et al. 2003; Shaw et al., 2010) that despite the proliferation of the GRI, organizations still speak "different languages" when measuring sustainability. As it applies to the Canadian context, Roca and Searcy (2012) offer a multi-faceted explanation to this finding. First, CSDRs differ in scope, therefore the indicators disclosed somewhat vary. Second, Canada does not have mandatory sustainability reporting requirements. ${ }^{2}$ Finally, from the stakeholder theory perspective, different stakeholder groups have different priorities; therefore requiring different information disclosed by different corporations (Roca and Searcy, 2012).

\footnotetext{
2 Two exceptions apply: limited requirements for the financial services industry sector; and mandatory reporting required under the National Pollutant Release Inventory (NPRI).
} 
The review of reports showed that one in every two companies (50\%) reported on a SSCM related standard or management instrument. The standards centred on three key themes: codes of business conduct, product/process-related certifications, and management systems and initiatives. As part of the global diffusion of standards and management practices in supply chains (Guler et al., 2002; Zutshi and Sohal, 2003; Lu et al., 2005; Ciliberti et al., 2008), Canadian corporations are increasingly institutionalizing codes of conduct and other SSCM related standards to operationalize their CSR strategies (Schwartz, 2002; Bondy et al., 2004). The literature (Adams et al., 2001; Kaptein, 2004) points to the proliferation of codes of conduct as an indicator of adopting ethical behaviour, particularly when firms engage in off shoring and outsourcing in developing countries (Tulder et al., 2009). Further, Okhmatovskiy and David (2012) illustrate the adoption of internal governance codes as a "substitution response" to external, mandatory national standards.

Although the majority of the CSDRs did not report on how they monitor their suppliers, most of them require their suppliers to abide by their business principles and codes of conduct. This may mean that codes of conduct have a particular use in supplier encouragement by keeping suppliers, and other stakeholders such as NGOs, at bay (Tulder et al., 2009). In fact, the interviews support this by revealing that Canadian corporations use codes of conduct and supplier contract requirements as a means to promote sustainable practices among their suppliers. However, both the reports and interviews demonstrated that the environmental pillar of sustainability tends to be more prevalent when it comes to supplier encouragement.

The interviews further elaborated on the ways in which supplier compliance is monitored on codes of conduct and other SSCM related standards. The monitoring activities included assessment guides and questionnaires, verification of third-party certifications, CSR audits, social impact assessments, and site inspections. The variety of supplier monitoring methods reflects the difficulties in conducting supplier audits, which was identified as a key barrier during the interviews. In many cases, corporations opt for a more economically feasible and less intrusive method of monitoring given the resource limitations and resistance from suppliers. Further, the CSDRs provided evidence that 
corporations that inform stakeholders on the outcomes of such monitoring activities are scarce.

The review of the CSDRs illustrates that the collaboration is primarily oriented upstream with suppliers whereas downstream collaboration with customers is scarce. Although it is acknowledged that there are a number of possible explanations, the RBV and RDT provide two particularly relevant theoretical perspectives to explain this. As stated earlier, RBV strives to improve organizational efficiencies and effectiveness to achieve and sustain competitive advantage (Barney, 1991). Firm's collaboration with suppliers of strategic importance enables such efficiencies and helps create core capabilities, particularly as they relate to risk management practices (Cousins et al., 2004; Teuscher et al., 2006). Further, RDT puts emphasis on managing inter-organizational relationships for organizational growth and increased long-term performance (Pfeffer and Salancik, 1978; Ulrich and Barney, 1984). Unsurprisingly, firms using collaboration as a strategic tool upstream in supply chains with suppliers may prove more efficient in increasing the triple-bottom-line results than downstream with customers (Daugherty et al., 2005; Attaran and Attaran, 2007; Sodhi and Son, 2009). The interviews and CSDRs also signal a growing trend in forming collaborative platforms within the supply chain. These platforms comprise different stakeholders, such as government, NGOs, and industry practitioners, that are drawn together to address sustainability challenges. As specified during the interviews, the needs in the areas of engaging supply chain partners in decision making, sharing information and best practices, and developing practitioner skills drive these collaborative initiatives. Pinske and Kolk (2012) point to the strategic importance of multi-stakeholder partnerships in addressing the "climate-change-sustainable development nexus." Collaboration with NGOs, in particular, is seen as a proactive management of stakeholder relations on socially responsible behaviour (Dahan et al., 2010). Baur and Schmitz (2012) draw attention to this increasing trend in corporateNGO partnerships and present how such partnerships can generate learning for the corporations, and concessions from NGOs.

Finally, the experts referred to shared responsibility while emphasizing the need to exercise life-cycle thinking as a way to address accountability across the supply chain. 
However, corporations are far from incorporating life-cycle practices beyond their primary suppliers due to barriers which centred on three key themes: resource requirement, lack of understanding the concept of sustainability, and risk management and monitoring. These cited barriers to integration are found to be congruent with the literature (Storey et al., 2006; Carter and Rogers, 2008; Seuring and Müller, 2008a). Engaging supply chain partners upstream with suppliers and downstream with customers to overcome these barriers is a compelling task. It is not surprising that when asked for areas for future work, many experts brought up the need to collaborate among all supply chain partners. Other areas for future work centred on the barriers previously cited.

\subsection{Conclusions}

This chapter presented the results of a content analysis of 100 Canadian CSDRs and indepth interviews with 30 corporate experts to address the key research objective: "Explore the extent to which CS principles are integrated into SCM in Canadian corporations." The key findings show that the metals-mining (23 reports), energy (22 reports), and financial sectors (17 reports) collectively made up a higher percentage $(62 \%)$ than the percentage of all the other industry sectors combined. Increasing the triple-bottom-line results and responding to the stakeholder pressures are the major drivers behind the sustainability initiatives. Although the majority of corporations studied have a strategy or operational plan to address sustainability issues within SCM, the focus is clearly on the economic and environmental pillars of sustainability. The same is true as it applies to measuring company success and supplier performance. One in two corporations implements a SSCM related standard or management instrument for SSCM, with the codes of conduct being the most prominent standard. Although collaboration between supply chain partners is deemed important, it is still heavily oriented towards

upstream in supply chain. Further, SSCM governance practices remain peripheral among Canadian corporations. This is an impediment to addressing accountability within supply chain, which constitutes a major barrier, amongst others. Finally, corporations' future priority areas in SSCM centre on increased collaboration and education, performance measurement, and supplier audits and monitoring. 
As stated earlier, corporations are integrating the principles of sustainability into their SCM practices to address the economic, environmental, and social implications of their activities. However, little research has been conducted on the extent to which corporations have integrated sustainability principles into the management of their supply chain. A key contribution of this study is that it provides a holistic perspective for a range of interrelated criteria on SSCM, which Canadian corporations adopt, and implement to address CS issues. 


\section{CHAPTER 3 - EVOLUTION OF SUSTAINABLE SUPPLY CHAIN MANAGEMENT}

\subsection{Introduction}

The integration of CS criteria into SCM has evolved considerably over the last two decades. Nevertheless, due to the ongoing conceptual development of CS, such integration is found to be multifaceted and, therefore, rather challenging (Marrewijk, 2003; Garriga and Mele, 2004; Steurer et al., 2005; Gray, 2010). This poses one likely explanation as to why the body of literature in SSCM is abundant and still growing. The numerous examples of research have investigated different system boundaries of SSCM from a number of theoretical perspectives (Rosen et al., 2002; Michelsen et al., 2006; Svensson, 2007; Font et al., 2008; Carter and Rogers, 2008). Other studies investigated a wide range of topics of integration of CS in to SCM (Gildia, 1995; Maignan, 2001; Carter and Jennings, 2002; Zhu and Sarkis, 2004; Seyfang, 2006; Ciliberti et al., 2008; Walker et al., 2008; Vermeulen and Seuring, 2009; Large and Gimenez Thomsen, 2011). However, the current research on the evolution of SSCM practices is scarce. A limited number of studies investigated the progress that the SSCM field has achieved by conducting systematic reviews of the literature (Guide et al., 2009; Sarkis and Zhu, 2011; Carter and Easton, 2011; Sarkis, 2012). There is an absence of research investigating the evolution of SSCM practices in corporations, particularly as it relates to longitudinal case studies that document and reveal the practice of SSCM over a period of time.

With the above in mind, the purpose of this study is to address the second research objective: "Investigate how SSCM has evolved in corporations. " To achieve this objective, a longitudinal study is conducted to provide new empirical insights on SSCM as an evolutionary process in a five-year period, i.e., between 2004 and 2009. Emphasis was placed on Canadian corporations. The study concentrates on seven interrelated criteria: supply chain governance; supply chain strategy; performance indicators; supplier standards; supplier monitoring; supply chain collaboration; and forward looking statements on SSCM. To investigate these criteria, a sequential content analysis of 26 Canadian CSDRs dating to 2004 was conducted. The previously conducted primary 
content analysis in Chapter 2 applied the same seven criteria to 100 CSDRs, most of which dated to 2009 , published by Canadian corporations. In relation to the primary content analysis, the sequential content analysis reveals a wide variety of ways in which SSCM practices evolved in Canadian corporations. This study yields empirical insights that will help: enable better predictions of the future directions of SSCM initiatives; guide the agents of firms and industry associations to achieve best practices such as public disclosure of SSCM initiatives; and improve the implementation and alignment of CS initiatives at intra-and inter-organizational levels in supply chains. In the remainder of the chapter, first, a brief survey of peer-reviewed literature on the concept and evolution of SSCM is presented. A section on methodology follows the literature review, which in turn, is followed by the results and discussions. The chapter closes with summary and conclusions.

\subsection{Literature Review}

As stated in Section 1.1, the integration of sustainability principles into SCM has led to new concepts and terminology associated with environmentally and socially responsible supply chain practices such as: SSCM, sustainable supply chain networks (SSCN), green supply chain management (GSCM), logistics social responsibility, purchasing social responsibility, product stewardship, green purchasing, extended supply chains, and closed-loop supply chains (Sarkis, 1995b; Carter and Jennings, 2002; Zhu and Sarkis, 2004; Michelsen et al., 2006; Vachon and Klassen, 2006b; Carter and Rogers, 2008; Winkler, 2011). In an attempt to capture the distinct system boundaries, the literature provides many definitions of the CS construct in SCM (Ciliberti et al., 2008). Seuring and Muller (2008) provide a comprehensive definition of SSCM as:

The management of material, information and capital flows as well as cooperation among companies along the supply chain while taking goals from all three dimensions of sustainable development, i.e., economic, environmental and social, into account which are derived from customer and stakeholder requirements. In sustainable supply chains, environmental and social criteria need to be fulfilled by the members to remain within the supply chain, while it is expected that competitiveness would be maintained through meeting customer needs and related economic criteria (p. 1700). 
As can be seen from the above definition, SSCM requires a broadened approach of SCM with an emphasis on economic, environmental, and social aspects of business practices and theory (Svensson, 2007). This means that a firm's goal of improving long-term economic return is facilitated by manufacturing products and providing services that do not create undue environmental damage or that violate social standards (Vermeulen and Seuring, 2009). Within this realm, the concept and understanding of sustainability is an evolutionary process (Lumley and Armstrong, 2004), which is reflected in the diversity of the concept and understanding of SSCM (Table 3.1).

\section{Table 3.1 Definitions Characterizing SSCM}

Author(s) Definition

Maignan et al., 2002, p. 642

Beamon, 2005, p. 222

Handfield et al., 2005, p. 7

Hervani et al., 2005, p. 334

Carter and Rogers, 2008, p. 368

Sarkis and Zhu, 2011, p. 3

Winkler 2011, p. 244
"Socially-responsible Buying (SRB) can be defined as the inclusion in purchasing decisions of the social issues advocated by organizational stakeholders."

"Environmentally-Conscious Supply Chain Management (ECSCM): the control exerted over all immediate and eventual effects of products and processes associated with translating raw materials into final products, with the objective of effectively balancing the interests of today with those of future generations."

"Environmental Supply Chain Management (ESCM) involves introducing and integrating environmental issues and concerns into supply chain management processes by auditing and assessing suppliers on environmental performance metrics."

"Green Supply Chain Management (GSCM): where reverse logistics "closes the loop" of a typical forward supply chain and includes reuse, remanufacturing, and/or recycling of materials into new materials or other products with value in the marketplace. The idea is to eliminate or minimize waste (energy, emissions, chemical/hazardous, solid wastes)."

"The strategic, transparent integration and achievement of an organization's social, environmental, and economic goals in the systemic coordination of key interorganizational business processes."

"Green Supply Chain management (GSCM): as integrating environmental concerns into the inter-organizational practices of SCM including reverse logistics."

"A sustainable supply chain networks ( $\mathrm{SSCN})$ is a set of different companies that work together to realize a sustainable circular economy that considers the potential for waste reduction and waste avoidance from the developmental to the end-of-life stages of a product's life cycle. These considerations are made with the goal of improving cost efficiency while satisfying customer needs." 
As can be seen from Table 3.1, some of the definitions that characterize the concept of SSCM reveal this evolutionary process. For example, Maignan et al. (2002) emphasize the integration of the "social issues" to "purchasing decisions" only; therefore, excluding the other activities of SCM, e.g., material extraction, logistics, inventory control, and information management. The definitions from other authors (Beamon, 2005; Handfield et al., 2005; Hervani et al., 2005; Sarkis and Zhu, 2011; Winkler 2011) focus solely on the environmental dimension of sustainability. The definition from Carter and Rogers (2008) includes the three pillars of sustainability while extending the system boundaries of SCM to all "key inter-organizational business processes" (p. 368).

Although the literature on SSCM has significantly grown, there is very little research addressing how SSCM practices evolved in corporations. Some authors investigated how CSR or sustainability strategies have been incorporated into SCM and evolved over time by conducting single case studies of multinational enterprises such as Gap Inc. (Ansett, 2007) and Volkswagen AG (Koplin et al., 2007). However, the existing research on the evolution of SSCM, in particular, almost solely focuses on the evolution by conducting systematic literature reviews (Guide et al., 2009; Sarkis and Zhu, 2011; Carter and Easton, 2011; Sarkis, 2012). For example, in a systematic review of 80 research papers published between 1991 and 2010, Carter and Easton (2011) analyze the evolution of SSCM research on four criteria: subject, industry, theoretical lens, and methodology and analysis. Based on each criterion employed, Carter and Easton (2011) identified trends and differences in SSCM research.

Another literature review conducted by Guide et al. (2009) categorizes the research on the evolution of the field of closed-loop supply chains into five phases from a strong business process view. Guide et al. (2009) view these five phases, i.e., remanufacturing, valuing the reverse-logistics process, coordinating the reverse supply chain, closing the loop, and prices and markets, as concurrent perspectives rather than chronological. While the research on the first three phases focused on process management and coordination perspectives, the latter two introduced product life cycle, and consumer behavior and product valuation respectively. 
A review of SSCM literature by Sarkis and Zhu (2011) focused exclusively on the theoretical background of SSCM research and utilized nine organizational theories to categorize the literature on green supply chain management (GSCM), which is identified as a variation of SSCM in the same study. Sarkis and Zhu (2011) devote particular attention to how each of the theoretical perspectives examined contributed to the "adoption, diffusion, and outcomes of GSCM practices" (p.1), while providing a foundation to expand on the theoretical framework for GSCM research. Another review of the literature by Sarkis (2012) attempts to understand the evolution and current state of numerous research streams in the GSCM field. Sarkis (2012) defines nine multidimensional and "systems-based" frameworks and introduces five major flows within green supply chains. Based on these frameworks and flows, Sarkis (2012) provides a "boundaries and flows" framework and describes future research directions on GSCM.

As can be seen above, the literature has made many meaningful contributions to SSCM field. However, there is an absence of research investigating the evolution of SSCM practices in corporations, particularly as it relates to longitudinal case studies that document and reveal the practice of SSCM over a period of time. The purpose of this chapter is to address this gap by investigating the key research objective: "Investigate how SSCM has evolved in Canadian corporations" in a five-year period and to provide a basis for future research.

\subsection{Methodology}

This is a longitudinal research study in which the emphasis is placed on Canadian corporations. The scope of this study consists of conducting a content analysis of 26 CSDRs published by Canadian corporations to address the key research objective: "Investigate how SSCM has evolved in Canadian corporations." Krippendorff (2004) defines content analysis as: "a research technique for making replicable and valid inferences from texts (or other meaningful matter) to the contexts of their use" (p. 18). The use of content analysis in organizational research has become increasingly common 
because it allows identification of trends, patterns, and differences in organizational constructs (Duriau et al., 2007).

Canada is a major player in the global economy and a member of the Organization for Economic Cooperation and Development (OECD) since 1961 (OECD, 2011). Further, CS practices have increasingly been adopted by Canadian corporations. For example, as of January 31, 2012, the Dow Jones Sustainability World Index (DJSWI, 2012) allocated $2.78 \%$ for Canadian corporations, which ranked Canada ninth amongst 30 countries. However, Canada is not always a front-runner in the matters that fall in the domain of sustainability. For example, according to the 2012 Environmental Performance Index (EPI) that ranks countries on 22 performance indicators of ecosystem vitality and environmental public health, Canada ranks $37^{\text {th }}$ out of 132 countries (EPI, 2012).

As presented in Chapter 2, Section 2.5.1, SSCM practices in Canadian corporations are investigated by conducting a primary content analysis of 100 CSDRs that were published between 2007 and 2010. In this primary content analysis, 70 out of 100 CSDRs dated from 2009. As identified from a review of the literature, the primary analysis focused on seven criteria: supply chain governance, supply chain strategy, performance indicators, standards, supplier monitoring, supply chain collaboration, and forward looking statements on SSCM. The selection of the criteria of analysis for this study, i.e., sequential content analysis, was based on the primary content analysis (Table 3.2).

\section{Table 3.2 Selection of Content Analysis Criteria}

\section{Criteria Examined}

\begin{tabular}{|c|c|}
\hline Supply Chain Governance & Explores the top management's mandate and accountability on SSCM. \\
\hline Supply Chain Strategy/Policy & $\begin{array}{l}\text { Explores whether or not companies have a supply chain strategy as it } \\
\text { relates to corporate sustainability issues. }\end{array}$ \\
\hline Performance Indicators & $\begin{array}{l}\text { Explores how company performance is measured as it relates to } \\
\text { environmental, economic, and social dimensions of sustainability. }\end{array}$ \\
\hline Standards & Explores the minimum acceptable standards or instruments are for SSCM. \\
\hline Monitoring & Explores the ways by which suppliers are monitored on the standards. \\
\hline Collaboration & Explores how supply chain partners cooperate to attain CS goals. \\
\hline Forward-looking Statement & Reveals top management's prospective strategies or approaches on SSCM. \\
\hline
\end{tabular}


The purpose of this sequential content analysis was to compare the findings with the results from the primary content analysis in order to identify how SSCM practices have evolved in Canadian corporations. Therefore, the sequential analysis applied the same seven criteria to 26 CSDRs published in 2004 in order to explore the extent to which Canadian corporations have implemented SSCM practices and, therefore, to identify the evolution of SSCM in a five-year period. The selection of Canadian corporations for the study was based on many factors, including the manageability of data gathering and analysis. The sample of 26 Canadian CSDRs was developed by reviewing the web archives of 100 Canadian corporations from the primary content analysis. When electronic copies of previous CSDRs were not found, corporations were contacted individually to request their CSDR archives. As a result, 34 corporations' CSDRs published in 2004 - the highest number of CSDRs identified between 1998 and 2004 were identified. However, to ensure that the comparisons apply to a five-year period in all cases, i.e., between 2004 and 2009, only 26 of these 34 CSDRs were selected for the sequential content analysis.

After the sample was established, the same keywords from the primary content analysis (Table 2.5) were systematically applied to CSDRs. The resulting statements from a combination of keyword searches and qualitative analysis (Krippendorff, 2004; Kvale, 2007) were categorized on the basis of each individual CSDR. The results were recorded in a worksheet for each corporation (by row) according to the each individual criterion employed (by column). A " $y$ " - indicating the existence of an individual criterion - or an " $n$ " - indicating the absence of an individual criterion - was entered in the worksheet.

Further, the results from 2009 were included in the same worksheet to allow comparison on the corporation basis (Appendix D).

\subsection{Results}

Section 3.4 focuses on describing the results of the study. The analysis of the results is presented in Section 3.5: Discussions. The key findings are presented in Table 3.3 to allow a comparative analysis of data gathered from both the primary and sequential content analyses. 
Table 3.3 Key Findings from Sequential and Primary Content Analyses

\begin{tabular}{lcccccc}
\hline \multicolumn{1}{c}{ Criteria Examined } & \multicolumn{3}{c}{ Corporations $\begin{array}{c}(\mathbf{n}=\mathbf{2 6}) \text { Reported on Each } \\
\text { Criterion }\end{array}$} & \multicolumn{2}{c}{ Change } \\
& \multicolumn{2}{c}{$\mathbf{2 0 0 4}$} & \multicolumn{2}{c}{$\mathbf{2 0 0 9}$} & \multicolumn{2}{c}{ (from 2004 to 2009) } \\
& Number & $\mathbf{\%}$ & Number & $\mathbf{\%}$ & Number & $\mathbf{\%}$ \\
\hline \hline Supply Chain Governance & 3 & 12 & 5 & 19 & 2 & 67 \\
Supply Chain Strategy & 17 & 65 & 20 & 77 & 3 & 18 \\
Performance Indicators & 20 & 77 & 12 & 46 & $(8)$ & $(40)$ \\
Standards & 16 & 62 & 14 & 54 & $(2)$ & $(13)$ \\
Monitoring & 11 & 42 & 14 & 54 & 3 & 27 \\
Collaboration & 15 & 58 & 10 & 38 & $(5)$ & $(33)$ \\
Forward-looking Statement & 9 & 35 & 9 & 35 & 0 & 0 \\
\hline
\end{tabular}

As it is seen in Table 3.3, the first column lists the criteria of analysis applied to both sequential and primary content analyses. The second and third columns show the key findings from the sequential content analysis, indicating the total number of corporations that have included a citation with respect to the analysis of criteria, out of 26 corporations, and the percentage value of the number of these corporations respectively. The fourth and fifth columns show the key findings from the primary content analysis in the same order. The sixth and seventh columns indicate the change in the number of corporations between 2004 and 2009 and percentage value of this change respectively.

The comparative analysis of the key findings is presented in the following subsections 3.4.1 through 3.4.7. Tables 3.4 to 3.10 are used to show example quotes from corporations (by row) according to the criteria of analysis both for the sequential and primary content analyses (by column).

\subsubsection{Supply Chain Governance}

The sequential analysis for the 2004 sample resulted in only three - approximately $12 \%$ corporations citing a governance system that ties sustainability to their procurement practices (see Table 3.4 for some representative examples). 
Table 3.4 Example Citations of Supply Chain Governance

\begin{tabular}{|c|c|c|}
\hline Corporation & $\begin{array}{c}\text { Example Citation } \\
2004\end{array}$ & $\begin{array}{c}\text { Example Citation } \\
2009\end{array}$ \\
\hline $\begin{array}{l}\text { PotashCorp } \\
\text { (PotashCorp, } \\
\text { 2004, p. 21) }\end{array}$ & $\begin{array}{l}\text { The Board of Directors is responsible for } \\
\text { supervising the successful management of } \\
\text { the company's global business. In pursuing } \\
\text { the best interest of the company, the board } \\
\text { considers PotashCorp's customers, } \\
\text { employees, suppliers and the communities } \\
\text { and environment where it does business; } \\
\text { recognizing that all are essential to a } \\
\text { successful business. }\end{array}$ & None \\
\hline $\begin{array}{l}\text { Scotiabank } \\
\text { (Scotiabank, } \\
2004, \text { p. } 24)\end{array}$ & $\begin{array}{l}\text { Our environmental activities are structured } \\
\text { to support Scotiabank's long-standing } \\
\text { environmental policy, which was introduced } \\
\text { in } 1991 \text { and covers both our direct and } \\
\text { indirect environmental impacts. } \\
\text { Responsibility for the policy is shared by } \\
\text { the Real Estate department (the officer } \\
\text { responsible is the Senior Executive Vice- } \\
\text { President and CFO), the Operations } \\
\text { department (the officer responsible is the } \\
\text { Senior Vice-President, Shared Services), } \\
\text { and the Head, Global Risk Management. On } \\
\text { a day-to-day basis, }\end{array}$ & None \\
\hline
\end{tabular}

As in the PotashCorp, a corporation in the mining industry sector, example, citations were mostly indirect references. This finding extends to the primary analysis for the 2009 sample in which only five of the corporations reported a governance mechanism. Further, governance mechanism citations in both analyses lacked clear descriptions regarding their mandates. This shows that reporting on sustainable supply chain governance practices has been peripheral by Canadian corporations.

\subsubsection{Supply Chain Strategy}

Seventeen corporations cited implementing a supply chain strategy or tactic to address at least one dimension of sustainability in 2004 (see Table 3.5 for some representative examples). 
Table 3.5 Example Citations of Supply Chain Strategy

$\begin{array}{ccc}\text { Corporation } & \text { Example Citation } & \text { Example Citation } \\ & 2004 & 2009\end{array}$

AXA Insurance Maintain excellent relationships with (AXA, 2004, p. suppliers by adhering to a set of clearly 1; AXA, 2009, defined procurement guidelines and p. 56)

\author{
A large part of our impact on society is \\ related not to our own production \\ processes, but rather to those of our \\ suppliers. Several years ago, our \\ procurement department rolled out a \\ responsible procurement policy with tools \\ that allow us to factor social and \\ environmental criteria into the selection \\ and management of our suppliers. \\ Examples of providing opportunities at \\ the local level include direct employment, \\ local procurement, and community \\ development projects. Associated with \\ these examples are our efforts to develop \\ lasting capacities, which will continue \\ after mine closure. \\ Our procurement policies are inclusive \\ and aim to promote sustainable business \\ practices and economic development \\ where possible and appropriate. We \\ consider social and environmental \\ policies and practices among other \\ criteria when awarding contracts through \\ our Requests for Proposal (RFP) process.
}

Barrick Gold
(Barrick, 2004,
p. 15; Barrick,
2009, p. 53)

The Company's operations promote regional economic growth through hiring services and buying goods from local suppliers whenever possible. As well, environmental, health, safety and human rights performance and standards are considered in procurement activities.

Royal Bank of Our Strategic Sourcing Group is

Canada (RBC) responsible for sourcing significant (RBC, 2004, p. products and services used across RBC, as 22; RBC, 2009, well as for maintaining a disciplined p. 29 ) process to keep our supply chain fair, open and competitive. Our procurement policies are inclusive and aim to promote sustainable business practices and economic development where possible and appropriate.

As can be seen from Table 3.5, some corporations, e.g., Barrick Gold and Royal Bank of Canada (RBC), communicated their SSCM policies and initiatives in a clear and succinct manner. However, as in the example of AXA Insurance, some corporations' strategic statements were very limited in scope and, therefore, uninformative. Most corporations referred to only the environmental aspects of sustainability, followed by the economic aspects. It should be noted that the social and economic criteria were implicit in the corporations' performance measurement of local-procurement preferences. Corporations that explicitly referred to all three dimensions of sustainability were in the minority. 


\subsubsection{Performance Indicators}

The sequential analysis showed that twenty - approximately $77 \%$ - corporations reported at least one supply chain related KPI in 2004. Some of the most cited indicators are as follows (see Table 3.6 for some representative examples):

Table 3.6 Example Citations of Performance Indicators

\begin{tabular}{lll}
\hline \multicolumn{1}{c|}{ Category } & \multicolumn{1}{c}{$\begin{array}{c}\text { Example Indicators } \\
\text { 2004 }\end{array}$} & \multicolumn{1}{c}{$\begin{array}{c}\text { Example Indicators } \\
\text { 2009 }\end{array}$} \\
\hline \hline Environmental & $\begin{array}{l}\text { Emissions (GHG, CO2, National } \\
\text { Pollution Release Inventory Emissions, } \\
\text { and others); Waste management; Green } \\
\text { energy purchased; Technology Disposal } \\
\text { Program; Materials } \\
\text { recovered/reused/recycled; Energy } \\
\text { efficiency; Material usage efficiencies } \\
\text { (paper usage) }\end{array}$ & $\begin{array}{l}\text { Emissions (GHG, CO2, and others); Green } \\
\text { product offerings; Percentage of green } \\
\text { purchases; Renewable energy purchased; }\end{array}$ \\
& $\begin{array}{l}\text { Contributions to the local } \\
\text { economy/Vendor payments by location; }\end{array}$ & $\begin{array}{l}\text { Contributions to the local economy/Vendor } \\
\text { payments by location }\end{array}$ \\
\hline Economic & $\begin{array}{l}\text { Purchases from suppliers identified as } \\
\text { minority }\end{array}$ & \\
\hline Social & $\begin{array}{l}\text { Policies and procedures to evaluate } \\
\text { human rights performance of suppliers } \\
\text { and contractors; Health and Safety } \\
\text { Incidents Global (including contractors) }\end{array}$ & $\begin{array}{l}\text { Percentage of significant suppliers and } \\
\text { contractors that have undergone screening } \\
\text { on human rights and actions taken (GRI } \\
\text { indicator HR2) }\end{array}$ \\
\hline
\end{tabular}

The results from the sequential analysis showed that the environmental KPIs took precedence over economic and social KPIs. Six companies cited only one environmental $\mathrm{KPI}$; four companies cited only one economic KPI; and three companies cited only one social KPI. Five corporations reported on both environmental and social KPIs. Similarly, five other corporations cited both environmental and economic KPIs. Only four corporations reported a KPI for all three dimensions of sustainability. The primary content analysis on the sample from 2009 resulted in twelve corporations' citing KPIs on the SSCM practices - a 40\% decrease over the sample from 2004. Akin to the results from the sequential content analysis, the primary content analysis showed that the environmental KPIs were given priority over economic and social KPIs. 


\subsubsection{Standards for SSCM}

The sequential analysis on the sample from 2004 resulted in sixteen - approximately 62 $\%$ - corporations' reporting at least one SSCM related standard (see Table 3.7 for some representative examples).

\section{Table 3.7 Example Citations of SSCM Standards and Management Instruments

Category Example Standard Example Standards 2004 2009}

\begin{tabular}{ll}
\hline $\begin{array}{l}\text { Business codes } \\
\text { of conduct }\end{array}$ & Guide to Business Conduct (Supplier \\
& Guide); Code of Business Conduct and \\
& Ethics; First Principles; Code of \\
& Integrity; Code of Corporate Ethics and \\
& Behaviour; Corporate Responsibility \\
& Policy; Business Conduct and Ethics \\
& Practice; Non-harassment Practice; Code \\
& of Conduct
\end{tabular}

Third-party Canadian Standards Association (CSA); certifications Forest Stewardship Council (FSC); EcoLogo; Fair Trade; Oeko-tex Standard 100; Worldwide Responsible Apparel Production (WRAP)

Management initiatives
Sustainable Forestry Initiative (SFI); North American Global Compact Network; Environmental Choice Program (ECP); ISO Standards (9001, 14001, 18001); Responsible Care ${ }^{\circledR}$
Code of Conduct, Code of Ethics and Business Conduct, Supplier Code of Business Conduct, Ethics and Compliance Guide, Code of Ethics and Professional Conduct, Standards of Business Conduct, Standard Terms and Conditions (STC), Environmentally Responsible Procurement Standard, Environmental Code of Practice, Supplier Guiding Principles

Canadian Standards Association (CSA); Energy Star; International Cyanide Management Code for the Gold Mining Industry; Marine Stewardship Council (MSC) standards; Forest Stewardship Council (FSC); FSC Chain-of-Custody (CoC) certification; Controlled Wood standard; Ontario Energy Board's Affiliate Relationships Code (ARC); GREENGUARD

Canada's Environmental Choice Program; United Nations Global Compact; ISO Standards (9001, 14001, 18001); Global Leadership and Commitment Standard; Global Food Safety Initiative (GFSI); Programme for the Endorsement of Forest Certification (PEFC); Responsible Care ${ }^{\circledR}$; Sustainable Forestry Initiative (SFI); Chartered Institute of Purchasing and Supply (CIPS); Electric Power Supply Association's Sound Trading Practices

Notes: Category 2 and 3 are not mutually exclusive, e.g., ISO Standards (9001, 14001, and 18001) could be included in either category.

Thirteen corporations cited one form of business code of conduct as a standard. Thirdparty certifications were the second most cited standard. Other standards, such as management initiatives and programs, followed the third-party certifications. In the primary analysis, the citations followed the same order. However, the primary analysis 
revealed that many corporations cited multiple standards and communicated more details regarding their standards.

\subsubsection{Supplier Monitoring}

The sequential analysis found that eleven - approximately $42 \%$ - corporations included a reference on how they monitor their suppliers on the SSCM-related standards in 2004. This number increased to fourteen - approximately a $12 \%$ increase - in the primary analysis in 2009 (see Table 3.8 for some representative examples).

Table 3.8 Example Citations of Supplier Monitoring

$\begin{array}{ccc}\text { Corporation } & \text { Example Citation } & \text { Example Citation } \\ & 2004 & 2009\end{array}$

$\begin{array}{ll}\text { Bell Canada } & \text { Bell's Procurement group identifies green- } \\ \text { Enterprises } & \text { friendly suppliers through the regular use of } \\ \text { (BCE) (BCE, } & \text { its environmental questionnaire. When } \\ \text { 2004, p.48; } & \text { necessary, on-site audits are conducted of } \\ \text { BCE, 2009, p. } & \text { key suppliers to verify their responses. }\end{array}$
20) Nexen (Nexen, 2004 p. 35 ; Nexen, 2009, p. 19)

Nexen Chemicals supplies redistribution terminals at Vancouver, Washington; Texarkana, Texas; and Red Deer, Alberta. Each of these terminals is subject to a regular Responsible Care ${ }^{\circledR}$ assessment of its ability to handle and re-ship our product safely and in an environmentally responsible way.

In 2003, we had an independent third party

Vancity

(Vancity, 2004,

p. 80; Vancity,

2009, p. 45) screen our existing strategic suppliers. Six suppliers required more follow-up to determine if they were in alignment with the Baseline Ethical Policy. By the end of 2005 , one was no longer a strategic supplier and two were found to be in alignment. Three we found to be potentially in conflict, and we are developing action plans to address them. Since late 2005, we've screened potential strategic suppliers before purchasing from them.
What we did need, we bought from vendors who could show that they too employed sustainability practices in their own processes and up and down their supply chains.

Our Responsible Care product stewardship policy requires both operations (Canadian and Yemen) to regularly assess the suppliers, contractors and carriers who deliver our products and ensure they are clear about our expectations, have information about the hazards of our products and are equipped to handle emergency situations. Our procedures for screening against the Ethical Policy are risk-based: the more significant the relationship in terms of dollars or profile, the deeper the level of analysis performed. Ethical Policy screening for business account relationships is well integrated into our policies and procedures. For strategic business relationships, such as our major suppliers and partners, we use our highest type of due diligence, which is a formal expert screen with 45 indicators across a broad range of environmental, social and governance criteria.

The percentage increase of supplier monitoring citations shows that supplier monitoring is increasingly becoming a priority for SSCM implementation. Both analyses 
demonstrate that supplier monitoring practices varied widely from a mandatory

environmental questionnaire to onsite audit inspections on multiple criteria such as ethics, environment, and health and safety.

\subsubsection{Collaboration}

The sequential analysis from 2004 found that fifteen - approximately $58 \%$ corporations reported forming a collaborative initiative with their supply chain partners versus ten companies - approximately $38 \%$ - in the primary analysis from 2009 (see Table 3.9 for some representative examples ).

Table 3.9 Example Citations of Collaboration

\begin{tabular}{|c|c|c|}
\hline Corporation & $\begin{array}{c}\text { Example Citation } \\
2004 \\
\end{array}$ & $\begin{array}{c}\text { Example Citation } \\
2009 \\
\end{array}$ \\
\hline $\begin{array}{l}\text { Enbridge } \\
\text { (Enbridge, } \\
\text { 2004, p. 51; } \\
\text { Enbridge, } \\
2009, \text { p. } 81 \text { ) }\end{array}$ & $\begin{array}{l}\text { In Colombia, where we operate the } \\
\text { OCENSA pipeline. OCENSA has } \\
\text { developed and implemented a new human } \\
\text { rights policy, using the Voluntary } \\
\text { Principles on Security and Human Rights } \\
\text { as a guideline. The policy commits } \\
\text { OCENSA and its employees and } \\
\text { contractors to respect human rights, reject } \\
\text { violence and avoid associating with illegal } \\
\text { armed groups in Colombia. Along with its } \\
\text { policy, OCENSA has implemented an } \\
\text { extensive education and outreach program } \\
\text { on human rights and social issues for } \\
\text { employees and contractors. }\end{array}$ & $\begin{array}{l}\text { Enbridge is committed to helping } \\
\text { customers use energy wisely. Enbridge } \\
\text { Gas Distribution (EGD) has more than } 40 \\
\text { demand-side management (DSM) } \\
\text { programs covering all market sectors that } \\
\text { encourage customers to adopt energy- } \\
\text { saving equipment and reduce } \\
\text { consumption of natural gas. EGD does } \\
\text { this by: } \\
\text {-Providing financial rebates and } \\
\text { incentives to all types of customers - from } \\
\text { homeowners to large industrial customers } \\
\text { - to encourage them to adopt energy } \\
\text { saving equipment and practices } \\
\text { - Partnering with governments, suppliers } \\
\text { and equipment manufacturers to invest in } \\
\text { new energy-efficient technologies that } \\
\text { benefit ratepayers and enhance the } \\
\text { competitiveness of EGD's business. }\end{array}$ \\
\hline $\begin{array}{l}\text { Scotiabank } \\
\text { (Scotiabank, } \\
\text { 2004, p. } 30 \\
\text { Scotiabank, } \\
\text { 2009, p. } 17 \text { ) }\end{array}$ & $\begin{array}{l}\text { We are working closely with a number of } \\
\text { vendors to develop hardware and software } \\
\text { solutions that fully comply with the } \\
\text { Canadian Standards Association (CSA) } \\
\text { standards. }\end{array}$ & $\begin{array}{l}\text { Scotiabank de Puerto Rico launched an } \\
\text { internal "Go Green" program, including } \\
\text { office paper recycling through } \\
\text { international supplier, Shred-it. It is } \\
\text { estimated that paper recycling at Bank } \\
\text { offices in Puerto Rico in } 2009 \text { saved } 819 \\
\text { trees from being harvested. }\end{array}$ \\
\hline
\end{tabular}

Both analyses show that the elements of collaboration, such as the number of collaborative initiatives and the level of involvement, varied greatly across corporations from consultations with suppliers to forming alliances for product development. As in 
the example of Enbridge, a corporation in the energy industry sector, (Table 3.9) only six companies referred to a downstream collaboration with their customers in 2004.

Similarly, the primary analysis revealed that downstream collaboration in the supply chain is in the minority.

\subsection{Forward-Looking Statement}

The sequential analysis revealed that nine - approximately $35 \%$ - corporations cited a forward-looking statement on SSCM practices (see Table 3.10 for some representative examples).

Table 3.10 Example Citations of Forward Looking Statements

\begin{tabular}{|c|c|c|}
\hline Corporation & $\begin{array}{c}\text { Example Citation } \\
2004\end{array}$ & $\begin{array}{c}\text { Example Citation } \\
2009\end{array}$ \\
\hline $\begin{array}{l}\text { Alcoa (Alcoa, } \\
\text { 2004, p. 54; } \\
\text { Alcoa, 2009, p. } \\
16 \text { ) }\end{array}$ & $\begin{array}{l}\text { For the remainder of } 2005 \text { : } \\
\text { - Conduct a series of internal procurement } \\
\text { forums to communicate the positions and } \\
\text { obtain feedback from our procurement } \\
\text { professionals. } \\
\text { - Identify areas where we may have gaps } \\
\text { related to our positions and develop action } \\
\text { plans to respond. } \\
\text { - Respond to any gaps and continue to align } \\
\text { with our overall sustainability framework. }\end{array}$ & $\begin{array}{l}\text { Objectives 2010: } \\
\text { - Develop a responsible procurement } \\
\text { approach based on the pilot project } \\
\text { carried out with suppliers in } 2010 \text {. }\end{array}$ \\
\hline $\begin{array}{l}\text { Bell Canada } \\
\text { Enterprises } \\
(\mathrm{BCE})(\mathrm{BCE}, \\
2004, \text { p. } 49 ; \\
\mathrm{BCE}, 2009, \mathrm{p} . \\
12)\end{array}$ & $\begin{array}{l}\text { Goals: } \\
\text { Continue to ensure that all new Bell } \\
\text { suppliers complete an environmental } \\
\text { questionnaire and that environmental } \\
\text { considerations are part of contract } \\
\text { negotiations. }\end{array}$ & $\begin{array}{l}2010 \text { Objective: } \\
\text { Pursue the development of policies and } \\
\text { internal processes that favour the } \\
\text { selection of responsible suppliers and } \\
\text { products. }\end{array}$ \\
\hline $\begin{array}{l}\text { Syncrude } \\
\text { (Syncrude, } \\
\text { 2004, p. 4; } \\
\text { Syncrude, } \\
2009, \text { p. 19) }\end{array}$ & $\begin{array}{l}\text { Initiatives such as the Syncrude Emission } \\
\text { Reduction Project, currently in early stage } \\
\text { engineering and scheduled for start-up in } \\
\text { 2009, will keep Syncrude moving forward } \\
\text { on its sustainability journey. }\end{array}$ & $\begin{array}{l}\text { Expected Results: } \\
\text { •Reduction in energy intensity of } 11 \% \\
\text { by } 2013 \text { from } 2009 \text { levels } \\
\text { • Further reductions in emissions of CO2 } \\
\text { per barrel of production }\end{array}$ \\
\hline
\end{tabular}

As is seen in Table 3.10, many of these citations involved introducing new initiatives or future targets for reducing the corporations' ecological footprints. As in the example of Syncrude, a corporation in the energy industry sector, (Table 3.10) some corporations' goals cited in 2004 were actually achieved by 2009. The same percentage of corporations included such forward looking statements in the primary analysis from 2009. 


\subsection{Discussion}

Stakeholder influence is a key motivation for corporations in adopting overall SSCM practices (Sarkis, 2001; Seuring and Muller, 2008a), of which, supply chain governance provides the necessary mechanisms in managing the risk of suppliers, particularly as it relates to suppliers' ability to produce to the required specification (Humprey and Schmitz, 2008). The literature notes that leading companies around the globe are seeking multi-stakeholder governance models to protect and improve their reputation, and oversee ethical aspects of their supply chains (Blowfield and Dolan, 2010). Improving overall supply chain performance through inter-organizational governance models and mechanisms has been a topic of investigation by many authors (Handfield and Bechtel, 2002; Alvarez et al., 2003; Ghosh and Fedorowicz, 2008). For example, Nikoloyuk et al. (2010) present the strengths and weaknesses of such multi-stakeholder models in addressing sustainable development issues in supply chains by conducting a case study on the Roundtable on Sustainable Palm Oil (RSPO) initiative. Levy (2011) points to the inertia of the current governance systems as part of the transition to sustainable economies on a global scheme and asserts that corporate governance must serve multiple stakeholders to generate change toward sustainability. Vermeulen (2010) discusses the nature of various multi-stakeholder (market and non-market actors) governance approaches for SSCM and concludes that the research in this field is in its infancy. Martinelli and Midttun (2010) argue the contribution of the media-driven civil societies to "socially and environmentally sustainable" governance - by utilizing multiple theoretical lenses including stakeholder theory, the reputational approach, cluster theory, and social innovation perspective - and posit that the expansion of sustainable governance exceedingly relies on NGO pressure. The findings from the content analyses, i.e., reporting on sustainable supply chain governance practices has been a marginal practice by Canadian corporations, may be attributed to two reasons. First, there may be a lesser tension exerted on Canadian corporations by civil society, including NGOs, for compliance on environmental and social issues in comparison to the tension exerted in supply chains that extend to developing countries (Lund-Thomsen and Nadvi, 2010). This may lead to a reduction in concerns associated with governing for sustainability 
issues as opposed to other stakeholder priorities. Second, agents of Canadian corporations may have limited awareness of the significance of the concept of governance for sustainability.

Organizations integrate sustainability initiatives into SCM to: address pressures and incentives from various stakeholders; comply with government regulations; manage company reputation; and increase overall competitive advantage (Seuring and Muller, 2008a; Gold et al., 2010; Bjorklund, 2011). Further, this integration can be driven by compliance or proactive strategies (King and Lenox, 2000; Matten and Moon, 2008). Extensive communication of the sustainability initiatives to internal and external stakeholders comprises one of the tenets for successful implementation of SSCM strategies (Seuring and Muller, 2008a). The number of corporations that cited implementing a strategic or operational initiative to address at least one dimension of SSCM increased from seventeen to twenty between 2004 and 2009. Further, the citations from 2009 were clearer and more specific. This may indicate that the agents of Canadian corporations have an increased awareness for the need to communicate SSCM related corporate strategies. However, both analyses showed that SSCM strategies focused on addressing the environmental issues and addressing all three aspects of sustainability is a rare practice. This is congruent with the evolution of SSCM research, where environmental aspects have taken precedence over social and economic aspects in SCM since 1990s (Carter and Easton, 2011).

The development and use of KPIs is imperative for making the business case for SSCM practices (Vasileiou and Morris, 2006; Keating et al., 2008). However, the set of KPIs that are developed; therefore, the success of measuring SSCM performance, is contingent upon what businesses consider as meaningful outcomes (Bai et al., 2012). For example, simultaneous consideration of environmental and economical outcomes provides organizations with the ability to identify and achieve results in both of these aspects (Bjorklund et al., 2012). Lozano (2012) finds that most voluntary initiatives on CS, including "assessment and communication" relate to the environmental aspects. This may be due to the complexity of developing social KPIs, particularly as it relates to describing the social value of products or services (Clift, 2002; Courville, 2003). The results from 
the sequential analysis were no exceptions. The prominence of the environmental aspects of SSCM strategies was reflected in the order KPIs were reported: environmental KPIs were the most-cited, followed by economic and social KPIs. Since the primary analysis reveals an increase in the number and percentage values on the SSCM strategy criterion between 2004 and 2009, there seems to be no apparent ground for the percentage decline in the number of corporations reporting on KPIs between 2004 and 2009. However, when interpreted in conjunction with the diversity of KPIs reported, the decline may be attributed to the following reason: The existence of manifold organizational approaches in communicating sustainability initiatives (Shaw et al., 2010; Tate et al., 2010; Roca and Searcy, 2012) may have put some corporations in a continuous state of looking for meaningful KPIs to report on, at times, to no avail. The scarcity of social KPIs in both analyses shows that measuring the social aspect of sustainability has been lagging among Canadian corporations. Vifell and Soneryd (2012) illustrate how social aspects of sustainability remain weak in organizations from the point of conception; and therefore, to the end results of an initiative. The findings confirm the shortage of social performance measures in SCM and the need to develop them (Akyuz and Erkan, 2010).

The literature underlines the proliferation of global standards and business codes of conduct to address environmental, social, and ethical issues in supply chains (Sobczak, 2006; Darnall et al. 2008; Prieto-Carron, 2008; Curkovic and Sroufe, 2011). The findings from both content analyses show that the majority of Canadian corporations are employing a combination of standards and business codes of conduct as instruments to implement their SSCM strategies. The risk exposure, in particular, may be an important factor for Canadian corporations in prompting this practice and broadening the scope of codes of conduct at the same time (Teuscher et al., 2006; Nadvi, 2008). However, the existence of a code of conduct, in particular, does not necessarily correlate to the existence of CS practices (Bondy et al., 2008). Further, different standards induce different levels of legitimacy amongst external stakeholder groups (Mueller et al., 2009), therefore imposing a multi-standard approach from corporations. This may explain the slight decline in the number of corporations' reporting a standard in the primary analysis: more corporations may have addressed SSCM issues in their codes of conduct; therefore, 
eliminating the need for other standards. Further, given that between 2004 and 2009 there is no decrease in the number of corporations for the SSCM strategy criterion (Section 3.4.2), this decline may be due to a shift in priorities of some companies' reporting practices.

Supplier commitment for compliance with codes of conduct is critical to their successful execution (Jiang, 2009; Tulder et al., 2009). Further, while providing opportunities for unrestricted action, codes of conduct necessitate monitoring and public disclosure (Veral, 2005). However, monitoring suppliers on their commitment and compliance with the codes of conduct and SSCM-related standards presents challenges due to economical, geographical, political, legal, and cultural differences across supply chains (Pedersen and Andersen, 2006). These contextual differences in developing countries have a significant impact on how developing country suppliers respond to external pressures for sustainability compliance (Nadvi and Lund-Thomsen, 2010). A particular limitation to codes of conduct or other SSCM-related standards is that they are created in the corporate headquarters of buyers from developed countries without any noteworthy input, if ever, from developing country suppliers or workers (De Neve, 2009). Consequently, many developing country suppliers feel uncertain and reluctant to comply with SSCM-related standards, in particular, when pressure from developed country buyers is vague or absent (Barrientos, 2008). The garment factory collapse in Dhaka, Bangladesh ${ }^{3}$ in 2013 is an unfortunate occurrence resulting from this reluctance to comply with the SSCM-related standards, amongst other internal and external factors. Further, the garment factory incident in Bangladesh point to the complexities and challenges to supply chain collaboration of buyers from developed countries, such as Canada, with partners in developing countries. With that in mind, the wide array in the number and depth of supplier monitoring activities in Canadian corporations may be taken as different operational approaches to address these challenges in supplier monitoring while striving to execute their SSCM strategies. Further, the primary analysis showed that several corporations referred to additional dimensions of sustainability in their monitoring practices. For example, Vancity, a corporation in the financial services industry sector,

3 A factory building collapse in April 24, 2013 killed 1,132 garment workers and sparked debate over labor safety and rights. 
(Table 3.8) made it explicit that suppliers were assessed on "environmental, social and governance criteria" in addition to "Ethical Policy" screening that was reported as the only criterion for supplier monitoring in the sequential analysis. This may indicate that the practice and understanding of SSCM in Canadian corporations, at least as they relate to supplier monitoring, have evolved to a more holistic, multi-dimensional concept of sustainability. This evolution, however, does not quite extend to SSCM strategies as the environmental dimension dominates the others, particularly the social dimension. This discrepancy may be attributed to two interrelated reasons. First, the acuity of inherent environmental, social, and ethical risks in supply chains requires corporations to take a more comprehensive approach in supplier monitoring. Second, despite the challenges associated with supplier monitoring, such a comprehensive approach provides a relatively straightforward and effective way to build the needed legitimacy among stakeholders of corporations.

Collaboration across supply chain partners is imperative to supply chain performance (Lee et al., 1997; Barratt, 2004; Schneeweiss et al., 2004), and is one of the key enablers of sustainability (Chalopingh-March, 2006; Lozano, 2007; Dienhart and Ludescher, 2010). However, the mechanisms of inter-organizational collaboration, such as trust and decision-making, are complex and context-specific (Nyaga et al., 2010; Domenech and Davies, 2011). Further, addressing CS issues through inter-organizational collaboration can be an exceedingly political practice in which the concerns regarding organizational reputation and legitimacy may supersede the overall sustainability concerns (Kearins and Sharma 2011; MacCarthy and Jayarathne, 2012). The decrease in the number of corporations that cited a collaborative initiative from sequential to primary analysis may be caused by these elements of organizational complexity, the level of strategic commitment required, and inter-organizational politics. Additionally, both the primary and sequential content analysis show that downstream collaboration in the supply chain is in the minority. The literature, in particular, identifies the lack of downstream practices, such as social and green marketing, in SSCM (Schaefer and Crane, 2005; Tukker et al., 2008; Peattie and Peattie, 2009). Sarkis (2012) finds that green supply chains do not focus on consumption practices and identifies the need for practices from "green supply" 
to "green demand" as an area of future investigation. The collaboration for CS area is fertile for further research.

Although nine corporations cited a forward-looking statement on SSCM practices in both content analyses, the primary content analysis revealed that the majority of these citations referred to strategic objectives on procurement as they relate to sustainability issues. This might indicate a trend that SSCM practices have evolved to be more of a strategic priority, rather than an operational target. As discussed in this section above, the increase in the number of corporations citing a supply chain strategy between 2004 and 2009 also confirms this trend.

\subsection{Conclusions}

This study has contributed to the literature on evolution of SSCM practices by providing a sequential content analysis of 26 Canadian corporations' CSDRs dating to 2004 in relation to a previously conducted primary content analysis of the same 26 CSDRs dating to 2009. The study has revealed how Canadian corporations have addressed SSCM issues over a five-year span on seven interrelated research criteria. Despite the increase in the number of supply chain governance citations in the primary analysis, governance for SSCM has remained peripheral by Canadian corporations. The area for SSCM governance presents opportunities for research. For example, future research may investigate the effects of stakeholder pressure, particularly from NGOs, on SSCM governance. Although Canadian corporations are increasingly adopting strategic or operational approaches to address sustainability issues in supply chains, integration of all three dimensions of sustainability into strategic and operational aspects of SCM is a rare practice. This finding in Canadian CSDRs augments the previous research (Carter and Easton, 2011) by identifying the sequence of the three dimensions of sustainability in SCM: first comes the environmental dimension, followed by the economic and social dimensions. This strategically incremental approach extends to SSCM performance measurement practices, in which the environmental and economic KPIs are given priority over social KPIs. Although it is speculated that corporations are finding it difficult to develop and report social KPIs, further research is needed to understand the reason 
behind the decline in the number of corporations that disclose KPIs on SSCM practices. Despite a slight decrease in the reported standards in the primary analysis, the majority of corporations use a combination of business codes of conduct, third-party certifications, and management initiatives and programs as SSCM standards respectively. Which combinations of standards achieve a higher-level of legitimacy and risk mitigation for corporations, however, constitutes a venue for further research. Monitoring suppliers on these standards has been an increasing practice between 2004 and 2009, with a widerange of monitoring activities. Further, citations on supplier monitoring point to an evolution in which the understanding of CS has evolved in to a holistic, multidimensional concept. Both analyses show that upstream collaboration through the supply chain surpasses downstream engagement with customers. The decrease in the collaboration criterion may have to do with the strategic commitment, interorganizational politics and complexity involved with cooperation in supply chains. The area of collaboration for SSCM provides ample opportunities for further research. Finally, corporations' forward looking statements on SSCM practices indicate a tendency in which SSCM is becoming more of a strategic priority, rather than an operational target. 


\section{CHAPTER 4 - INTEGRATION OF CORPORATE SUSTAINABILITY INTO SUPPLIER SELECTION}

\subsection{Introduction}

One of the critical contributions of SCM professionals to firms' strategic competitiveness is to measure supplier performance for supplier selection (de Boer et al., 2001; Chen et al, 2006). However, supplier selection is a complex decision-making process, which involves vague and often-conflicting objectives and numerous qualitative and quantitative criteria (Degraeve et al., 2000; Jain et al., 2009). Further, the increased strategic nature of SCM requires supplier selection constructs that take strategic alignment of suppliers into consideration (Huang and Keskar, 2007; Esposito and Passaro, 2009; Hsu et al., 2011).

The literature on supplier evaluation and selection is plentiful and still growing. Many authors have tackled the supplier selection topic by employing different methodological approaches (Weber et al., 2000; Narasimhan et al., 2001; Choy and Lee, 2003; Huang and Keskar, 2007; Ferreira and Borenstein, 2012) based on a variety of economic and operational criteria such as regulatory compliance, financial position, cost, quality, reliability, risk, and supplier profile (Asamoah et al., 2012). The consideration of the sustainable, and strategic, nature of SCM also necessitates the integration of environmental and social issues into the supplier evaluation and selection processes (Sarkis and Talluri, 2002; Bai and Sarkis, 2010). Measurement of supplier performance is a commonly cited challenge to the integration of CSR or CS into the supply chain (Storey et al., 2006; Linton et al., 2007; Carter and Rogers, 2008). Although research that integrates environmental and social criteria in supplier selection is emergent (Enarsson, 1998; Sarkis and Talluri, 2002; Baskaran et al., 2012), the existing supplier selection models and tools have focused primarily on the environmental aspects of CS (Handfield et al., 2002; Hsu and Hu, 2009; Baboulet and Lenzen, 2010; Shaw et al., 2012). Very little research has explicitly integrated the social dimension of CS into supplier selection (Bai and Sarkis, 2010; Kuo et al., 2010; Buyukozkan and Cifci, 2011; Amindoust et al., 2012). Further, the literature identifies the need to develop measurement frameworks that 
include the social dimension of $\mathrm{CS}$, in addition to the environmental and economic dimensions (Akyuz and Erkan, 2010).

This chapter addresses the research gap on the integration of the environmental and social criteria of CS into supplier assessment and selection by conducting a study to address the third research objective: "Develop a model to integrate environmental and social criteria of CS into supplier assessment and selection." To achieve this objective, this phase of the dissertation applies the Sustainable Supplier Selection (3S) Design Process to two major Canadian case companies (as a single unit of analysis), an electric utility and a financial services corporation, to develop a sustainable supplier selection model. As a result, this phase provides a contingency-based and practice-oriented approach to identify the relevant CS criteria for supplier selection. With this in mind, the remainder of the chapter is organized as follows. A review of the literature pertaining the supplier assessment and evaluation is provided in the next section. This is followed by the methodology section, which introduces the process that was used to develop the sustainable supplier selection model. Following the section on methodology, results from the application of the process to the case studies are presented. The chapter continues with a discussion of the implications of the results and ends with conclusions.

\subsection{Literature Review}

The literature review focuses on two sub-themes of the supplier selection research. The review in Section 4.2.1 introduces the supplier selection issue and the multi-criteria decision-making (MCDM) approaches applied to the topic. The review in Section 4.2.2 introduces the construct of CS in SCM and how it has affected the supplier selection issue, particularly as it relates to the integration of environmental and social criteria into the MCDM approaches.

\subsubsection{Supplier Assessment and Selection}

Performance measurement can be simply defined as "the process of quantifying the efficiency and effectiveness of past actions" (Neely et al., 2002, p. xiii). Performance measurement is imperative to strategy formulation and implementation by forming 
diagnostic control mechanisms and measuring actual results (Wouters, 2009). From this perspective, measuring supplier performance for supplier selection is crucial to successful, strategic implementation of organizations' SCM practices (Weber et al., 1991; Esposito and Passaro, 2009). Supplier assessment and selection based on criteria such as cost, quality, geographical location, service, on-time delivery, responsiveness, and information sharing has a positive influence on the economic performance and competitiveness of organizations (Ghodsypour and O'Brien, 2001; Degraeve and Roofhooft, 2001; Kannan and Tan, 2002). Consequently, buying firms have developed strategic and operational approaches to select suppliers that possess supply chain competencies. The single criterion approaches, such as cost-based or quality-based only, to identify global optimal suppliers are far from accommodating the intricacies of contemporary SCM (Ho et al., 2010; Degraeve et al., 2000). Therefore, the use of MCDM models to assess and select suppliers has been the norm among researchers and, to some extent, practitioners. For example, Huang and Keskar (2007) assemble a total of 101 criteria under seven categories - reliability, responsiveness, flexibility, cost and financial, assets and infrastructure, safety, and environment - and identified cost, quality, on-time delivery, and flexibility as the most common criteria used to assess suppliers respectively. Ho et al. (2010) identify hundreds of supplier assessment and selection criteria proposed in the literature and list the most prevalent criteria as: "quality, followed by delivery, price/cost, manufacturing capability, service, management, technology, research and development, finance, flexibility, reputation, relationship, risk, and safety and environment" (p.21).

Notwithstanding the wealth of assessment criteria, the complexity of decision-making for a certain supplier selection model is further exacerbated by factors such as: the attributes and type of the product, the number of suppliers available, the nature of market conditions and uncertainty present, the strategic or operational importance of the sourcing decision, the size of capital outlay, and the nature of the supplier relationship (de Boer et al., 2001; Vanteddu et al., 2011). This might explain the multitude of decision-making models and approaches to supplier selection in the literature. Since the 1960s, the multicriteria nature of supplier selection has been investigated extensively. Researchers have 
used a variety of MCDM approaches to address supplier evaluation and selection problems. For example, Akarte et al. (2001) and Asamoah et al. (2012) apply AHP methodology to select suppliers based on eighteen and three criteria, respectively. Kirytopoulos et al. (2008) use ANP to present the decision maker with the effect of supplier selection criteria. Guo et al. (2009) apply an AI-based approach, the hierarchical potential support vector machine, to accomplish multiclass classification and feature selection of suppliers. Choy and Lee (2003) use the CBR technique for decision making on outsourcing and automating the supplier selection process. Songhori et al. (2011) employ a DEA model to find out the relative efficiency of suppliers. Based on fuzzy sets theory, Chen et al. (2006) propose the TOPSIS model to evaluate and select suppliers. Jain et al. (2007) develop an approach by utilizing fuzzy association rule mining to enhance decision-making flexibility in supplier selection based on both tangible and intangible criteria. $\mathrm{Ng}$ (2008) presents a linear programming mathematical model to determine the relative importance of the criteria weightings.

All of the supplier selection approaches identified above have limitations such as: "types of factors included, data requirements, transparency of process, integration of managerial perceptions and intangibility, and integration of previous knowledge and decisions into decision analysis“(Bai and Sarkis, 2010, p. 253). Therefore, many authors have proposed integrated approaches to overcome these limitations and deal with different aspects of the supplier selection issue. For example, Weber et al. (2000) combine multi-objective programming with DEA; whereas, Mendoza and Ventura (2008) apply a two-stage method by combining AHP and mixed integer non-linear programming to address supplier selection and optimal order quantity issues simultaneously. Kahraman et al. (2003) use a fuzzy AHP approach to identify the importance of selection criteria. Hong et al. (2005) utilize a mixed-integer linear programming model to maximize revenue. Chou and Chang (2008) apply a fuzzy SMART to assess and rate suppliers on both qualitative and quantitative criteria. Other examples of integrated approaches to supplier selection include: SMART and DEA (Seydel, 2005); AHP and DEA (Saen, 2007); MAUT and linear programming (Sanayei et al., 2008); strategy-aligned fuzzy SMART (Chou and 
Chang, 2008); Bayesian networks (BN) and total cost of ownership (TCO) methods (Dogan and Aydin, 2011); and fuzzy Bayesian (Ferreire and Borenstein, 2012).

The abundance of research on supplier selection issue has prompted many authors to conduct literature reviews on the existing approaches applied to the topic. Early reviews of the literature were conducted by Dickson (1966), Weber (1991), Holt (1998), Degraeve (2000), and de Boer et al. (2001). In an attempt to identify the variety of approaches to the supplier selection problem, Ho et al. (2010) review seventy-eight journal articles on MCDM methodologies. Ho et al. (2010) group MCDM approaches as "individual approaches" and "integrated approaches" and identified eight methodologies under individual approaches - DEA, mathematical programming, CBR, ANP, AHP, fuzzy set theory, SMART, and generic algorithm - and three methodologies under integrated approaches - integrated AHP approaches, integrated fuzzy approaches, and other approaches such as integrated DEA and SMART. Further, Ho et al. (2010) find that the DEA is the most widely applied approach, followed by mathematical programming, to supplier selection. A similar review of the literature by Agarwal et al. (2011) investigates sixty-eight research papers published from 2000 to 2011 on MCDM approaches to supplier assessment and selection. Agarwal et al. (2011) present nine categories on MCDM approaches and also identify DEA as the most prevalent methodology employed by researchers.

\subsubsection{Supplier Selection for Sustainable Supply Chain Management}

Beginning in the 1990s, increased emphasis on environmental and social impacts of firms' activities gave rise to the theory and practice of CSR or CS. The conceptualization of the economic, social, and environmental dimensions of both the CSR and CS constructs are similar (Montiel, 2008). One representative definition of CS by Marrewijk et al. (2003, p. 102): "demonstrating the inclusion of social and environmental concerns in interactions with stakeholders" clearly implies that companies go beyond what is required by law and operate in a way that takes the morals and values of society into consideration (Carroll, 1991). Motivated by institutional pressures, stakeholder concerns, and gaining competitive advantages, amongst others, organizations have increasingly 
started to integrate the principles of CSR or CS into SCM (Roberts, 2003; Cousins and Menguc, 2005; Seuring and Muller, 2008a). Many authors (Carroll, 1991; Carter and Jennings, 2002; Murphy and Poist, 2002; Carter and Rogers, 2008; Mueller et al., 2009) position environmental and social responsibilities, e.g., ethical behaviour, respect for society, human rights, diversity, philanthropy, and ecological relationship with individuals and organizations, within the context of voluntary SCM practices and thus SSCM.

Organizations' environmental and social performance across supply chains is affected by the suppliers' environmental and social performance (Foerstl et al., 2010). Therefore, decision-making on supplier selection is a fundamental component for a successful implementation of SSCM practices (Rao, 2005; Seuring and Muller, 2008a). Businesses must not only select their first tier suppliers, but also take the entire supply chain into consideration to meet global market demand and alleviate reputational risk, particularly as it relates to environmental and social issues (Cousins et al., 2004; Matos and Hall, 2007). From a dynamic capabilities view perspective, firms that integrate CS criteria with supplier management and selection create core competencies and capabilities, such as resource accumulation, increased reputation, and organizational learning processes, that lead to competitive advantages (Reuter et al., 2010; Ehrgot et al., 2010). Organizational learning refers to: "the ways firms build, supplement and organize knowledge and routines around their activities and within their cultures, and adapt and develop organizational efficiency by improving the use of the broad skills of their workforces, processes and outcomes" (Dodgson, 1993, p. 377). The notion of organizational learning closely relates to RBV for that the very purpose of learning is seen as to achieve, improve, and sustain competitiveness, in particular, in uncertain environmental uncertainties (Dodgson, 1993). With that in mind, firms that are proactive in evaluating suppliers on the CS criteria gain competitive advantage as it relates to managing sustainability-related risks: "Without structured supplier assessment, effective management of supplier sustainability can only be achieved randomly, which might lead to potentially detrimental negative effects on corporate reputation" (Foerstl et al., 2010, p. 127). 
As identified in Section 4.2.1, the vast amount of research on supplier selection mainly focused on economic and operational criteria. With the introduction and integration of environmental and social criteria into supplier evaluation and selection, many researchers have conducted studies on supplier selection for SSCM by utilizing different approaches. For example, one of the early studies by Enarsson (1998) introduces the Ishikawa diagram as an environmental evaluation tool for suppliers. Humphreys et al. (2003) delineate several qualitative and quantitative environmental criteria and present a framework for integrating these criteria in to the supplier selection process by employing the CBR and MAA approaches. Lee et al. (2009) propose a model for evaluating green suppliers by employing the Delphi method and the fuzzy extended AHP. Shaik and Abdelkader (2011) propose a framework for the green supplier selection process by utilizing MAUT. Similarly, other authors focused on environmental criteria for supplier selection by utilizing different approaches (Handfield et al., 2002; Sarkis and Talluri 2002; Humphreys et al., 2006; Lu et al. 2007; Feyzioglu and Buyukozkan, 2008; Hsu and Hu, 2009; Baboulet and Lenzen, 2010; Hsu et al., 2011; Shaik and Abdelkader, 2011).

Although rather limited, the supplier selection literature presents studies in which environmental criteria are combined with economic criteria. For example, Kannan et al. (2008) use ISM and AHP to analyze and select green suppliers. However, when applying the model, Kannan et al. (2008) consider only one environmental criterion, the existence of ISO 14000 certification, in addition to flexibility, cost, and service criteria. Shaw et al. (2012) focus on the carbon emission criterion, along with the criteria of cost, quality, rejection percentage, and late delivery percentage, and present an integrated fuzzy-AHP and fuzzy multi-objective linear programming approach for supplier selection.

With the above in mind, research that explicitly integrates the CS discussion into the supplier evaluation and selection modeling area is scarce. Bai and Sarkis (2010) illustrate the application of environmental, social, and economic criteria for supplier selection by using Grey system and Rough set theory. Kuo et al. (2010) develop a green supplier selection model based on an integrated ANN-DEA-ANP method and apply the method to a case company. Buyukozkan and Cifci (2011) employ fuzzy ANP to present a decision framework for sustainable supplier selection. Based on the FIS approach, Amindoust et 
al. (2012) propose a supplier-ranking model that considers environmental, social, and economic criteria simultaneously. By employing the Grey approach, Baskaran et al. (2012) evaluate sixty-three suppliers from the Indian textile industry on the basis of six CS criteria: discrimination, abuse of human right, child labor, long working hours, unfair competition, and pollution.

As can be seen from Section 4.2.1, it is noticeable that the literature has made significant theoretical and anecdotal contributions to the conventional supplier evaluation and selection field. The studies cited in Section 4.2.2 show that research on the integration of the environmental criterion into supplier selection is growing. Efforts to incorporate the social dimension of CS into supplier selection remain in their embryonic stages. Given that there is an ever-increasing pressure on businesses to consider and measure the social impacts of their supply chain decisions (Hutchins and Sutherland, 2008), the need to develop supplier evaluation and selection models that include social and environmental criteria is quite evident. This fact is also substantiated by the corporate expert interviews presented in Chapter 2. This study aims to address this gap in sustainable supplier selection with the objective of: "Develop a model to integrate environmental and social criteria of CS into supplier assessment and selection."

\subsection{Methodology}

The development of the supplier selection models was based on a bespoke approach: $3 \mathrm{~S}$ Design Process, which was adapted from the SDI Design Process by Searcy et al. (2005; 2006; 2008). Bespoke approaches to supplier selection "tend to be evidenced in terms of ad hoc evaluation/selection methods having been developed by, and therefore familiar to, a particular construction owner. They tend to incorporate several decisional techniques simultaneously, and evidence much variance” (Holt, 1998, pp. 153-154).

Depicted in Figure 4.1, the 3S Design Process provides a systemic approach to designing a system of indicators, which, in this study, characterize the environmental and social aspects of CS for the supplier selection model. Further, the process recognizes continuous feedback loops between its components - steps 1 through 5. 


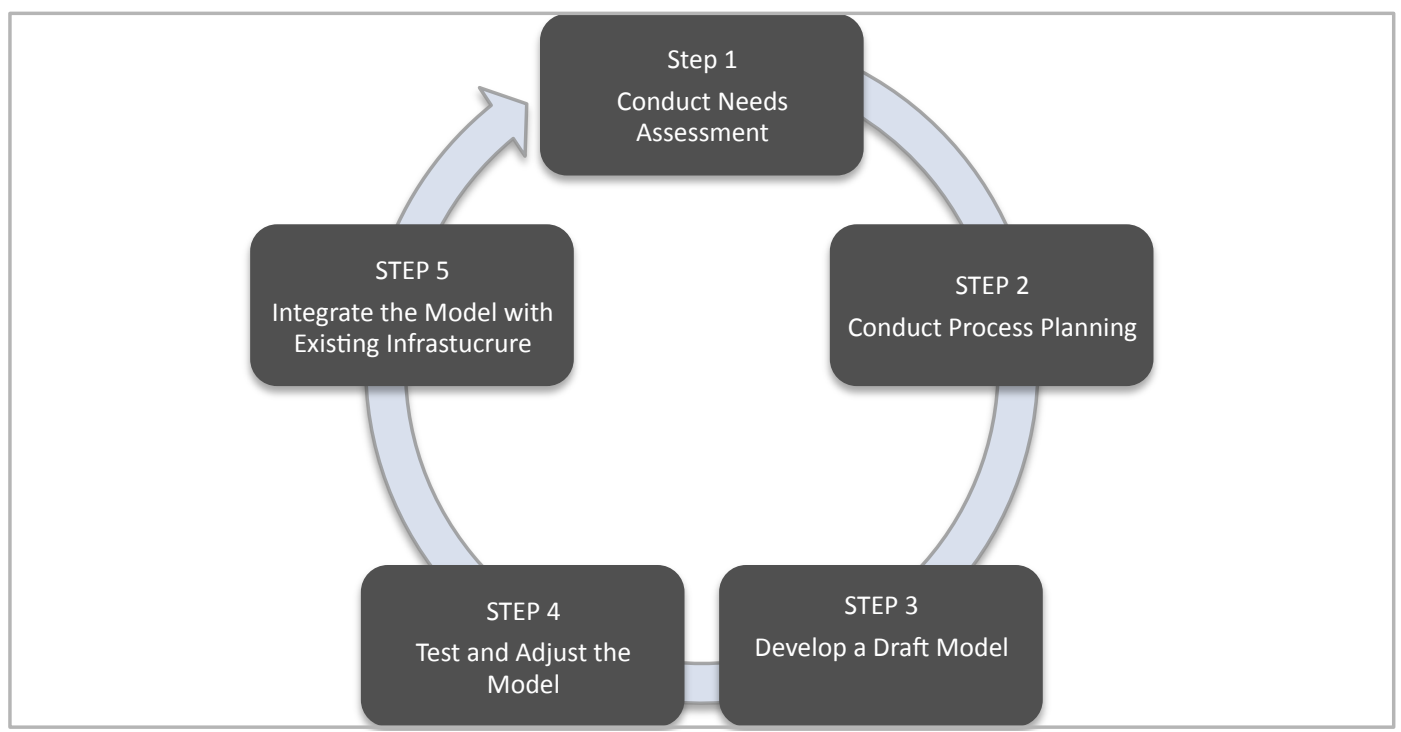

Figure 4.1 The 3S Design Process (adapted from Searcy et al., 2005)

The 3S Design Process incorporates engineering and management literature to facilitate the accomplishment of the goals of the project - in this case, the development of the sustainable supplier selection model. For example, the vast amount of literature on environmental scanning and gap analysis supports Step 1, which aims to observe, identify, and evaluate internal organizational practices and the external environment to provide input and direction to strategic and tactical planning (Fahey and King, 1977; Thomas, 1980; Auster and Choo, 1994; Tontini and Picolo, 2010). The purpose of Step 2 is to analyze the model development project in order to identify the preliminary scope, and therefore, resources required, relevant stakeholders, the level of stakeholder involvement, sub tasks and deliverables (Bailetti et al., 1994; Jensen, 1994; Harrison and Lock, 2004). At the core of the 3 S Design Process for sustainable supplier selection is Step 3. This step focuses on identifying the characteristics of the supplier assessment criteria and determining how the criteria should be selected (Hearnshaw et al., 2001). To achieve this objective, data from a variety of internal and external sources, supported by an exploration of relevant stakeholder perspectives, are needed to ensure the validity of the supplier assessment (Campbell et al., 2002). Further, Step 3 extensively borrows from the process on the design of composite indicators by Nardo et al. (2008), particularly as it relates to scaling, weighting, and presenting the results. Step 4 aims to further validate the end use of the model as a decision making tool and relies on relevant stakeholder 
consultations to do so (Gay and Borus, 1980; Campbell et al., 2002; Bockstaller and Girardin, 2003). Further, Step 4 explicitly links the process to the plan-do-check-act (PDCA) cycle of continuous improvement (Deming, 1993; Langley et al., 1996). The final step looks at the ways in which the model can be integrated with existing infrastructure, in particular supplier performance measurement systems. Incorporating sustainability measures into business processes varies for individual organizations (Searcy et al., 2006; Gates and Germain, 2010). Therefore, Step 5 focuses on identifying tactical approaches to the challenges of such integration. Further, the precise nature of the end goals and the ways by which these goals are achieved are unique to every organization; therefore, Step 1 through Step 5 require highly iterative and participatory decision-making practices that involve individual and group consultations to yield continuous progress towards end goals (Ford and McLaughlin, 1992; Paley, 1993). The application of the $3 \mathrm{~S}$ Design Process to the case study companies is summarized in Table 4.1.

Since the steps of the SDI Design Process from which the 3S Design Process was derived have been previously described by Searcy et al. $(2005 ; 2006 ; 2008)$, they will not be discussed further in this section, but will rather be explained in detail during the application of the process to the case studies in Section 4.4. 
Table 4.1 Application of the 3S Design Process to Case Studies

$\begin{array}{lllll}\text { STEP 1 } & \text { STEP 2 } & \text { STEP 3 } & \text { STEP 4 } & \text { STEP 5 }\end{array}$

Conduct Needs Conduct Process Develop a Draft Test and Adjust Integrate with

Assessment

Planning

Model

the Model

Existing

Infrastructure

\begin{tabular}{|c|c|c|c|c|c|}
\hline Key Steps & $\begin{array}{l}\text { - } \begin{array}{l}\text { Identify the } \\
\text { preliminary }\end{array} \\
\text { scope } \\
\text { - } \begin{array}{l}\text { Identify the } \\
\text { guiding } \\
\text { principles }\end{array}\end{array}$ & $\begin{array}{ll}\text { - } & \text { Refine the } \\
\text { scope } \\
\text { Identify the } \\
\text { preliminary } \\
\text { priority areas } \\
\text { for criteria } \\
\text { selection } \\
\text { Identify the } \\
\text { stakeholders } \\
\text { and the extent } \\
\text { of their } \\
\text { involvement } \\
\text { Review } \\
\text { internal and } \\
\text { external data } \\
\text { sources } \\
\text { Identify } \\
\text { challenges }\end{array}$ & $\begin{array}{l}\text { Elaborate the } \\
\text { key priority } \\
\text { areas for } \\
\text { criteria } \\
\text { selection } \\
\text { Tailor key } \\
\text { priority areas } \\
\text { to the case } \\
\text { company } \\
\text { Develop the } \\
\text { prototype } \\
\text { questionnaire } \\
\text { with } \\
\text { indicators } \\
\text { Identify } \\
\text { options } \\
\text { regarding } \\
\text { scaling, } \\
\text { weighting, } \\
\text { and } \\
\text { presenting } \\
\text { results }\end{array}$ & $\begin{array}{ll}\text { Critical } \\
\text { review of the } \\
\text { draft model }\end{array}$ & $\begin{array}{l}\text { Develop a } \\
\text { roadmap for } \\
\text { the integration } \\
\text { process }\end{array}$ \\
\hline $\begin{array}{l}\text { Techniques } \\
\text { Employed }\end{array}$ & - Consultations & $\begin{array}{ll}\text { - } & \text { Consultations } \\
\text { - } & \text { Content } \\
\text { analysis of } \\
\text { data sources }\end{array}$ & $\begin{array}{ll}\text { - } & \text { Consultations } \\
\text { - } & \text { Interviews } \\
& \text { Content } \\
& \text { analysis of } \\
& \text { data sources }\end{array}$ & - Consultations & $\begin{array}{ll}\text { - Consultations } \\
\text { - Interviews }\end{array}$ \\
\hline $\begin{array}{l}\text { Supporting } \\
\text { Literature }\end{array}$ & $\begin{array}{l}\text { Fahey and King, } \\
\text { 1977; Thomas, } \\
\text { 1980; Auster and } \\
\text { Choo, 1994; } \\
\text { Tontini and } \\
\text { Picolo, } 2010\end{array}$ & $\begin{array}{l}\text { Bailetti et al., } \\
\text { 1994; Jensen, } \\
\text { 1994; Harrison } \\
\text { and Lock, } 2004\end{array}$ & $\begin{array}{l}\text { Hearnshaw et al., } \\
\text { 2001; Campbell et } \\
\text { al., 2002; Nardo } \\
\text { et al., } 2005\end{array}$ & $\begin{array}{l}\text { Gay and Borus, } \\
\text { 1980; Deming, } \\
\text { 1993; Langley et } \\
\text { al., 1996; } \\
\text { Campbell et al., } \\
\text { 2002; Bockstaller } \\
\text { and Girardin, } \\
2003\end{array}$ & $\begin{array}{l}\text { Deming, 1993; } \\
\text { Langley et al., } \\
\text { 1996; Searcy et al., } \\
\text { 2006; Gates and } \\
\text { Germain, } 2010\end{array}$ \\
\hline
\end{tabular}

\subsection{Case Studies}

This section presents two individually conducted case studies to illustrate how the $3 \mathrm{~S}$

Design Process was applied to the development of a supplier selection model. The case companies were selected based on their extensive experience in sustainability reporting, their interest in enhancing their supplier selection processes, their willingness to commit 
internal resources to the study, and their potential to yield meaningful new insights into the process of developing a sustainable supplier selection model. Founded on these criteria, six corporate experts were contacted representing five corporations: one operating in the metals-mining, one in the energy, one in the retail, and two in the financial services industry sectors. These five corporations were selected from 100 Canadian corporations whose reports were reviewed in the primary content analysis. Three of these corporations - one in the metals-mining, one in the retail, and one in the financial services sector - did not want to commit internal resources to the study; therefore, were not selected.

When approached to the case utility, the principal informant stated that the company's environmental policies were soon to be revised and better linked to corporate SCM practices. Consequently, the senior management of the case utility had identified the need to make the environmental criteria an explicit part of the supplier selection process. Similarly, the initial contacts with the case financial services company revealed that company was planning to update its environmental procurement policy to align its strategic sourcing initiatives with the changing internal and external stakeholder interests, and therefore, its overall corporate strategy. As a result, the case financial services company planned to update its existing environmental criteria and add the social criteria into its supplier assessment and selection process. With that in mind, Section 4.4.1 introduces a brief profile of the case utility and presents the process and results of the case study. Section 4.4.2 follows the same order for the case financial services company.

\subsubsection{First Case Company Profile}

The case utility is a major Canadian electric utility corporation and is one of the largest energy companies in North America. International and interprovincial aspects of the electric utility industry are heavily regulated at the federal and provincial levels in Canada. As Duffy et al. (2012) state:

The provinces have primary responsibility for energy regulation through their jurisdiction over local works and undertakings, non-renewable natural resources and electrical energy. The provinces exercise jurisdiction through legislative enactments, various forms 
of delegated legislation and through independent energy and utility commissions.

Provincial legislation and tribunals also govern most environmental matters pertaining to the development of energy projects. The federal government has jurisdiction over international and inter-provincial trade and commerce, which includes authority over international and inter-provincial transmission lines and energy exports. The federal government also has jurisdiction over nuclear safety, aboriginal affairs, and a number of environmental matters that affect energy projects.

The case utility owns and operates nuclear, thermal, and hydroelectric power stations and wind power turbines. Bound by the federal and provincial regulations to address the wide-ranging environmental and social impacts of its activities, the case utility has programs and policies in place to operate in a safe, transparent, and environmentallyfriendly manner. More than ninety per cent of the case utility's electricity generation comes from nuclear and hydroelectric, with virtually no emissions. The case utility takes its responsibility to be a good corporate citizen seriously and has published a sustainable development report annually since 1999 . The case utility bases its supplier relationships on price, quality, delivery and service level requirements. Although the case utility's thousands of approved suppliers are expected to adhere to high standards of ethical behaviour and act with integrity, environmental criteria were not an explicit part of their supplier selection. In the sub-sections that follow, the application of the $3 \mathrm{~S}$ Design Process to the case utility to develop the sustainable supplier selection model is explained on a step-by-step basis.

\subsubsection{Conduct needs assessment}

This step aimed to identify the scope of the supplier selection model and involved two consultations with the principal informant, the case utility's Director of Sustainable Development. The consultations centred around two themes: commitment to greening the supply chain, and the current state of green SCM practices. The case utility had a strong commitment to the environmental dimension of sustainable development and had an Environmental Policy in place to support that commitment. Further, the case utility has established a number of voluntary internal initiatives and management systems, such as an ISO 14001 Environmental Management System, to help improve its environmental 
performance beyond compliance. As a major public utility, the case utility was aware of the need to align its values and operations with those of its stakeholders such as government, customers, suppliers, communities within which it operates, advocacy groups, industry experts, and academics. Further, the case utility recognized many of the benefits to greening the supply chain mentioned in Section 4.2.2, including risk management and potential benefits to the economic bottom line. The case utility's commitment to green purchasing was explicitly stated within the Corporate Supply Chain department's purchasing governance and implicitly stated within its Environmental Policy. Although the case utility employed a variety of supplier selection criteria on areas such as health, safety, quality, and some product-related third party certifications, a supplier selection model based exclusively on environmental criteria was needed to help implement green SCM practices. Based on the consultations conducted during this step, the supplier selection model would be developed according to the following principles:

- The model will be applicable to all of the case utility's suppliers.

- The model will be readily understood by experts and non-experts alike.

- The model will be practice-oriented.

- The model will be populated with readily available data.

- The model will yield objective, repeatable evaluations of the case utility's suppliers.

- The model will be integrated with existing supplier selection processes.

- The model should contain between 6 and 12 indicators.

\subsubsection{Conduct process planning}

This step involved an initial consultation with the principal informant and another consultation with ten internal experts, who were identified by the principal informant, at the case utility. These experts represented the Corporate Supply Chain, Commodity Sourcing, Demand Planning, and Sustainability departments. The discussions during the process planning step were focused around three themes: develop an action plan; identify preliminary priority areas for criteria selection; and discuss potential integration and implementation challenges. 
The development of the model required the involvement of internal experts from five corporate bodies, namely, the Environmental Group, Corporate Supply Chain, Commodity Sourcing, Demand Planning, and Sustainability departments. The model would be used by buyers, commodity specialists, material analysts, and contract engineers during the procurement life cycle of supplier selection and preparing and maintaining supplier contracts and agreements. The internal experts identified the preliminary criteria for supplier selection as: measurement of environmental impacts, provision of continual improvement, publication of a sustainable development report, and implementation of an environmental management. These preliminary criteria set the basis for the criteria selection efforts discussed in the following section. Finally, the experts elaborated on some of the key challenges anticipated over the course of the process, including obtaining corporate buy-in of the model by different business units, determining an appropriate implementation strategy for the model, including subcontractors in the model, measuring the performance of second and third tier suppliers, weighting the selection criteria of the model, and clarifying the next steps following the use of model. Overall, these challenges initiated the thinking on the final step of the project: integrating the model with existing infrastructure in supplier performance measurement systems.

\subsubsection{Develop draft supplier evaluation model}

This step involved conducting a content analysis of the case utility's five major suppliers' CSDRs, a consultation with the principal informant, and a group consultation with eight internal experts. The draft model was developed in Microsoft Excel. In the subsections that follow, the results from this process are presented as: identification of key priority areas, indicator selection criteria, prototype questionnaire, and scaling, weighting, and presenting results.

\section{Identification of Preliminary Priority Areas}

A content analysis of CSDRs of the case utility's five major suppliers was conducted in order to identify the preliminary key priority areas for the model. This resulted in the 
identification of 31 environmental KPIs (Appendix E). The KPIs identified in the content analysis helped provide a starting point for discussions with internal experts at the case utility to tailor the key priority areas.

\section{Tailoring Key Priority Areas to the Case Utility}

This step involved two consultations: one individual consultation with the principal informant and another group consultation with eight internal experts, including: Director, Sustainable Development; Manager, Commodity Sourcing and Purchasing; Senior Supply Chain Specialist, Corporate Supply Chain; Material Analyst, Demand Planning; and four commodity specialists from the Nuclear Supply Chain and Corporate Supply Chain departments. The internal experts were provided with the pool of KPIs identified in the content analysis to start the consultations. This was followed by open discussions regarding the fit of these KPIs to the case utility's strategy and operations and the ways in which some of the KPIs could be modified to the needs of the case utility. As a result, the experts identified eight key issues organized around three key themes. The rationale for selecting these three themes along with the eight key priority areas is summarized in Table 4.2.

Table 4.2 Key Environmental Issues for the Case Utility's Suppliers

\begin{tabular}{|c|c|c|}
\hline Theme & Key Priority Area & Rationale \\
\hline $\begin{array}{l}\text { Existence of an } \\
\text { environmental } \\
\text { strategy/policy. }\end{array}$ & $\begin{array}{l}\text { 1. Company has an environmental policy or a } \\
\text { direction relating to corporate social } \\
\text { responsibility or sustainability. } \\
\text { 2. If yes to above, this environmental policy is } \\
\text { publicly available. }\end{array}$ & $\begin{array}{l}\text { An indication of senior } \\
\text { management's commitment or } \\
\text { philosophy towards environmental } \\
\text { dimension of sustainability. }\end{array}$ \\
\hline $\begin{array}{l}\text { Environmental } \\
\text { impact of } \\
\text { production } \\
\text { activities. }\end{array}$ & $\begin{array}{l}\text { 3. Company measures its environmental } \\
\text { impacts. } \\
\text { 4. Company publicly reports on its emissions. } \\
\text { 5. Company publicly reports on its } \\
\text { environmental infractions. } \\
\text { 6. Company sets specific reduction targets on its } \\
\text { emissions and infractions. } \\
\text { 7. If yes to above, these targets are publicly } \\
\text { available. }\end{array}$ & $\begin{array}{l}\text { An indication of transparency and } \\
\text { dedication to continual } \\
\text { improvement of company's } \\
\text { environmental aspects. }\end{array}$ \\
\hline $\begin{array}{l}\text { Existence of } \\
\text { environmental } \\
\text { management } \\
\text { systems and/or } \\
\text { practices. }\end{array}$ & $\begin{array}{l}\text { 8. Company has management mechanisms in } \\
\text { place to identify } \\
\text { and mitigate the environmental impact of its } \\
\text { activities, products or services. }\end{array}$ & $\begin{array}{l}\text { An indication that companies } \\
\text { prioritize their environmental } \\
\text { aspects and have systems in place } \\
\text { to capture the environmental } \\
\text { impact of its activities. }\end{array}$ \\
\hline
\end{tabular}




\section{The Prototype Questionnaire}

Following the development of the key priority areas tailored to the case utility, the prototype questionnaire was prepared according to the criteria described in Table 4.4. The first question in the questionnaire was a gateway question that would determine if the remaining questions were necessary: a typical trait of bespoke supplier selection approaches (Holt, 1998). The gateway question focused on whether the company under evaluation had its commodity certified to an applicable internationally recognized standard, such as EPEAT (Electronic Product Environmental Assessment Tool) for technology-related products. If the answer to the gateway question was "yes", then the remainder of the questionnaire would no longer be needed. If the answer was "no", then the assessor at the case utility would proceed with the remaining questions. With that in mind, the prototype questionnaire is presented in Exhibit 4.1.

\section{Green Procurement Assessment}

Gateway Question: Does an internationally recognized standard exist and is the commodity certified to it?

Questions

\section{Environmental Strategy/Policies}

1.1 Company has an environmental policy or a high-level direction relating to corporate $\quad \square$ Yes $\quad \square \mathrm{N}$ social responsibility or sustainability?

1.2 If yes, is this environmental policy publicly available? $\quad \square$ Yes $\square$ N

1.3 Company has a publicly available purchasing guideline that considers environmental $\quad \square$ Yes $\quad \square \mathrm{N}$ performance of its direct suppliers and sub-contractors?

1.4 Company has published a social responsibility or sustainability report? $\quad \square$ Yes $\square \mathrm{N}$

\section{Environmental Impact of Production Activities}

2.1 Company measures its environmental impacts in hazardous or non-hazardous waste, $\quad \square$ Yes $\quad \square \mathrm{N}$ effluents, and air emissions?

2.2 Company publicly reports on hazardous or non-hazardous waste, effluents, and air $\quad \square$ Yes $\quad \square \mathrm{N}$ emissions?

2.3 Company publicly reports on its environmental infractions? $\quad \square$ Yes $\square$ \

2.4 Company sets specific improvement targets on hazardous or non-hazardous waste, $\quad \square$ Yes $\quad \square \mathrm{N}$ effluents, and air emissions, and infractions?

2.5 If yes, are these targets publicly available?

$\square$ Yes $\square \mathrm{N}$

\section{Management Systems and Practices}

3.1 Company has environmental management systems or practices to identify and control $\square$ Yes $\quad \square \mathrm{N}$ the environmental impact of its activities, products or services (e.g., ISO 14001)?

\section{Exhibit 4.1 The Prototype Questionnaire}




\section{Scaling, Weighting, and Presenting Results}

A measurement scale is the process of grouping individual observations into qualitative or quantitative classes (Nardo et al., 2008). The eight internal experts at the case utility were presented with four different scaling options, i.e., categorical, ordinal, interval, and ratio, to measure the outcome of the questionnaire. In light of the six guiding principles mentioned above in Section 4.4.1.1, the consultations with the same group of eight internal experts resulted in unanimously selecting a binary scale of "Yes/No." Further, the experts at the case utility were presented with two options regarding the weighting of the indicators: equal weighting, and budget allocation. In the equal weighting method, all factors are given the same weight, which essentially implies that all indicators are "worth" the same. Alternatively, the budget allocation method asks experts to allocate a "budget" of $\mathrm{N}$ points such as 100 , to a number of individual indicators, distributing more for those indicators they deem as more influential than the others. This method is considered to be optimal for a maximum of 10-12 indicators (Nardo et al., 2008). To indicate the case utility's priority areas in evaluating the environmental performance of its suppliers, the emphasis was given to the budget allocation method.

Finally, the experts were given several options to present the resulting outcomes from the assessment questionnaires. These options were organized under three main categories: bar charts, column charts, and radar charts. Within each of these categories, a number of options were presented, including a 100\% stacked bar chart, clustered column chart, stacked column chart, column chart decomposition presentation, radar with markers at each data point, and radar chart decomposition presentation.

\subsubsection{Test and adjust the model}

Following the development of the draft model, the model was critically reviewed in consultations with the ten key internal experts, who were previously identified in Section 4.4.1.2, to finalize it. The consultations resulted in the participants unanimously requesting the following items that fall into four categories (see Table 4.3). 


\section{Table 4.3 Feedback on Finalizing the Model}

\begin{tabular}{|c|c|}
\hline Category & Experts' Feedback \\
\hline Scaling & Select a binary scale of "Yes/No". \\
\hline Weighting & Use the budget allocation method and assign different weights to the indicators. \\
\hline Presenting Results & $\begin{array}{l}\text { To display the values of each indicator on the company basis, use the radar chart } \\
\text { decomposition presentation. Instead of presenting the actual weighted scores of } \\
\text { individual factors on the Radar Chart, apply a score of " } 0 \text { to } 1 \text { " for enhancing the } \\
\text { visual representation. }\end{array}$ \\
\hline Running the model & $\begin{array}{l}\text { Create an Annex in the Excel sheet that contains the model. In the Annex include: } \\
\text { 1. A list of "keywords" for conducting searches on the suppliers' corporate websites } \\
\text { and CSDR on a thematic basis (e.g., existence of an environmental strategy/policy). } \\
\text { 2. A list of other factors, chosen from environmental KPIs to help the assessor with } \\
\text { identifying the case utility's suppliers' environmental impacts of production } \\
\text { activities (i.e., Theme 2). } \\
\text { 3. A list of management initiatives, chosen from environmental KPIs to help the } \\
\text { assessor with identifying the case utility's suppliers' management systems and } \\
\text { practices (i.e., Theme 3). }\end{array}$ \\
\hline
\end{tabular}

The experts' feedbacks were incorporated into the draft model and the model was finalized in Microsoft Excel format. To display the values of each indicator on the company basis, the experts collectively decided on the radar chart decomposition presentation. Radar charts are a useful way to display multivariate observations with an arbitrary number of factors or variables (Nardo, 2008). A screenshot of the model is presented in Figure 4.2. 


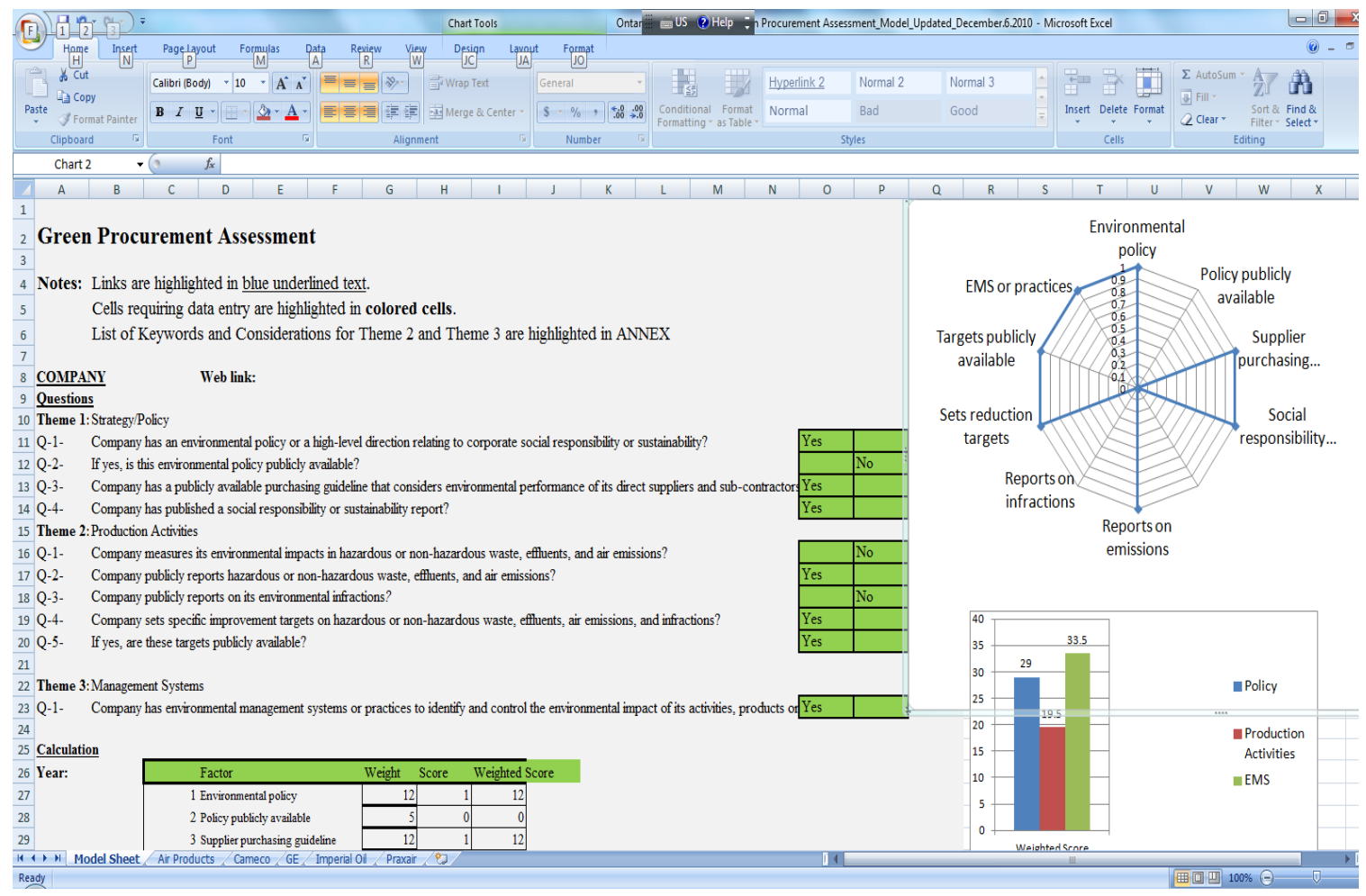

Figure 4.2 Screenshot of the Green Supplier Selection Model

As shown in the radar chart (Figure 4.2), a score of 1 was awarded if the relevant criterion was met. A score of 0 was given if the relevant criterion was not met. The radar chart provides a concise summary of how the supplier is doing with respect to the identified criteria. To visualize the results from the assessment questionnaire on a thematic basis, the experts decided on the bar chart decomposition presentation. Bar charts are particularly useful to display relative numbers of multiple categories (Nardo, 2008). In this case, the bar chart displayed the total weighted score of each theme in relation to others (see Figure 4.2).

The model provides a clear input into decision-making on supplier selection based on environmental criteria. Further, the model is user friendly and facilitates a straightforward sensitivity analysis. For example, as can be seen in Figure 4.3, the lack of criteria on Theme 2 (Production Activities) and Theme 3 (Management Systems) for a specific supplier under the assessment (Supplier X) is easily identifiable from the radar chart. In this case, the total weighted score for the supplier is " 25 " and is simultaneously displayed in the bar chart on the basis of each individual theme (Figure 4.3). 


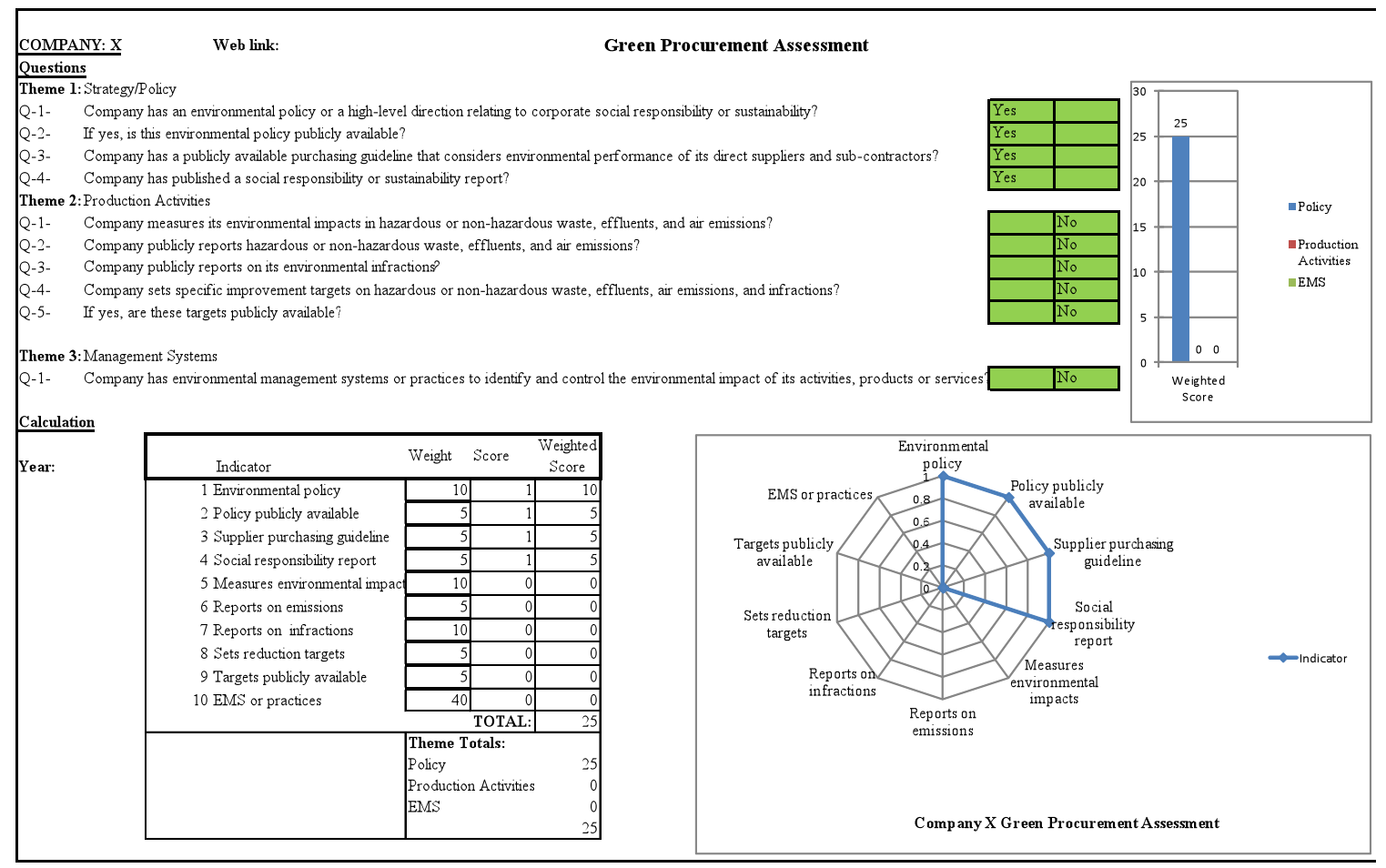

Figure 4.3 Application of Green Supplier Selection Model (Part 1)

If the agents of the case utility change the weightings of the existing indicators in Theme 1 (Strategy/Policy) to reflect the changes in corporate strategic objectives, the total weighted score for the supplier becomes "40." The indicators within Theme 1 are, without any change, displayed in the radar chart (Figure 4.4).

When the same supplier under the assessment (Supplier X) meets all of the criteria in all three themes during the follow-up assessment, the total weighted score then becomes "100" and would be displayed accordingly in the bar chart (see Figure 4.5 above). Further, the supplier's meeting of all of the assessment criteria would be easily identifiable in the radar chart (Figure 4.5). 


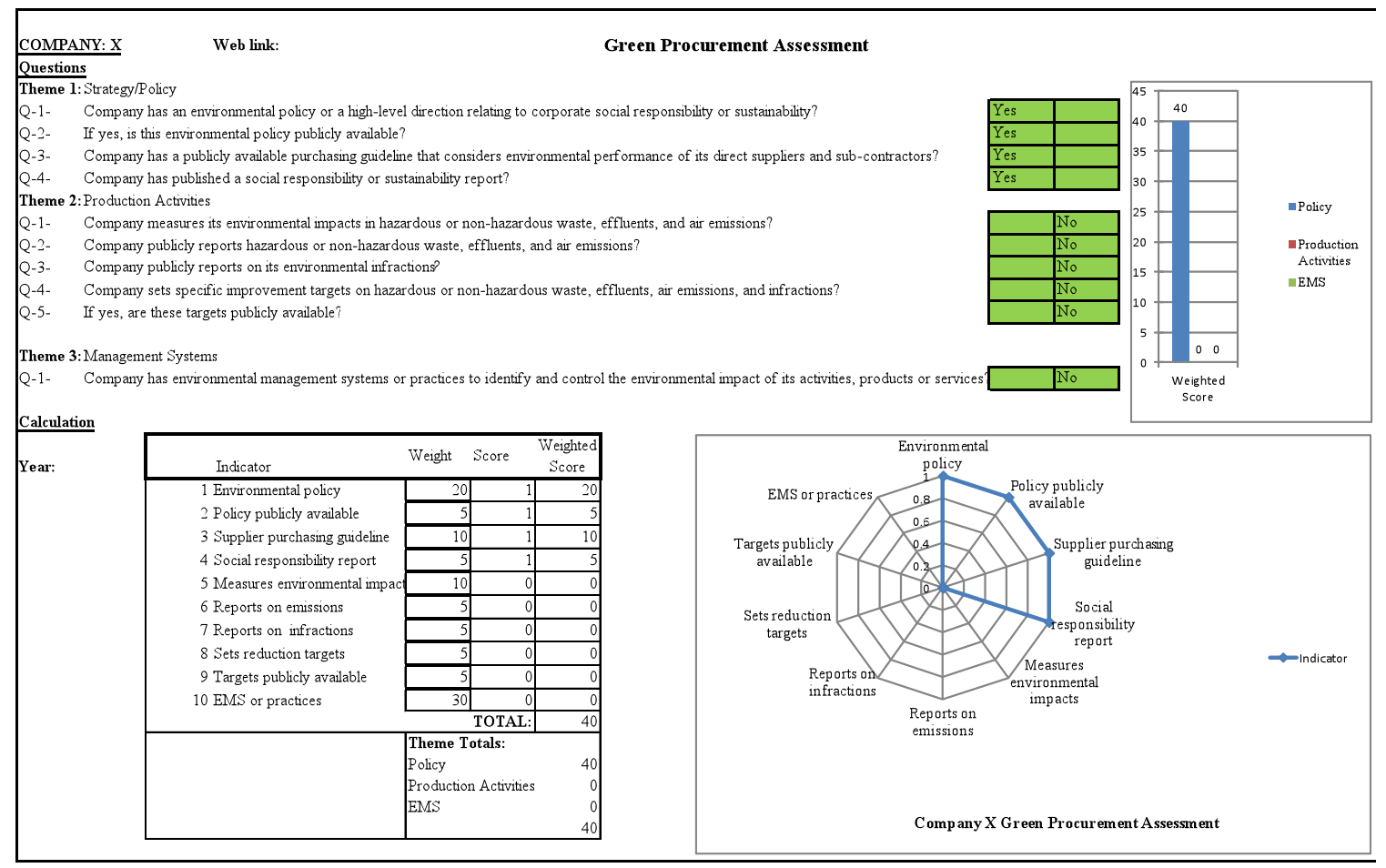

Figure 4.4 Application of Green Supplier Selection Model (Part 2)

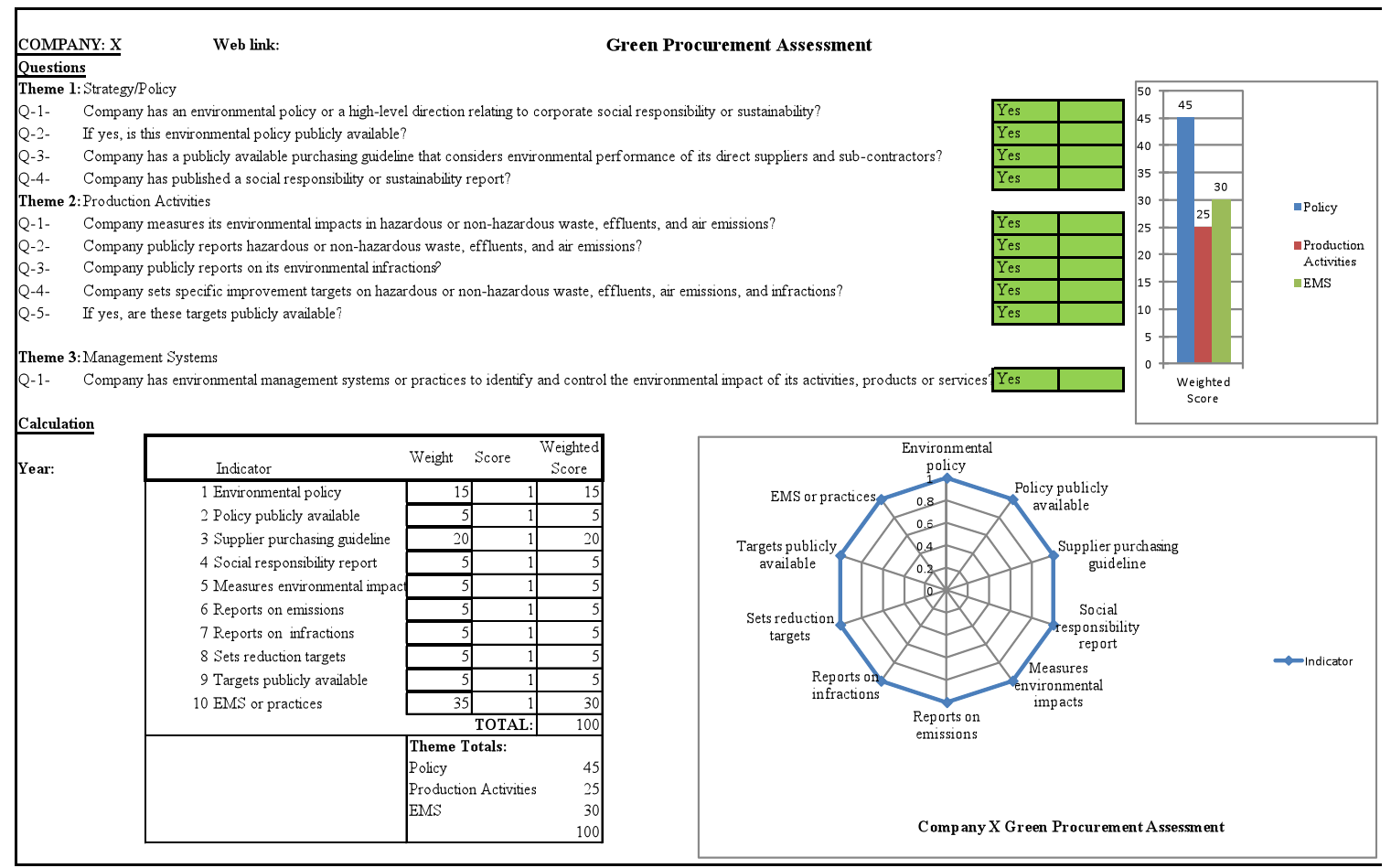

Figure 4.5 Application of Green Supplier Selection Model (Part 3) 


\subsubsection{Integrate the model with existing infrastructure}

The final step in the process was identifying the ways in which the model could be integrated with the existing infrastructure in supplier performance measurement systems in the case utility. Consultation with the same 10 internal experts identified the following key points (Table 4.4).

\section{Table 4.4 Integrating the Model at the Case Utility}

\section{Key Discussion Items}

1. The Supply Chain Department (SCD) at the case utility owned the model; therefore, the model was to be integrated into SCD's governance.

2. For this integration, the case utility needed to acquire the majority of buy-in at the director level of all business units within SCD.

3. There seemed to be no barriers for this buy-in since the model is in alignment with the current environmental policy objectives of the case utility.

4. The case utility typically renewed procurement contracts every 3 years (i.e., the contract cycle). The estimated phase-in time of the model to the entire supplier base was 2-3 contract cycles.

5. The estimated phase-in time would also allow the case utility to modify the model according to feedback received by the internal stakeholders and suppliers.

6. During the first contract cycle, the case utility could apply the model to high-volume suppliers and to commodities with higher opportunities. This would cover the majority of corporate procurement.

A follow up interview with the principal informant in April 2012, sixteen months following the completion of the case study, revealed that the model had been introduced into the corporate web platform. As of December 2012, the implementation of the model commenced and the model was integrated to the case utility's Purchasing and Asset Disposal Policy (PADP), which carries out operational impacts, quality, safety, and environmental issues in the procurement decision.

\subsubsection{Second Case Company Profile}

The case financial services company is a major Canadian bank with offices around the world. The case financial services company offers a full range of financial products and services to a corporate, commercial, personal, and small business clientele through its banking, wealth management, insurance, and securities businesses.

International and interprovincial aspects of the banking industry are heavily regulated at the federal and provincial levels in Canada. There are 50 regulating bodies (federal, 
provincial and self-regulating) that monitor aspects of financial services activities. For example, the Office of the Superintendent of Financial Institutions (OSFI) is a branch of the federal government that regulates the financial condition of all the banks operating in Canada. ${ }^{4}$ Bound by the federal and provincial regulations to address the wide-ranging environmental and social impacts of its activities, the case financial services company has a wide-ranging corporate responsibility programs that are committed to the environment and community relations, and annually publishes a corporate responsibility report and public accountability statement prepared in accordance with the G3 GRI v3.0 guidelines, including the GRI's financial services sector supplement.

The case financial services company has a Strategic Sourcing Group (SSG) that provides support to all business units for their sourcing initiatives and uses a regimented process, including an Environmental Procurement Policy, for the selection of major suppliers. Further, the case financial services screens its suppliers according to wide-ranging criteria, including environmental issues. However, at the time of the study the case financial services company was looking to review its Environmental Procurement Policy and revise its criteria for supplier selection. The following sub-sections explain the stepby-step application of the $3 \mathrm{~S}$ Design Process to the case financial services company to develop the sustainable supplier selection model.

\subsubsection{Conduct needs assessment}

The first step involved two consultations with the principal informant, the Senior Manager of the SSG, and the Senior Vice President and Chief Procurement Officer of the case financial services company. The consultations focused on two interrelated items: current SSCM initiatives, and the motivation and need behind the sustainable supplier selection model. The case financial services company had initiatives and policies related to SSCM practices, which included: fair and transparent request for proposal (RFP) processes and record keeping, code of conduct, environmental procurement policy, environmental policy, environmental questionnaire and assessment tool, health assessment, sustainability study pilot results, and environmental framework. However,

\footnotetext{
${ }^{4}$ Canadian Bankers Association (CBA)
} 
SCM practices required alignment with the company's vision and strategic objectives. Therefore, the case financial services company's future plans included revision of the existing environmental procurement policy to be inclusive of the broader scope of supplier sustainability criteria in support of its overall corporate responsibility program. Further, mitigation of reputational risk that is inherent across its supply chain was paramount to the case financial services. Although the case financial services company had recently formed a working committee to tackle these issues, there still was a need for a supplier selection model to evaluate its suppliers exclusively based on the environmental and social criteria.

\subsubsection{Conduct process planning}

The second step involved two consultations with the principal informant and the Manager of the Procurement Social Responsibility department. Discussions during the process planning meetings were focused around five themes: proposed scope, guiding principles, action plan, key internal documents to review, and integration and implementation challenges.

The case financial services company worked with over 20,000 suppliers. However, a major component of purchasing (over 70\%) was spent on the company's top 50 suppliers. It was determined that the model should accommodate all or a portion of this segment, though discussions were also held regarding the possibility of having the model go by category, i.e., top X\% by category. Further, it was noted that it was not the intention for the model to drive remedial action, but to use as a tool to identify where remedial action is appropriate and, where action plans are agreed upon, to be able to measure progress against action plans.

The development of the model was to be in alignment with the GRI principles and based on the case financial services company's vision and culture as reflected in its strategic priorities. It was emphasized that the model should be objective, simple to administer, applicable enterprise-wide, and be populated with readily available data. Further, the model was required to be: generalizable to all suppliers, illustrative of progress over time, 
potentially expandable to second tier suppliers, and useable through all phases of the life cycle, e.g., vendor selection, periodic evaluation, and contract renewal.

The SSG assumed the ownership of the model and identified the necessary internal data sources to help with the development of the model. It was determined that internal stakeholders from the case financial services company representing the business units in Community and Environment, Corporate Marketing, Human Resources, Compliance, Enterprise Real Estate, Enterprise Technology Solutions, and SSG would be involved with the development of the model. Finally, the key challenges anticipated for the integration and implementation of the model focused on: developing an adaptable model; integrating the model into existing RFP process and other life-cycle phases; and buy-in and adoption of the model by different business units who may have unique requisites.

\subsubsection{Develop draft supplier evaluation model}

The development of the draft model involved conducting a content analysis of the eight key internal data sources, structured interviews with 16 key stakeholders, and a group consultation with 13 internal stakeholders. In the subsections that follow, the results from this process are presented as: identification of key priority areas; indicator selection criteria; prototype questionnaire; and scaling, weighting, and presenting results.

\section{Identification of Preliminary Priority Areas}

The case financial services company provided eight key internal documents to review. These included: 2010 Corporate Responsibility Report (CRR), Environmental Procurement Policy (EPP), Code of Conduct (CoC), Risk and Health Assessment (RHA), Anti-corruption Policy (ACP), North American Request for Proposal (NA RFP); Top 50 Suppliers List (SL); and Guidelines for the Anti-corruption Policy (GACP). A content analysis of these eight documents was conducted to: explore how the environmental, social, and economic criteria and priority areas were communicated in these documents; and provide a basis for the identification of supplier evaluation criteria for the model.

The findings from the content analysis centred on two key themes: strategic priority areas 
and current practices, and risk. Further, the findings revealed that the case financial services company's strategic priorities as they relate to sustainability practices are environmentally focused. For example, the review and analysis of the RFP document resulted in the identification of no social criteria, either from the strategic priorities or risk management perspectives.

\section{Tailoring Key Priority Areas to the Case Financial Services}

This step involved a series of structured interviews with 16 key internal experts and a group consultation with 13 internal experts to collect views on the key priority areas for the model and to further define the scope of the project. The participants included: Senior Vice President and Chief Procurement Officer; Senior Vice President, Enterprise Real Estate; Vice President and Chief Environmental Officer; Vice President, Community Relations; Associate Vice President, Procurement Infrastructure; Associate Vice President, Enterprise Real Estate; Associate Vice President, Enterprise Regulatory Human Resource Policies; Associate Vice President, Compliance; Senior Manager, Environment; Senior Manager, Vendor Management; Senior Manager, IT; Manager, Corporate Responsibility; Manager, Green IT Systems; Architecture \& Design Director; Manager, Procurement Corporate Responsibility; and Lead, Real Estate Procurement. The interviews centred on seven open-ended questions (Table 4.5).

\section{Table 4.5 Case Financial Services Interview Questions}

\section{Questions}

1. In your organization, what is the primary motivation for sustainability or corporate social responsibility (CSR) initiatives? How does this relate to supply chain management practices?

2. What are the key issues, impacts, or strategic/operational concerns of your business unit as they relate to sustainability criteria? Why?

3. What are the current initiatives that your business unit has undertaken to address these issues, impacts, or concerns?

4. What kind of internal indicators or metrics, if any, does your business unit currently use to measure performance in sustainability initiatives?

5. Does your business unit have any sustainability or social responsibility standards required for supplier selection?

6. Who do you think should administer the supplier evaluation model (for example, business owner of the relationship, a third party, or self assessment)? Why?

7. When in the life cycle of the supplier arrangement should the supplier evaluation model be used? 
The interviews took place between September 28 and October 31, 2011. Eight interviews were held in person and seven over the phone. Each interview lasted between 10 to 45 minutes, with an average of 25 minutes. During the interviews notes were taken. The data were analyzed using text analysis through coding. The results from the interviews are presented as follows (Table 4.6):

\section{Table 4.6 Case Financial Services Interview Summary Results}

\begin{tabular}{|c|c|c|}
\hline \multicolumn{2}{|r|}{ Question $\quad$ Answer Themes } & Examples \\
\hline$\overline{1} 1$ & $\begin{array}{l}\text { Increase economic bottom-line } \\
\text { brand management, } \\
\text { reputation, risk management, } \\
\text { core to vision/strategy, } \\
\text { stakeholder pressures, doing } \\
\text { the right thing, drive } \\
\text { innovation }\end{array}$ & $\begin{array}{l}\text { It is the right thing to do; Being a responsible corporate citizen; } \\
\text { Positive economic impact (through expense management); It is } \\
\text { integral to the community and environment in which we work; } \\
\text { Brand perspective }\end{array}$ \\
\hline 2 & $\begin{array}{l}\text { Operational footprint, risk } \\
\text { management, stakeholder } \\
\text { engagement, products/services }\end{array}$ & $\begin{array}{l}\text { Energy consumption; Paper use; Water use; Carbon footprint; } \\
\text { Managing environmental risk; Sanctions; Corruption; Supplier } \\
\text { encouragement/monitoring; Community involvement; Engagement } \\
\text { from internal employees and customers; HR Diversity }\end{array}$ \\
\hline 3 & $\begin{array}{l}\text { Operational footprint, risk } \\
\text { management, stakeholder } \\
\text { engagement, products/services }\end{array}$ & $\begin{array}{l}\text { Reduce energy use; Metric development; Create and revisit } \\
\text { policies; Due diligence process for regulatory checks; Community } \\
\text { Involvement; Training employees; Innovation (product, service, } \\
\text { and process); Standards and management initiatives (e.g., LEED, } \\
\text { building management systems, Supply Chain Working Committee) }\end{array}$ \\
\hline 4 & $\begin{array}{l}\text { Operational footprint, risk } \\
\text { management, stakeholder } \\
\text { engagement, products/services }\end{array}$ & $\begin{array}{l}\text { Water consumption; Metric tonnage [paper] sheet per employee; } \\
\text { Recycling/Reuse; Waste management; GHG emissions (Type } 1 \text { and } \\
\text { 2); } \\
\text { KW consumption; Carbon per employee ; Energy intensity per } \\
\text { square feet; Commissioning methodologies; Integrity survey; } \\
\text { Supplier diversity; Products that are environmentally friendly }\end{array}$ \\
\hline 5 & $\begin{array}{l}\text { Third-party certification, } \\
\text { management systems }\end{array}$ & $\begin{array}{l}\text { Energy Star; Leadership in Energy and Environmental Design } \\
\text { (LEED); Forest Stewardship Council (FSC); EcoLogo; ISO } 14001 \\
\text { Environmental Management System }\end{array}$ \\
\hline 6 & Centralization, administration & $\begin{array}{l}\text { SSG; Another department within the bank; Business units; SSG and } \\
\text { Business Units }\end{array}$ \\
\hline 7 & Supplier selection life-cycle & Supplier selection; Contract renewal; Periodic reviews \\
\hline
\end{tabular}

Overall, the interviews with key internal experts highlighted the relationship between the 
sustainability initiatives and corporate value creation. In terms of key areas of concern, it was clear that the environmental dimension of sustainability took precedence over the social dimension. Taken collectively, the participants expressed 36 areas of concern that explicitly fall into the environmental criteria, e.g., energy use, paper use, green products and services, versus 14 areas of concern that fall into the social criteria, e.g. bribery, anticorruption, diversity. This fact was also reflected in the sustainability initiatives, including measurement practices, taken within the enterprise. As one participant stated: "We have a ton of small suppliers. We need a method that allows us to quickly go through them, and be comprehensive but not heavy-handed." This was supported by the fact that the participants unanimously pointed to the Environmental Questionnaire within RFP process as a means to provide suppliers with the examples of standards required for supplier selection. Further, the supplier selection standards that were cited almost exclusively related to the environmental criteria. The majority of participants thought that the supplier evaluation model must be centralized by the SSG and implemented by either the SSG or another department within the enterprise. This was stated due to the need for an impartial assessment and the SSG has a better understanding of the concept of sustainability. Finally, all of the participants cited the need to implement the model during supplier selection and to re-evaluate suppliers somewhere during the contact life. Following the interviews, a group consultation meeting with 13 internal experts, who had previously participated in the interviews, was held to identify the supplier selection criteria based on the work completed to date. All but two stakeholders centred on three key themes: environmental sustainability; social sustainability; and ethics (Table 4.7).

\section{Table 4.7 Key Issues for the Case Financial Services' Suppliers}

\begin{tabular}{lll}
\hline Theme & Key Priority Area & Rationale for Themes \\
\hline \hline $\begin{array}{l}\text { Environmental } \\
\text { Sustainability }\end{array}$ & $\begin{array}{l}\text { 1. Existence of environmental policy or } \\
\text { environmental management system. } \\
\text { 2. Operational footprint (energy consumption, water } \\
\text { use, waste management, recycling, reuse, material } \\
\text { selection). }\end{array}$ & $\begin{array}{l}\text { 1. Proactively identify and } \\
\text { mitigate risks. } \\
\text { 2. Strategic and operational } \\
\text { alignment, i.e., requesting data } \\
\text { from suppliers on the areas that } \\
\text { the case financial services itself }\end{array}$ \\
$\begin{array}{ll}\text { Sustainability } \\
\text { 3. Health and safety practices } \\
\text { 4. Human rights }\end{array}$ & $\begin{array}{l}\text { emphasizes and measures. } \\
\text { 5. Diversity }\end{array}$ & \\
& 6. Existence of code of conduct & \\
\hline
\end{tabular}




\section{The Prototype Questionnaire}

\begin{tabular}{|c|c|c|c|}
\hline \multicolumn{2}{|r|}{ Does internationally recognized standard exist and is commodity certified to it? } & \multirow[t]{2}{*}{ Yes } & \multirow[t]{2}{*}{ No } \\
\hline $\begin{array}{l}\text { Questions: } \\
\text { Theme 1 }\end{array}$ & ENVIRONMENTAL SUSTAINABILITY & & \\
\hline Sub-theme & Environmental Strategy and Policy & & \\
\hline \multirow{2}{*}{ Q-1 } & Does your organization have an environmental policy in place? & Yes & No \\
\hline & If "Yes", please provide a soft copy or web link in the "Description" section. & & \\
\hline \multirow[t]{2}{*}{ Q-2 } & Does your organization have an environmental management system in place? & Yes & No \\
\hline & If "Yes", please specify in the "Description" section. & & \\
\hline Q-3 & $\begin{array}{l}\text { Does your organization have environmentally responsible procurement guidelines that commit your } \\
\text { organization to reduce its environmental footprint? }\end{array}$ & Yes & No \\
\hline \multirow[t]{2}{*}{ Q-4 } & Does your organization report on corporate social responsibility or sustainability? & Yes & No \\
\hline & If "Yes", please provide a soft copy or web link in the "Description" section. & & \\
\hline \multirow[t]{4}{*}{ Sub-theme } & Operational Footprint & & \\
\hline & Does your organization measure the environmental impacts of its operational activities (e.g., water/energy & Yes & \\
\hline & use, air emissions, hazardous or non-hazardous waste generation, recycling and reuse)? & Yes & No \\
\hline & If "Yes", please specify in the "Description" section. & & \\
\hline \multirow[t]{2}{*}{ Q-6 } & Does your organization have a recycling program? & Yes & No \\
\hline & If "Yes", please specify in the "Description" section. & & \\
\hline \multirow[t]{2}{*}{ Q-7 } & Has your organization received any environmental violations within the past 5 years? & Yes & No \\
\hline & $\begin{array}{l}\text { If "Yes", please summarize the violation, enforcement actions taken (if any), fines paid (if any), and steps } \\
\text { taken to correct the problem in the "Description" section. }\end{array}$ & & \\
\hline \multirow[t]{2}{*}{ Q-8 } & Does your organization have any significant investments or environmental activities during the past 5 years & Yes & No \\
\hline & If "Yes", please specify in the "Description" section. & & \\
\hline \multirow{2}{*}{$\begin{array}{l}\text { Theme } 2 \\
\text { Sub-theme }\end{array}$} & SOCIAL SUSTAINABIITY & & \\
\hline & Health and Safety & & \\
\hline \multirow[t]{2}{*}{ Q-9 } & Does your organization have a health and saf ety policy in place? & Yes & No \\
\hline & If "Yes", please provide a soft copy or web link in the "Description" section. & & \\
\hline \multirow[t]{2}{*}{ Q-10 } & Does your organization have a health and safety management system in place? & Yes & No \\
\hline & If "Yes", please specify in the "Description" section. & & \\
\hline \multirow{4}{*}{ Q-11 } & Has your organization had any incident of non-compliance with regulations and voluntary codes & & \\
\hline & concerning any form of the health and safety impacts of your products, services, or operational activities & Yes & No \\
\hline & within the past 5 years? & & \\
\hline & If "Yes", please summarize the incident, enforcement actions taken (if any), fines paid (if any), and steps & & \\
\hline \multirow[t]{4}{*}{ Sub-theme } & Human Rights & & \\
\hline & Has your organization had any incident of non-compliance with regulations and voluntary codes & Yes & No \\
\hline & If "Yes", please summarize the incident, enforcement actions taken (if any), fines paid (if any), and steps & & \\
\hline & taken to correct the problem in the "Description" section. below. & & \\
\hline Sub-theme & Diversity & & \\
\hline \multirow[t]{2}{*}{ Q-13 } & Does your organization have any diversity policy or initiative in place? & Yes & No \\
\hline & If "Yes", please specify in the "Description" section. & & \\
\hline \multirow[t]{6}{*}{ Theme 3} & ETHICS & & \\
\hline & Does your organization have a business code of conduct in place? & Yes & No \\
\hline & If "Yes", please provide a soft copy or web link in the "Description" section. & & \\
\hline & $\begin{array}{l}\text { Does your organization have any legal action for anti-competitive behaviour, anti-trust, and monopoly } \\
\text { practices taken against it within the past } 5 \text { years? }\end{array}$ & Yes & No \\
\hline & If "Yes", please summarize the incident, enforcement actions taken (if any), fines paid (if any), and steps & & \\
\hline & taken to correct the problem in the "Description" section. & & \\
\hline \multirow[t]{4}{*}{ Q-16 } & Has your organization been the target of any Non-Governmental Organization (NGO) review or action & Yes & No \\
\hline & (e.g., environmental infractions, human rights violations, corruption, anti-competitive behaviour)? & Yes & No \\
\hline & If "Yes", please describe the nature of the review/action and explain your company's response in the & & \\
\hline & "Description" section. & & \\
\hline & Sustainable Procurement Questionnaire & & \\
\hline
\end{tabular}


Subsequent to the identification of key priority areas for supplier selection, the prototype model questionnaire was prepared in Excel format (Exhibit 4.2). As illustrated in Exhibit $4.2,16$ indicators were incorporated into the questionnaire. The indicators were classified according to three key themes: environmental sustainability, social sustainability, and ethics. The environmental sustainability theme included eight indicators organized around two sub-themes: environmental policy and management and operational footprint. The social sustainability theme included five indicators focused around two sub-themes: health and safety and human rights. Finally, the ethics theme included three indicators.

\section{Scaling, Weighting, and Presenting Results}

During the group consultation, 13 internal experts were presented with four different scaling options, i.e., categorical, ordinal, interval, and ratio, to measure the outcome of the questionnaire. The internal stakeholders unanimously decided on a binary scale of "Yes/No" and, initially, set the values at 0 for a "No" and 1 for a "Yes". Further, the 13 experts were presented with two options regarding the weighting of the indicators: equal weighting, and budget allocation. To indicate the case financial services' priority areas in evaluating the environmental, social, and ethical performance of its suppliers, the emphasis was given to the budget allocation method. Finally, during a subsequent consultation with the principal informant, three options were provided to present the resulting outcomes from the assessment questionnaires: bar charts, column charts, and radar charts. The principal informant requested that the results to be initially presented in radar plots, across indicators, and column charts, across themes.

\subsubsection{Test and adjust the model}

Following the development of the draft model, the model was critically reviewed in consultation with the principal informant to finalize it. The only adjustment request was to remove the gateway question: "Does an internationally recognized standard exist and is the commodity certified to it?" in the model. The rationale behind this adjustment request was that the case company aimed to identify and manage supplier risks (regardless of the existence of a third-party certification) in its supply chain. Aside from 
that, the model was found to have met the case financial services company's needs and expectations. Following the feedback from the principal informant, the model was finalized in Microsoft Excel format. A screenshot of the model is presented in Figure 4.6.

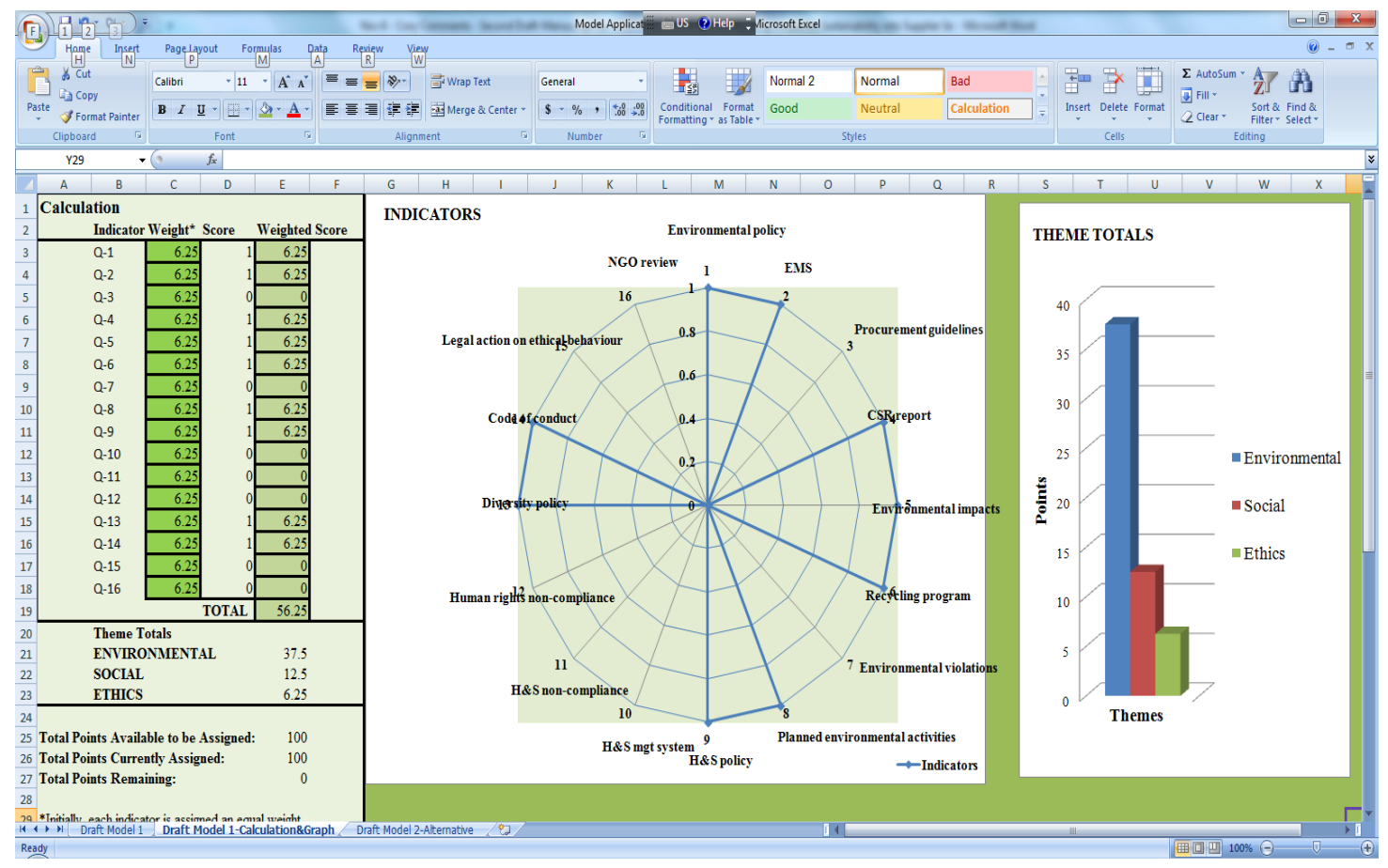

Figure 4.6 Screenshot of the Sustainable Supplier Selection Model

As shown in the radar chart in Figure 4.3, a score of 1 was awarded if the relevant criterion was met. A score of 0 was given if the relevant criterion was not met. The bar chart displayed the total weighted score of each theme in relation to others (Figure 4.6). The model provides a clear input into decision-making on supplier selection based on the environmental and social criteria. Further, the model is user friendly and facilitates a straightforward sensitivity analysis. For example, as can be seen in Figure 4.7, the existence of the "Health and Safety Non-compliance" (as identified by Question 11 in the model) and the existence of "Human Rights Non-compliance" (as identified by Question 12 in the model) for a specific supplier under assessment (Supplier Y) are easily identifiable from the radar chart. In this case, the total weighted score for the supplier is " 85 " and is simultaneously displayed by the bar chart on the basis of each individual theme (Figure 4.7). 


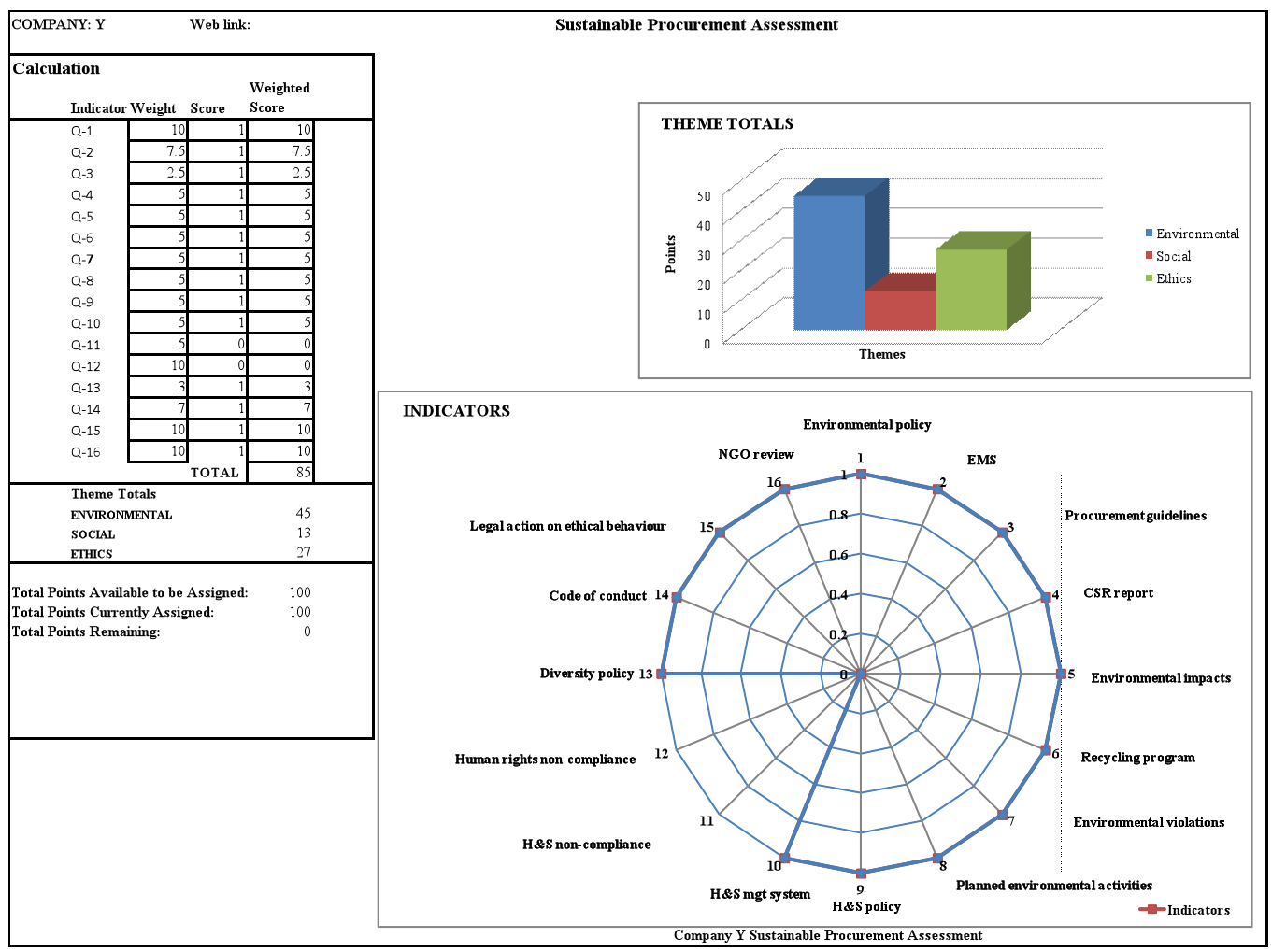

Figure 4.7 Application of Sustainable Supplier Selection Model (Part 1)

If the agents of the case financial services change the weightings of Question 11 and Question 12 to reflect the changes in corporate strategic objectives, the total weighted score for the supplier then becomes "80." The existence of the criteria on "Health and Safety Non-compliance" and "Human Rights Non-compliance" remains unchanged in the radar chart (see Figure 4.8 below). Further, the bar chart on the top right corner of Figure 4.8 displays the total weighted score on the basis of each individual theme.

If the same supplier under the assessment (Supplier Y) meets all of the criteria in all three key themes during the follow-up assessment, the total weighted score then becomes " 100 " and would be displayed accordingly in the bar chart on the basis of the individual themes (see Figure 4.9 below). Further, when the supplier meets all of the assessment criteria this would be easily identifiable in the radar chart (Figure 4.9). 


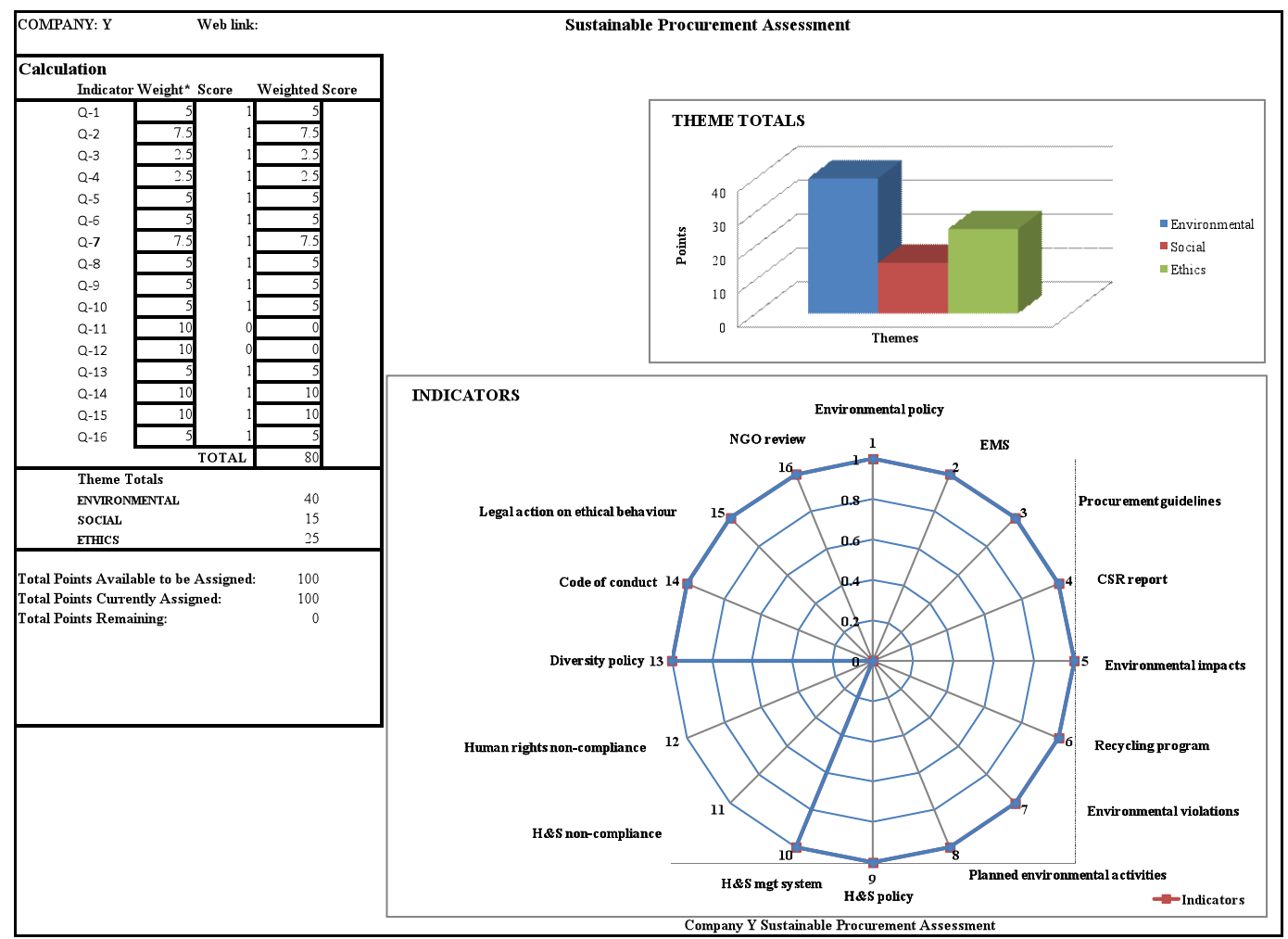

Figure 4.8 Application of Sustainable Supplier Selection Model (Part 2)

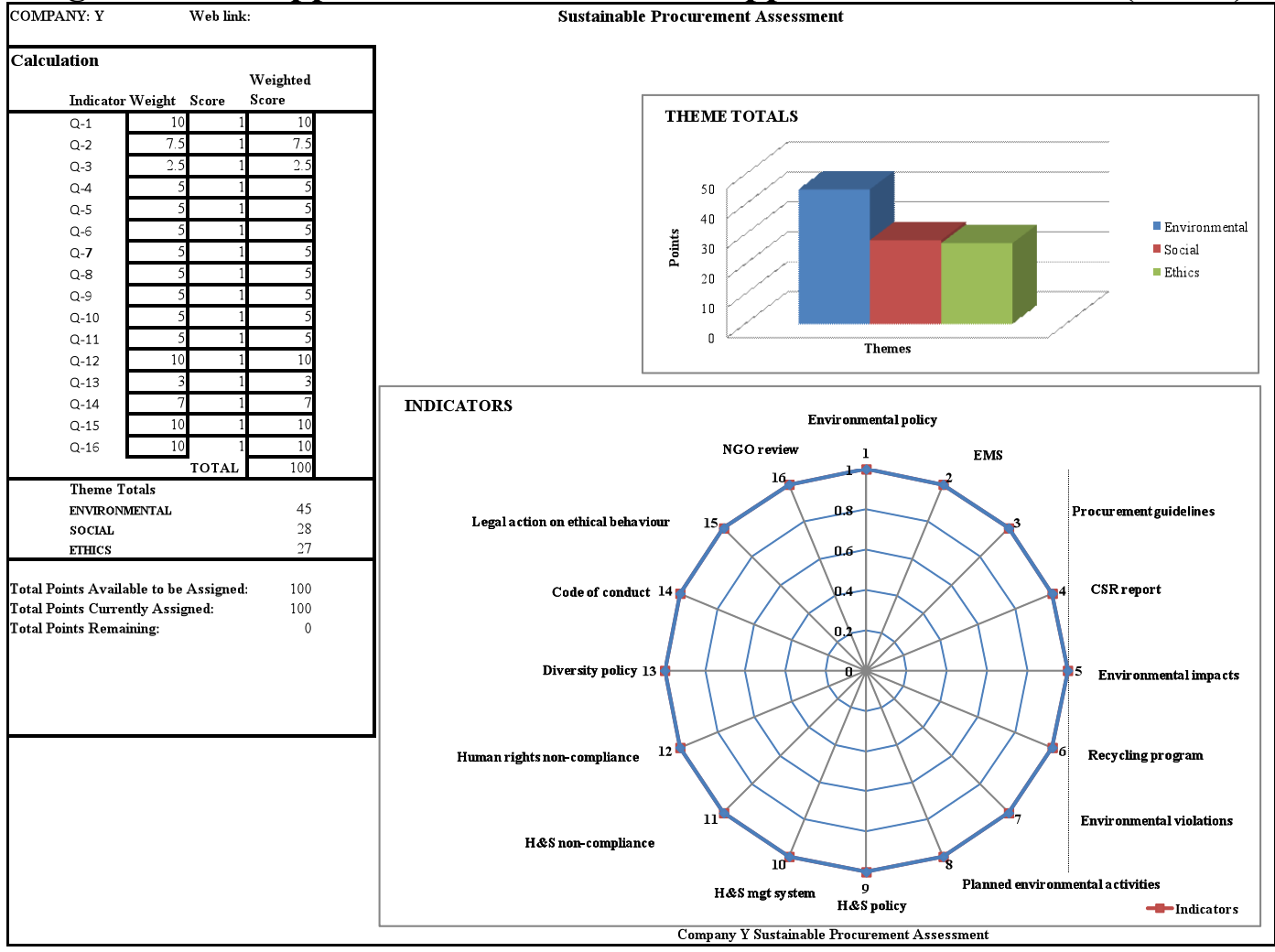

Figure 4.9 Application of Sustainable Supplier Selection Model (Part 3) 


\subsubsection{Integrate the model with existing infrastructure}

One of the key considerations throughout the development of the model was how it related to existing internal infrastructure at the case financial services company. Therefore, a final consultation with the key stakeholder was held to focus on how the model could be incorporated into existing decision-making processes at the company. The results from this consultation are summarized in Table 4.8.

\section{Table 4.8 Integrating the Model at the Case Financial Services}

1. The SSG owned the model; therefore, the model was to be integrated into SSG's governance.

2. The SSG will further review the model within the following 3-6 months to identify necessary changes.

3. Following the SSG's review, the model will be presented to the senior management to finalize it.

A follow up interview was conducted with the principal informant in April 2013, fourteen months into the completion of the case study, to determine the current state of the integration efforts of the model. The results from this interview include:

- The revisions to the "sustainable supplier selection model" and Environmental Procurement Policy (EPP) were completed in November 1, 2012. The new policy was named as Responsible Procurement Policy (RPP). However, the specifics of the revisions to the model, e.g., wording and weightings of the indicators, were not provided.

- The implementation of the sustainable supplier selection model commenced as of November 1, 2012. During sourcing initiatives when engaging with suppliers, the suppliers were asked to complete the questionnaire of the model. Based on a risk management approach, further scrutiny was applied by asking additional questions.

- Further, depending on the products or services being procured, other internal experts representing other departments, e.g., Human Resources or Environment, were asked to provide recommendation during the supplier assessment process. 
- Information regarding the new RFP and sustainable procurement model, and the extent to which they apply to corporate procurement practices, was reported in the 2012 CSDR of the case financial services.

\subsection{Discussion}

This study addressed the integration of the construct of CS into supplier selection issue. Based on five key steps, two sustainable supplier selection models were developed: one exclusively based on environmental criteria and one based on environmental and social criteria. Although the same methodological approach was applied to two case companies, the individual results varied, particularly as they relate to the indicators for supplier selection criteria. Based on our application of the model to the case companies, new insights about the consideration of the CS criteria for supplier selection and the model development process were gained. These insights and the implications of this study are summarized below.

There is an increasing need for contingency-based approaches to sustainable supplier selection. As explained in Section 4.2, there is a multitude of methodologies on supplier assessment, including emerging approaches that integrate environmental and social issues in supplier selection (Buyukozkan and Cifci, 2011; Baskaran et al., 2012). However, the case study consultations revealed that a major challenge for supply chain professionals and businesses in general is the scarcity of practice-oriented approaches and tools for sustainable supplier selection that can be integrated into existing supplier assessment and selection tools; and modified to the needs of the individual firm. Further, identifying the needs and specific circumstances of businesses and, therefore, the scope of such tools requires the involvement of different business units from across the organization. This is a crucial element of implementation in integrating the supplier selection tool with existing organizational structures and achieving the overall sustainability-related end goals of the organization (Paley, 1993; Searcy et al., 2006).

The case studies revealed clear linkages to stakeholder theory, institutional theory, and legitimacy theory. Although there are many organizational theories that are applicable to 
SSCM practices in general (Sarkis et al., 2011), stakeholder theory provides a particularly helpful theoretical perspective to explain the growing need for integrating CS into supplier assessment and selection and why the end results will differ from company to company. Stakeholder theory posits that different organizations have different internal and external stakeholders who exert pressure on organizations to reduce negative externalities and increase positive impacts of their activities (Freeman et al., 2010). Although all stakeholder interests should be considered, some stakeholder interests take precedence over others due to the level of power, legitimacy, and urgency, and therefore, pressure exerted on organizations (Donaldson and Preston, 1995; Mitchell et al., 1997). When urgency is combined with power or, in particular, legitimacy, it: "promotes access to decision-making channels, and in combination with power, it encourages one-sided stakeholder action" (Mitchell et al., 1997, p. 870). The case utility's operations create substantial and widespread environmental impacts: a fact (urgency) recognized by its internal and external stakeholders. Therefore, the case utility is subject to intense form of regulations at the federal and provincial levels (power) more so than firms in other industry sectors such as toy or apparel manufacturers. This might explain why the agents of the case utility have focused solely on the environmental dimension of CS for its sustainable supplier selection model. Similarly, the case financial services company's operations encompass wide-ranging social and ethical issues - e.g., health and safety, human rights, and corruption - in addition to environmental impacts - e.g., paper and energy usage. Therefore, the agents of the case financial services company addressed the environmental and social and ethical aspects of supplier selection. With that in mind, particular attention must be devoted to generalizing the findings from the case studies to other companies operating in other industry sectors and in other jurisdictions because both energy and financial services sectors are heavily regulated at the provincial and federal levels in Canada.

Institutional theory and legitimacy theory are also helpful in explaining the similarities or differences between the two case studies. According to institutional theory, the institutional environment, and, therefore, stakeholder pressure influence organizational and individual behaviour, particularly as it relates to prompting institutional mimicry to 
increase organizational legitimacy (DiMaggio and Powell, 1983; Mitchell et al., 1997). From this perspective, organizational practices that enable socially responsible behaviour are not only promoted by social structures within which businesses operate, but are also spread or institutionalized globally (Guler et al., 2002; Brown et al., 2009; Bjorklund, 2011). The case studies illustrate that within the same Canadian institutional context, the agents of both case study companies identified very similar key environmental priority areas for criteria selection, along with similar rationale for focusing on these areas. Consequently, the prototype questionnaires showed strong parallels, particularly with respect to the environmental indicators.

The identification of CS criteria is the focal point of sustainable supplier selection. The centrality of delineating distinct performance indicators for supplier selection has been widely recognized (Vanteddu et al., 2011; Bai et al., 2012). The case studies demonstrated that the agents of firms are increasingly seeking guidance on how to identify, measure, and report KPIs as they relate to supplier performance on SSCM initiatives. Despite the interest of the study participants in what other corporations, including their own suppliers, are measuring and reporting, the multiplicity of companyspecific KPIs that were publicly available provided little guidance. With that in mind, when it came time to identify the supplier assessment criteria, the agents of both case study companies opted for intangible performance indicators. However, the literature highlights that the complexities of supplier assessment and selection are particularly exacerbated when tangible and intangible performance metrics and indicators are integrated (Giannakis, 2007). This provides one possible explanation for why the case study companies opted to develop a separate sustainable supplier selection model rather than integrating the CS criteria directly into the existing economic and operational supplier selection criteria. Further, the consultations with the internal experts in the case companies pointed to the need to align the case companies' strategic priorities, as reflected in KPIs, with suppliers' interests and capabilities. However, the scarcity of social indicators (Hutchins and Sutherland, 2008) and the limitations of the GRI-based KPIs in addressing a contingency-based approach to performance measurement and disclosure (Moneva et al., 2006) posed major challenges to such alignment. From this 
perspective, the $3 \mathrm{~S}$ Design Process proved particularly useful to the case companies in that it provided a structured and detailed approach to identifying and tailoring the CS criteria to include in the sustainable supplier selection models.

The simultaneous consideration of the three pillars of sustainability in supplier selection criteria presents additional challenges. Sustainable supplier selection calls for the supplier assessment on all dimensions of the CS criteria (Kuo et al., 2010; Amindoust et al., 2012). However, the case studies demonstrated that the decision makers' individual areas of expertise, e.g., environmental, human resources, health and safety, legal, and economic, posed limitations to the evaluation of suppliers from a holistic view of CS. Although the literature in this area is rather limited, some authors have addressed this issue by using different approaches (Bai and Sarkis, 2010; Buyukozkan and Cifci, 2011). Additionally, the case studies identified the limited number of purchasing related indicators (Roca and Searcy, 2012) as a major barrier to a balanced construct of CS, and therefore, implementation of sustainable supplier selection. For example, as of July 2011, "the policy, practices, and proportion of spending on locally-based suppliers" was the most prevalent purchasing related economic indicator reported by Canadian companies (Chapter 1) In fact, the case financial services company found very limited use of this economic indicator in supplier selection and, therefore, chose not to include it in the model. Further, the decision to not include this particular economic indicator was supported by the fact that the case companies each had a vast number of suppliers that significantly varied in size. Consequently, expecting small and medium sized suppliers to measure their local spending values seemed impractical, if not unrealistic.

The process employed in the case studies explicitly recognized the exceedingly iterative nature of developing a sustainable supplier selection model. This presents two interconnected implications. First, the process employed in this study differs from other approaches to sustainable supplier selection in that it underlines the need for a continuous structured revision to the model. This, in turn, allows a better alignment of the operational and strategic objectives of the organization with shifting stakeholder interests, and, ultimately, organizational structures and processes. For example, at the conclusion of the case studies, the principal informants of both case companies clearly stated that the 
models developed provided a starting point for sustainable supplier selection and that they would be continuously updated. More importantly, the case studies show clear linkages to the dynamic capabilities view in that the efforts of integrating CS criteria into supplier selection enhanced core competencies and capabilities through organizational learning (Reuter et al., 2010). For example, the results from the internal stakeholder interviews and content analysis of internal data sources at the case financial services company demonstrated that the CS initiatives in the company were heavily skewed towards the environmental dimension, more so than the agents of the company had realized. Consequently, the agents of the case financial services company stated how this discovery may influence their future strategic direction by focusing more on the social and ethical issues in its supply chain. The second implication is that, due to its explicit iterative nature, the process allows a better utilization of organizational resources by enabling the organizational agents to better foresee, plan, and implement the development of a sustainable supplier selection model.

Notwithstanding the insights gained from the case studies, challenges to sustainable supplier selection remain. Despite the differences in organizational structure and culture of the case companies, the challenges for integration and implementation were rather similar. Some of these challenges related to intra-organizational system boundaries. For example, the agents of both case companies identified the adoption of the model by different business units that may have distinct implementation requirements as a key challenge. Some of the other challenges, such as how to seek remedial action with certain suppliers, extended to inter-organizational system boundaries across supply chains. Although some of these integration-related challenges have been addressed by the literature (Searcy et al., 2006; Pun and White, 2005; Busco et al., 2006; Gates and Germain, 2010; Kangwu, 2011) challenges to integration and implementation identified in the case studies present opportunities for future research from the sustainable supplier management perspective.

\subsection{Conclusions}

There is a scarcity of research that explicitly investigates the integration of CS criteria 
into supplier assessment and selection. This study concentrated on this gap and contributed to future research by conducting two case studies to develop sustainable supplier selection models. The same methodological approach, the 3S Design Process, was applied to both case companies. However, the outcomes produced differed. The model for the case utility focused exclusively on the environmental criteria and included ten key indicators structured around three key themes: environmental strategy, environmental impact, and environmental management. The model for the case financial services company focused on environmental and social criteria and included 16 key indicators organized around three themes: environmental sustainability, social sustainability, and ethics. Results from both models were visually presented in radar plots and column charts in Microsoft Excel.

From a theoretical perspective, the case studies demonstrated clear linkages to stakeholder theory, institutional theory, legitimacy theory, and dynamic capabilities view. The results from each case study illustrated the need for contingency-based and practiceoriented approaches to the sustainable supplier selection issue. Key challenges include the identification of tailored selection criteria, the simultaneous consideration of multiple dimensions of CS, and the shortage of social and economic purchasing related indicators. The results from each case study point to other integration and implementation related opportunities and challenges, including the need to align inter-organizational performance measurement strategies across supply chains; to construct a model applicable to business units with distinct operational requirements; and to build the model into existing supplier selection life-cycle stages. 


\section{CHAPTER 5 - RESEARCH SUMMARY AND CONCLUSIONS}

The overarching purpose of this dissertation was: to examine the extent of integration of CS into SCM practices in corporations; and to provide a basis for improved supplier selection with respect to sustainability criteria. To achieve its purpose, the dissertation had three interrelated research objectives: to explore the extent to which CS principles are integrated into SCM in corporations; to investigate how SSCM has evolved in corporations; and to develop a model to integrate the environmental and social criteria of CS into supplier assessment and selection. The dissertation employed a mixed-model research design comprised of three phases. Each research phase corresponded directly to the three research objectives identified above.

\subsection{Research Summary}

The research conducted in this dissertation is summarized in this section. Three interrelated research gaps were studied: to provide a holistic viewpoint for a variety of CS criteria which Canadian corporations adopt and implement to address SSCM issues; to assist decision making for various stakeholders across supply chains; and to identify areas for future research in the theory and practice of SSCM. In the subsections that follow, a summary of the research conducted to address the three objectives is provided. The overarching conclusions and recommendations derived from the dissertation are summarized in Section 5.2.

\subsubsection{A Review of Sustainable Supply Chain Management in Canadian Corporations}

The first part of this research focused on exploring the extent to which CS principles are integrated into SCM in Canadian corporations. This was achieved by conducting a mixed-method study, which involved a primary content analysis of 100 Canadian CSDRs and in-depth interviews with 30 corporate experts representing 26 Canadian corporations. Guided by the first research objective and two interrelated research questions, the primary content analysis analyzed seven criteria: supply chain governance, supply chain strategy, performance indicators, standards, supplier monitoring, supply chain 
collaboration, and forward looking statements on SSCM. Guided by the first research objective and two interrelated research questions, and the results from the primary content analysis, the in-depth interviews focused on eight questions (Table 2.6). The results from the study are summarized as follows:

1. The large percentage (62\%) of the CSDRs published by Canadian corporations that operate in the metals-mining, energy, and financial sectors suggested that industries with higher environmental footprints communicated more with stakeholders on CS initiatives than other industries.

2. Governance for SSCM was a marginal practice among the Canadian corporations studied. It was speculated that this was a major impediment to addressing accountability within supply chains.

3. The interviews showed that SSCM initiatives were a strategic and/or operational response from corporations to address stakeholder concerns with the goal of increasing their triple-bottom-line results.

4. Although the majority ( $72 \%$ ) of the corporations studied addressed sustainability issues within the supply chain, both the CSDRs and the interviews demonstrated that the integration of all three dimensions of sustainability into supply chain operations was rather limited.

5. Less than half (45\%) of CSDRs reported SSCM related indicators. Interviews revealed that the need to measure the success of sustainability initiatives in supply chains was recognized. Six experts, representing six different corporations, stated that they were in the process of developing KPIs to measure the success of sustainability initiatives in supply chains.

6. Although specific examples regarding the measurement of sustainability in the supplier selection area were limited, twenty of the thirty corporate experts interviewed stressed the need to assess suppliers on the basis of sustainability criteria by adopting new KPIs and/or specific standards for supplier selection.

7. Although the types of SSCM standards varied, corporations opted for a combination of: codes of conduct; third-party certifications; and other management systems and initiatives as the minimum acceptable standards for SSCM. However, 
corporate experts pointed to difficulties in auditing and monitoring suppliers on these standards.

8. In an attempt to extend accountability and enhance sustainability in the supply chain, 41 corporations engaged in collaborative activities either with their suppliers or with their customers. However, collaboration is heavily skewed towards upstream in the supply chain.

9. Apart from the previously-cited barriers in the literature, the interviews identified a long list of barriers to integrating sustainability into SCM. These included: lack of leadership from policy makers, lack of platforms to share expertise and best practices, required formal processes and bureaucracy to adopt and implement sustainability initiatives, communication or lack thereof across supply chain partners, and supplier reluctance to comply, amongst others.

10. The overall view among corporate experts was that all supply chain partners must share accountability. However, shared accountability was hindered by many barriers mentioned above.

11. As a response to overcome the barriers to integrating sustainability with SCM, corporate experts identified future priority areas in SSCM as: increased collaboration and education upstream and downstream across supply chains, performance measurement (of companies and suppliers), transparency and information sharing, and supplier audits and monitoring, amongst others.

12. The interviews revealed the ways in which corporations encouraged their suppliers to adopt SSCM initiatives. These included: codes of conduct, product specifications and other bidding requirements, collaboration with suppliers, forming multi-stakeholder collaborative platforms, and supplier assessment and monitoring activities.

As can be seen from the summary of key findings above, Canadian corporations address SSCM issues in a wide range of manners. Further, it is clear that many challenges in integrating sustainability into SCM remain. This study provided valuable insights about a number of SSCM related criteria, which Canadian corporations adopt and implement to address SSCM issues, from a holistic perspective. 


\subsubsection{Evolution of Sustainable Supply Chain Management}

The second part of this research concentrated on the evolution of SSCM as it relates to seven criteria: supply chain governance, supply chain strategy, performance indicators, standards, supplier monitoring, supply chain collaboration, and forward-looking statements on SSCM. The study was based on a sequential content analysis of 26 CSDRs to compare the findings with the results from the primary content analysis (see Chapter 2, Section 2.5.1) in order to identify how SSCM practices may have evolved in Canadian corporations. The key findings are summarized as follows:

1. The number of CSDRs issued by the corporations studied from 2004 to 2009 almost tripled (a 194\% increase). Although the energy, financial, and metals-mining sectors made up a large percentage in both sequential and primary analyses, $82 \%$ and $62 \%$ respectively, the percentage decrease in the latter showed that corporations from other industry sectors started reporting on sustainability initiatives.

2. Between 2004 and 2009, there was a $40 \%$ increase in the studied corporations that have cited a governance system that tied CS to their SCM practices. However, the governance for SSCM criterion remained significantly sidelined by the other SSCM criteria that have been studied.

3. The number of corporations that explicitly cited a SSCM related strategy or operational activity increased (approximately 18\%) between 2004 and 2009. However, the environmental dimension took precedence over the economic and social dimensions. 4. Despite a $40 \%$ decrease in the primary content analysis, approximately one in two corporations reported KPIs on sustainability issues in SCM. The number of environmental KPIs substantially outweighed the number of social KPIs. It was speculated that the decrease was due to difficulties in developing meaningful KPIs that measure the social dimension of CS.

5. Notwithstanding a $12.5 \%$ decrease, more than half of Canadian corporations utilized a combination of multiple SSCM standards to mitigate risk and increase legitimacy. These standards were business codes of conduct, third-party certifications, and management initiatives and programs.

6. Supplier monitoring has been an increasing practice. With over a $27 \%$ increase 
from 2004, more than half of the Canadian corporations (approximately 54\%) reported at least one monitoring initiative by 2009. However, the wide range of monitoring activities predominantly took place upstream in supply chains.

7. Reporting on collaboration among supply chain partners decreased by $33 \%$ by 2009. It was speculated that the decrease was due to complexities at intra- and-inter organizational system boundaries. Akin to supplier monitoring, upstream collaboration through the supply chain surpassed downstream engagement with customers.

8. Although the percentage of corporations that have cited an SSCM related target remained unchanged, the contents of forward-looking statements pointed to a trend in which SSCM was becoming more of a strategic priority, rather than an operational target.

As can be seen from above, the findings revealed that each criterion has shown, or not shown, progress at a different pace. Further, the longitudinal aspect of this study provided companies and their agents with a deeper understanding and appreciation of issues and challenges in decision making with respect to SSCM. It also revealed the need for further research on the evolution of SSCM, including the need to investigate other recorded human communications of corporations on other SSCM related criteria, case studies, and other systematic literature reviews.

\subsubsection{Integration of Corporate Sustainability into Supplier Selection}

The third and final part of this research addressed the integration of the environmental and social criteria of CS into supplier assessment and selection. This was achieved by conducting two case studies on the design of a supplier selection model. One case study focused exclusively on the environmental criteria while the other addressed both the environmental and social criteria of CS. The case studies were based on a five-step $3 \mathrm{~S}$ Design Process to design the models: conduct needs assessment, conduct process planning, develop a draft model, test and adjust the model, and integrate the model with existing infrastructure. Each case study involved extensive consultations with experts from the case companies. The results from the case studies are summarized as follows: 
1. The model for the case utility included ten key indicators that were organized around three key themes: environmental strategy, environmental impact, and environmental management. The first theme included four indicators, the second included five indicators, and the third included one indicator. Using the budget allocation method, weights were assigned to the indicators based on consultations with the internal experts. A prototype of the model was developed in Microsoft Excel, with the results being visually presented in radar plots and column charts. The model was linked to other relevant initiatives in the case company.

2. The model for the financial services corporation included 16 indicators that were classified according to three key themes: environmental sustainability, social sustainability, and ethics. The environmental sustainability theme included eight indicators organized around two subthemes: environmental policy and management, and operational footprint. The social sustainability theme included five indicators focused around two sub-themes: health and safety, and human rights. Finally, the ethics theme included three indicators. Equal weights were assigned to the indicators based on consultations with the internal experts. The results were presented in radar plots, across indicators, and column charts, across themes.

3. The case studies demonstrated that successful implementation of the sustainable supplier selection model was contingent upon the involvement of as many relevant business units as possible at the intra-organizational level. The level of such involvement should extend to every step of the supplier selection process with continuous feedback loops built among them.

4. The process of integrating CS criteria into supplier selection was beneficial in a number of ways. These included: increasing the triple-bottom-line results of the organization; encouraging suppliers to adopt sustainability principles; enhancing communication practices with stakeholders; and improving core competencies and capabilities through organizational learning.

5. The identification of CS criteria was central to sustainable supplier selection. However, delineating meaningful KPIs which reflect and communicate the organizations' values constituted a major challenge. This is an area in which the agents of firms were 
seeking guidance from academia, sustainability-related standards, and industry best practices.

6. The integration of a continuous improvement cycle into sustainable supplier selection approaches is imperative for the strategic alignment of such approaches with the ever-shifting stakeholder interests.

7. A balanced construct of CS in supplier selection proved particularly challenging due to two key factors. First, organizations' strategic directions, which include SCMrelated objectives, may or may not address all three pillars of sustainability. Second, knowhow and expertise of the internal stakeholders who provided input for the sustainable supplier selection process differed substantially. Consequently, the supplier selection criteria reflected the priorities of these stakeholders who are involved in the process.

8. Finally, the case studies pointed to additional challenges to sustainable supplier selection at intra- and inter-organizational levels. Some of the key challenges included: buy-in of the supplier selection model by different business units with distinct operational requisites; alignment of the selection criteria with suppliers' strategic and operational realities; and employment of remedial action with suppliers that do not qualify on certain selection criteria.

As stated in Section 4.2, successful implementation of SSCM practices necessitates the integration of environmental and social criteria of CS into the supplier evaluation and selection processes. Taken together, the case studies demonstrated: some key challenges to assessing suppliers on the basis of environmental and social criteria; and the need for contingency-based approaches to integrate CS into supplier selection. The 3S Design Process described in this study provided agents of firms with a practice-oriented tool and useful approach to address the sustainable supplier selection issue.

\subsection{Conclusions and Recommendations}

The purpose of this dissertation was to examine the extent of integration of CS into SCM practices in corporations and to address the sustainable supplier selection issue. To achieve this purpose, three interrelated research objectives were defined. 
The first objective of the dissertation was to explore the extent to which corporate sustainability principles are integrated into SCM in corporations. Chapter 2 addressed this objective. It provided an extensive review of the literature that focused on the concept of sustainable development and SSCM and the state of SSCM implementation by corporations. Building on the theoretical background and discussions of SSCM, the first research objective and two research questions were posed to guide the criteria of analysis for the study. In this study, the intention was not been to build a framework for best practices to integration and implementation to SSCM practices. However, the findings from the study revealed the wide array of ways in which Canadian corporations address SSCM issues and many challenges in integrating sustainability into SCM.

The second objective of the dissertation was to identify how SSCM has evolved in corporations. Chapter 3 of the dissertation explored how Canadian corporations have addressed SSCM issues over a five-year span on seven interrelated research criteria. A sequential content analysis of 26 Canadian CSDRs dating to 2004 was conducted to compare the results from the primary content analysis of the same Canadian CSDRs dating to 2009. The study yields valuable insights on emergent themes. This, in turn, helps: enable better predictions of the future directions of SSCM initiatives, the agents of firms and industry associations to identify best practices such as public disclosure of SSCM initiatives, and improve the implementation and alignment of CS initiatives at intra-and inter-organizational levels in supply chains.

The third objective of the dissertation was to address the integration of the environmental and social criteria of CS into supplier assessment and selection. In relation to this objective, Chapter 4 first provided an extensive review of the literature on supplier assessment and selection. It, then, applied the $3 \mathrm{~S}$ Design Process to two major Canadian case companies, an electric utility and a financial services corporation, to develop a green and sustainable supplier selection model. The case study with the electric utility focused exclusively on the environmental criteria while the case study with financial services corporation addressed both the environmental and social criteria of CS. Each case study involved extensive consultations with experts from the case companies. 
As stated earlier, supplier assessment and selection is a complex decision-making process, which involves simultaneous consideration of often-conflicting objectives and numerous qualitative and quantitative criteria. Although different approaches to sustainable supplier selection are emerging, most of them address only the environmental dimension of CS. With that in mind, organizations are in need of contingency-based approaches and practice-oriented tools for sustainable supplier selection that can be integrated into existing supplier assessment and selection infrastructure. Chapter 4 introduced an effective and practical bespoke modeling approach to the supplier selection issue within the context of SSCM. The 3S Design Process employed in the case studies enables the agents of organizations to plan, design, implement, control, and continuously improve the sustainable supplier selection practices.

With the above in mind, a set of specific recommendations is defined to guide the agents of firms to apply the knowledge and insights derived from this dissertation. These include:

- In an effort to address accountability within the supply chain, corporations should consider developing governance mechanisms that commit to SSCM practices in their mandate and communicate that to stakeholders.

- It is imperative that corporations integrate all three dimensions of sustainability into SCM strategy and operations to attain overall sustainability goals.

- There is an urgent need to align corporations' performance measurement practices with suppliers' interests and capabilities. To address this need, corporations should consider increasing transparency with respect to communicating their supplier performance measurement and monitoring initiatives. This, in turn, would serve as a means: to encourage suppliers to adopt sustainability initiatives and align them with those of buying firms; and to improve overall stakeholder relationships.

- It is important to establish collaborative platforms amongst supply chain partners to address sustainability issues, particularly as they relate to education, integration, and implementation of sustainability principles within the supply chain. 
- Corporations should consider introducing collaborative initiatives downstream in supply chains as a way to increase their SSCM performance, and, in due course, their overall triple-bottom-line results.

- Challenges in sustainable supplier selection can partially be addressed by developing supplier assessment models that can be modified according to the needs and resource structures of individual companies. However, the involvement of as many relevant business units as possible from across the organization is imperative to the success of the development of such models.

- Continuous and structured revisions to sustainable supplier selection tools are necessary for a better alignment of the operational and strategic objectives of organizations with shifting stakeholder interests.

Although it is acknowledged that there are a number of possible theoretical lenses to explain how agents of firms will apply these recommendations to their organizations, contingency theory provides a particularly relevant perspective. Contingency theory holds that the leadership and best possible structure of an organization is contingent upon a variety of internal and external restraints. Therefore, an effective and successful organization, and its structure, must fit with the environment in which it operates (Donaldson, 2001). As a result, it is up to the agents of firms in Canada and around the world to identify the internal and external restraints and apply the insights gained from this study to provide an optimal fit between the SSCM initiatives and institutional environment.

\subsection{Research Limitations and Areas for Further Research}

This dissertation research is comprised of three main phases corresponding directly to the research objectives stated in Section 1.2. The research limitations of each phase and the areas for future research drawn from these limitations are presented in the following subsections.

\subsubsection{A Review of Sustainable Supply Chain Management in Canadian Corporations}

The first phase explored the extent to which CS principles are integrated into SCM in 
Canadian corporations through a content analysis and interviews. Although the research design utilized between-methods triangulation to strengthen data collection and analysis, some limitations to this study exist.

First, communicating CS initiatives through CSDRs is a voluntary practice for Canadian corporations, with the exception of limited requirements for corporations in the financial services industry. Therefore corporations are likely to not report on activities that may damage their reputation (Gray et al., 1995). In an effort to enhance reputation and gain legitimacy, corporations can engage in decoupling formal structures, therefore, portraying superficial appearances (Fasterling, 2012) on the criteria examined for the study. However, it is critical to acknowledge that the reports may not have contained all information relevant to corporations' SSCM programs. For example, the interviews with the corporate experts revealed that corporations' supplier evaluation schemes were rarely made public (Section 2.5.2.3). Inclusion of other written communication, e.g., business magazines and papers, NGO reports, and other web databases, may alleviate this issue and present opportunities for future research.

Second, notwithstanding the richness of the insight gained from the expert interviews representing 26 Canadian corporations, the inclusion of other, small and medium-sized enterprises in the interviews would enhance the data construction and yield additional insights. Similarly, conducting surveys with not only the corporate experts, but with organization and industry-specific stakeholders, e.g., employees, suppliers, NGOs, and local community members, would provide a more holistic perspective on corporate SSCM practices and issues. Guided by the results from this study, these additional indepth and survey interviews could probe deeper into criteria of analysis from this study. For example, guided by the results from sections 2.5.1.5 and 2.5.2.4, future research might investigate which combinations of standards achieve a higher-level of legitimacy and risk mitigation for corporations. Similarly, as identified in Section 2.5.1.7, future research might address the scarcity of downstream collaboration in supply chains by conducting survey interviews with consumer groups. Other areas of further research include: how performance indicators are currently used in SCM, how accountability 
could be extended in supply chains, and how suppliers can be encouraged to be more sustainable, amongst others.

Third, as a well-established rule with case studies, generalizing the findings and, therefore, analysis of this Canadian case study to other countries is limited. As stated in sections 2.4 and 3.3 above, this is due to Canada's institutional and contextual peculiarities. Organizations in other jurisdictions, however, can adapt the insights from the findings of this Canadian case study by factoring in the internal and external environment, e.g., political systems, financial systems, structure of the firm, market processes, education and labour systems, and cultural systems (Matten and Moon, 2008), within which they operate. Further, this limitation presents ample opportunities for future research in investigating how corporate SSCM practices differ across countries or institutional settings. Such comparative analyses would provide additional insights for corporations, other supply chain partners, and policy makers on a global scheme.

\subsubsection{Evolution of Sustainable Supply Chain Management}

The second phase investigated how SSCM has evolved in Canadian corporations in a five-year period through a content analysis of CSDRs. Although the study addressed a key research gap, it is acknowledged that additional research is necessary to explore the evolution of SSCM. This could focus on addressing the limitations of this study as follows.

First, as stated in sections 2.4 and 3.3 above, Canada has distinct economic and institutional characteristics. Therefore, caution must be exercised in generalizing the findings to other countries. However, the results from this study provide a starting point for future longitudinal studies. For example, future research might employ the criteria of analysis from this study to investigate and compare the evolution of SSCM in other countries or institutional settings. Second, there is inherent bias in CSDRs, particularly those that relate to disclosures amplifying the corporations' positive SSCM initiatives while minimizing the discussion of the negative issues. Similarly, there may well be discrepancies between the reported sustainability initiatives and what is actually 
implemented (Kolk, 2003). For example, as stated in Section 5.3.1 above, many corporations chose not to disclose their supplier assessment schemes. Third, it is not clear exactly when the changes may have occurred during the five-year period or why they occurred. For example, some of the differences might relate to changes in the external environment. Further, the changes highlighted in this study may be attributed to improvements in reporting rather than improvements in SSCM practices. In this sense, additional research on the evolution of SSCM might include investigating other recorded communications of corporations over a longer time period on other SSCM-related criteria and application of other methodological approaches such as case studies and other systematic literature reviews. Further, conducting survey interviews and questionnaires with the agents of corporations and other stakeholder groups across supply chains would provide additional insights as to how, why, and when the changes in SSCM integration and implementation have occurred. For example, as guided by Section 3.4.6, future research might investigate trends in which multi-stakeholder collaborative practices are evolving in Canada or other institutional settings.

$\mathrm{n}$ the future research section, talk about how your existing research needs to be complemented by research and writing on the external environment.

\subsubsection{Integration of Corporate Sustainability into Supplier Selection}

The third phase addressed the integration of environmental and social dimensions of CS into supplier selection. This was achieved by conducting two case studies of Canadian corporations to develop two sustainable supplier selection models: one exclusively based on environmental criteria and one based on environmental and social criteria. The major limitation to this research, as is customary with case studies, is that caution must be exercised in directly applying the results elsewhere. Another limitation to the case studies is that no suppliers were involved in the consultations. Inclusion of first and second tier suppliers along with focal companies would address this limitation and would provide valuable insights.

With that in mind, the case studies pointed to a number of future research opportunities. 
To address the challenges associated with the integration and implementation of sustainable supplier selection models, further research may include longitudinal case studies that explore how the models are executed and revised over time. For example, regardless of the types and system boundaries of challenges, such longitudinal research may examine the best practices and shortcomings to integration and implementation of the model. This would provide insights for further improvement of the process. Other case study research may investigate the alignment of sustainable supplier selection efforts and strategies across supply chains and the effects of such alignment on the triple bottom line. Finally, other methodological approaches such as focus groups, survey interviews and questionnaires may be conducted to explore other challenges to the sustainable supplier selection issue in general.

It is clear that many challenges in integrating sustainability into supply chain management remain. Overall, additional research is necessary in three key areas: to explore approaches to integrate all three pillars of sustainability into SCM; to develop performance measurement systems for SSCM; and to refine sustainability reporting practices with respect to SCM. Further, future research must go beyond studying these three areas separately and focus must move towards a more integrated approach, particularly as it relates to integrating the elements from the external environment into this existing research.

\section{$5.4 \quad$ Research Contributions}

As stated earlier, stakeholder demands and institutional pressures are increasingly creating a sense of urgency for corporations to address sustainability issues in their supply chains. This dissertation addresses three interrelated research gaps in the field of SSCM by applying a mixed-method methodological approach, which includes: content analyses; in-depth interviews; and cases studies. Taken together, this dissertation advances understanding and learning with respect to integrating sustainability into SCM. The main benefits of this dissertation are twofold:

1. The first study presented in Chapter 2 (Phase 1) provides a holistic perspective for 
a range of interrelated SSCM criteria, which Canadian corporations adopt and implement to address CS issues in supply chains. The second study presented in Chapter 3 (Phase 2) provides the same holistic perspective with the inclusion of the time dimension. The details of the contributions of Phase 1 and Phase 2 of this dissertation are as follows:

- It provides a comprehensive summary of the SSCM practices in 100 major Canadian corporations on manifold interrelated criteria: supply chain governance, supply chain strategy, performance indicators, standards, supplier monitoring, supplier encouragement, accountability, supply chain collaboration, forward looking statements, and challenges and future work on SSCM.

- It provides a holistic interpretation of SSCM practices; therefore, it enables crossassociations among the interrelated criteria listed above.

- It identifies additional barriers to integration and implementation of sustainability principles with SCM within the Canadian context.

- It identifies some areas for future work in SSCM as desired by corporate experts. - It enables better predictions of the future directions and trends of SSCM. Consequently, it helps organizations develop and align strategic and operational approaches to address sustainability issues in supply chains.

- It provides insights to streamline the communication practices of SSCM initiatives. This is an important contribution given that public disclosure of corporations varies widely despite the growth in the GRI-based reporting practices.

- It provides policymakers with information to develop overall sustainable development goals and align them with those of corporations. For example, the dissemination of the results from this dissertation may provide input to advancing the Government of Canada's federal sustainable development initiatives.

2. The creation and implementation of sustainable supplier selection remains an emerging discipline. The case studies that presented in Chapter 4 contribute to these efforts by providing a practical, adaptable, and contingency-based approach to sustainable supplier assessment and selection. This provision will help corporations: further link CS issues with other initiatives in the organization, better utilize organizational resources, demonstrate organizational commitment to sustainability 
principles, and enhance accountability to stakeholders through the provision of greater transparency on SSCM issues. For example, as the firms' SSCM related strategic objectives change or evolve over time, the agents of firms can simply: develop other indicators to add to existing set of indicators; revise existing indicators; or change the weightings of the existing indicators in the model to reflect the changes in corporate strategic objectives. Another important contribution is that the results from the sustainable supplier selection model development process have been widely disseminated at the industry meetings (Morali and Searcy, 2011; Morali and Searcy, 2013). Furthermore, the case utility has made the end product, the green supplier selection model, available online in its corporate website. Taken together, this presents agents of other corporations and business owners with opportunities to utilize a practice-oriented process and tool to address the sustainable supplier selection issue in their organizations. In summary, the contributions from Phase 3 of this dissertation include:

- $\quad$ Providing agents of companies and supply chain management professionals with a systematic, adaptable, yet relatively simple process for supplier assessment and evaluation, particularly as it relates to selection of CS criteria to include in the sustainable supplier selection models.

- $\quad$ Identifying additional challenges to integrating CS criteria with supplier assessment and selection.

- $\quad$ Providing agents of companies with a "value based" approach to sustainable supplier selection in which corporate values and priorities are clearly linked to supplier selection process.

- $\quad$ Facilitating organizational learning and; therefore, helping enhance core organizational capabilities. This benefit, in particular, is achieved by employing the $3 \mathrm{~S}$ Design Process with internal experts at the case companies.

- $\quad$ Guiding future research that might focus on the areas identified in Section 2.3.

Overall, this dissertation makes considerable contributions to the practice of SSCM. Further, it reveals clear theoretical linkages to SSCM practices in Canadian corporations. The agents of firms perceive the change processes and managing change to take on CS issues as increasingly complex and multifaceted. New approaches are needed on linking 
knowledge to action for addressing sustainability issues across supply chains. Therefore, it is imperative to make knowledge available to supply chain partners, such as corporations, industry practitioners, and customers, through a number of initiatives to further facilitate the integration of all three dimensions of sustainability into SCM. 